\title{
Rankings and risk-taking in the finance industry.
}

Michael Kirchler, Florian Lindner, Utz Weitzel

Working Papers in Economics and Statistics

2016-02 


\section{University of Innsbruck \\ Working Papers in Economics and Statistics}

The series is jointly edited and published by

- Department of Banking and Finance

- Department of Economics

- Department of Public Finance

- Department of Statistics

Contact address of the editor:

Research platform "Empirical and Experimental Economics" University of Innsbruck

Universitaetsstrasse 15

A-6020 Innsbruck

Austria

Tel: $\quad+435125077171$

Fax: $\quad+435125072970$

E-mail: eeecon@uibk.ac.at

The most recent version of all working papers can be downloaded at http://eeecon.uibk.ac.at/wopec/

For a list of recent papers see the backpages of this paper. 


\title{
Rankings and Risk-Taking in the Finance Industry*
}

\author{
Michael Kirchler, Florian Lindner and Utz Weitzel ${ }^{\dagger}$
}

September 14, 2017

forthcoming in: Journal of Finance

\begin{abstract}
Rankings are omnipresent in the finance industry, yet there is no research how they impact financial professionals' behavior. We run lab-in-the-field experiments with 657 professionals and lab experiments with 432 students to investigate how rank incentives affect investment decisions. We find that both rankings and tournament incentives increase risktaking among underperforming professionals, but rankings do not affect students. We show that the rank-effect is robust to the experimental frame (investment frame versus abstract frame), to payoff consequences (own return versus family return), to social identity priming (private identity versus professional identity), and to professionals' gender (no gender differences among professionals).
\end{abstract}

JEL: G02, G11, D03, C93

Keywords: Experimental finance, behavioral finance, rank incentives, rankings, financial professionals, social identity theory, lab-in-the-field experiment, tournament incentives.

${ }^{*}$ We are grateful to the Editor Bruno Biais, one Associate Editor, and two anonymous referees for excellent and constructive comments during the editorial process. We thank Loukas Balafoutas, Gary Charness, Alain Cohn, Oege Dijk, Florian Englmaier, Sascha Füllbrunn, Cary Frydman, Maximilian Germann, Fabian Herweg, Jürgen Huber, Michel Andre Marechal, Peter Martinsson, Kurt Matzler, Stefan Palan, David Porter, Jianying Qiu, Stephanie Rosenkranz, David Schindler, Simeon Schudy, Joep Sonnemans, Rudi Stracke, Matthias Stefan, Matthias Sutter, Alexander Wagner, Janette Walde, Erik Wengström, Stefan Zeisberger, seminar participants at the Universities of Bergen, Innsbruck, Lund, Munich, Nijmegen, London, Salzburg, Trento, Trier, Utrecht, as well as conference participants at the AEA Annual Meeting 2017 in Chicago, Hållbara Finanser in Stockholm 2017, Status and Social Image Workshop (WZB) 2017 in Berlin, Experimental Finance 2017 in Nizza, Research in Behavioral Finance Conference 2016 in Amsterdam, Behavioral Economics of Financial Markets Workshop in Zurich 2016, EFA 2016 in Oslo, ESA 2016 in Bergen, ESA 2015 in Heidelberg, Experiment a BIT 2015 in Trento, Experimental Finance 2015 in Nijmegen, and eeecon Workshop 2015 in Innsbruck for very valuable comments. We are grateful to Michael Dünser, Achiel Fenneman, Felix Holzmeister, Dirk-Jan Janssen, Patricia Leitner, Fritz Pöllmann, Melanie Prossliner, Lorenz Titzler, Alexander Wolf, and Jan Zatocil for excellent research assistance. We particularly thank Rani Piputri and all financial institutions and participating professionals for the excellent collaboration. Financial support from the Austrian Science Fund (FWF START-grant Y617-G11 and SFB F63), Radboud University, and the Swedish Research Council (grant 2015-01713) is gratefully acknowledged. This study was ethically approved by the IRB of the University of Innsbruck. All three authors declare that they have no additional relevant or material financial interests that relate to the research described in this paper.

${ }^{\dagger}$ All authors contributed equally. Kirchler: Corresponding author. University of Innsbruck, Department of Banking and Finance, Universitätsstrasse 15, 6020 Innsbruck, and University of Gothenburg, Department of Economics, Centre for Finance, Vasagatan 1, 40530 Gothenburg. Phone: +43 512507 73014, E-mail: michael.kirchler@uibk.ac.at. Lindner: University of Innsbruck, Department of Banking and Finance, Universitätsstrasse 15, 6020 Innsbruck. Phone: +43 512507 73008, E-mail: florian.lindner@uibk.ac.at. Weitzel: Utrecht University School of Economics, Kriekenpitplein 21-22, 3584 EC Utrecht, E-mail: u.weitzel@uu.nl; Radboud University, Institute for Management Research, Thomas van Aquinostraat 5.1.26, 6525 Nijmegen. 
In recent years, excessive risk-taking in the finance industry has been depicted as one of the main contributors to the global financial crisis (Financial Crisis Inquiry Commission, 2011; Dewatripont and Freixas, 2012). In particular, bonus schemes and tournament incentives have been identified among the main drivers for excessive risk-taking in developed financial markets (Rajan, 2006; Diamond and Rajan, 2009; Bebchuk and Spamann, 2010). These tournament incentives are characterized by two major components. The first and more obvious component is that salary and other material rewards depend on performance, creating rank-dependent "monetary incentives" for outperforming others. The second and less obvious component consists of "non-monetary incentives" to do better than peers. This second component-called "rank incentives"- provides utility to those at the top of the ranking and disutility to those at the bottom (Barankay, 2015), representing preferences for relative performance. ${ }^{1}$ This nonmonetary preference for relative performance can be driven by the desire for a positive self-image (Bénabou and Tirole, 2006; Köszegi, 2006), but also by concerns about public status (Frank, 1985; Moldovanu et al., 2007). Hence, rank incentives not only have an implicit relevance in tournaments, but also play a more prominent, explicit role. In the finance industry, rankings, ratings, and awards are the visible hallmarks of a strong culture of relative performance and social competition. Funds are ranked or rated annually and so are their managers. ${ }^{2}$ Awards to the "Fund Manager of the Year", the "Banker of the Year", or the "Analyst of the Year" are recurring and sought-after distinctions in many areas of finance. ${ }^{3}$ More informally, financial professionals (henceforth professionals) often compare themselves with others in their discussions about investments and their successes ("cheap talk", see Crawford, 1998), effectively ranking each other on a permanent basis. Recent evidence from laboratory and field experiments documents that rank incentives, on average, increase individuals' effort and performance (Azmat and Iriberri, 2010; Blanes-i-Vidal and Nossol, 2011; Tran and Zeckhauser, 2012; Bandiera et al., 2013; Delfgaauw et al., 2013), but also promote unethical behavior (Charness et al., 2014).

In an industry where competition and relative performance take center stage, it is striking that no scientific evidence exists showing how competition for rank affects professionals' behavior. This study narrows this gap by investigating the impact of rankings on professionals' risk-taking in investment decisions. We conducted lab-in-the-field experiments and online experiments with 657 financial professionals from major financial institutions in various OECD countries and laboratory experiments with 432 students. Importantly, we only recruited professionals who regularly engage in investment decisions in their professional life. The experiments differ in the selection of participants (professionals versus students), in the frame the investment decisions were made

\footnotetext{
${ }^{1}$ See Veblen (1899) and Festinger (1954) for classical papers and Roussanov (2010) for a finance application.

${ }^{2}$ See, for example, http://www.morningstar.com/; http://money.usnews.com/funds/mutual-funds; http://www.bloomberg.com/news/articles/2014-01-08/glenview-s-robbins-tops-hedge-fund-ranking-with-bet-onobamacare.

${ }^{3}$ See, for example, http://www.fmya.com/; http://www.investmentawards.com; http://excellence.thomsonreuters.com/award/starmine.
} 
(investment frame versus abstract lottery frame), in the payoff consequences (own return versus family return), in professionals' social identity that was made salient (private identity versus professional identity), and whether the ranking was payoff-relevant (non-incentivized ranking versus tournament incentives). This allows us to draw a comprehensive picture of the role of rankings in professionals' risk-taking behavior.

In the first experiment, PROF, we investigate whether and to what extent non-incentivized rankings and tournament incentives drive professionals' risk-taking in framed investment decisions. For this, we recruited 252 professionals and administered repeated portfolio choices between a risk-free alternative and a risky asset for eight periods. In the baseline treatment professionals faced linear incentives and were paid according to their final wealth. In the ranking treatment everything was kept identical but, in addition, participants received feedback on their position in an anonymous ranking among peers. The ranking itself was not payoff-relevant. We find that, compared to the baseline, significantly more risk is taken among underperformers when an anonymous and non-incentivized ranking is displayed. We also administered a tournament treatment which was identical to the ranking treatment except that the ranking was relevant for payout. In line with literature on bonuses and risk-taking (e.g., Rajan, 2006; Kleinlercher et al., 2014), we find that average risk-taking of professionals increases with tournament incentives compared to the baseline. This increase in risk-taking is mainly driven by underperformers. When zooming in on rank-dependent risk-taking, our data suggest that rank incentives shape risk-taking in the tournament treatment. In fact, monetary incentives in the tournament treatment hardly change rank-dependent risk-taking we already observe in the ranking treatment. This indicates that, solely by displaying a non-incentivized ranking, professionals' concerns for relative performance are activated, often at tournament level.

If concerns for relative performance are universal in framed investment decisions, one could expect that rank-driven behavior is equally strong among professionals and non-professionals. Hence, in a second experiment, STUD, we analyze whether results hold with a sample of 432 students who obviously have no financial professional identity. We kept the experiment identical in treatments and design (except for lower stakes). We observe fundamentally different results as students' risk-taking in the ranking treatment is not driven by rank incentives. In the tournament treatment, however, incentivized rankings increase risk-taking among underperformers similarly to the professionals.

These findings raise the question about the origins and the robustness of behavioral differences between industry professionals and non-professionals. One candidate explanation is that professionals might import their professional identity and experience from years in the industry to the laboratory. According to social identity theory of Akerlof and Kranton (2000) decision makers have multiple social identities (e.g., gender, ethnicity, or occupation) prescribing how they behave when a certain identity is salient. Behavior is influenced because individuals experience a disutility if their behavior deviates from what their identities specify. Cooper et al. 
(1999), for example, observe that the behavior of Chinese managers in their experiment depends on whether the framing of the task refers to the managers' business reality or is presented in abstract terms. The authors suggest that the business frame activates managers' experience from outside the laboratory and increases comprehension. Cohn et al. $(2014,2017)$ present related evidence. They show that financial professionals cheat more and take less risks when their professional identity is salient as opposed to situations when their private identity is salient. Translated to our results this suggests that rank-driven behavior could be imported from professionals' experience in the industry where rankings, relative performance and tournament incentives are salient and important.

To investigate this channel and to check for robustness, we report survey evidence from the experiments and we run two additional treatments with 102 professionals and one online experiment with 303 professionals. In particular, we find significantly stronger preferences for relative performance among professionals compared to students and a positive correlation with their risk-taking in the investment game in Experiment PROF. This corroborates the notion that concerns for relative performance play a major role for the observed rank-driven investment behavior. Moreover, in the first additional treatment we changed the investment frame of the experiment to an abstract lottery frame, thereby trying to de-activate or downplay participants' professional identity. In the second treatment we kept the original frame of the investment task, but downplayed the professional identity by letting participants invest jointly for themselves and a self-selected family member. Results of both treatments show that professionals' rankdriven behavior is still pronounced. One critical issue with the lab-in-the-field treatments is that professionals knew that they played against other professionals. It is possible that this common knowledge kept the professional identity (partly) activated and overpowered possible effects of the abstract lottery frame and of family concerns.

To test the role of professional identity importing in a cleaner setting we run an online experiment, PROF ${ }^{\text {ONLINE }}$, where we have more control over professionals' knowledge about others. We recruited another 303 financial professionals and designed two treatments: one in which professionals were primed (like in Cohn et al., 2014, 2017) with their professional identity and were informed that they played with other professionals; and one in which professionals were primed with their private identity and were informed that they played with others from the general population. Again, we find strong and similar rank-driven behavior in both treatments. Professionals seem to care about rankings no matter whether their private or professional identity is salient. Importantly, we consciously recruited almost $50 \%$ female professionals in the online experiment, allowing us to investigate gender differences in the finance industry. We find no differences between male and female professionals in their general level of risk-taking and in their rank-driven behavior, suggesting similar and robust concerns for relative performance independent of gender and private or professional identity.

Our paper contributes to several emerging strands of literature. First, we contribute to 
the body of literature analyzing behavior of financial professionals, which is still in its infancy. Learning more about the behavior of professionals is important as they take a central role in the economy with major implications for society. Moreover, they differ from students (and other subject pools) in many dimensions like age, income, education, and experience in the industry. Therefore, it is not surprising that professionals' behavior can differ from the behavior of students substantially. Professionals exhibit a higher degree of myopic loss aversion (Haigh and List, 2005), but also show herd behavior similar to students (Cipriani and Guarino, 2009) and behavior in line with prospect theory (Abdellaoui et al., 2013). We show that professionals' preferences for relative performance are fundamentally different from students, which has not been subject of research so far.

Second, we contribute to the emerging literature on rank incentives, in particular to those studies investigating the relationship between rank incentives and risk-taking. For instance, Kuziemko et al. (2014) show that individuals are last-place averse and take higher risks at the very bottom of a ranking. Furthermore, Dijk et al. (2014) find that underperformers invest predominantly in positively skewed assets, while outperformers mainly choose assets with negative skewness. Frydman (2016) provides biological foundations of humans' preferences over relative wealth. In a portfolio choice experiment, he finds that neural activity in reward-related regions of the brain is increasing in a participant's own wealth, but decreasing in a peer's wealth. We contribute by showing that rankings drive risk-taking among professionals but not among students in framed investment decisions and that this effect is very robust.

Third, we contribute to the literature on social identity theory (Akerlof and Kranton, 2000). Studies by Cooper et al. (1999) and Cohn et al. (2014, 2017) show that behavior of industry professionals in lab-in-the-field experiments can differ depending on framing and identity priming. With our study we provide evidence that the origin for rank-driven behavior among professionals is not solely due to the import of their professional identity, because they show similar concerns for relative performance when their private identity is salient. This indicates that professionals care for relative performance and rankings in general.

Our findings offer a number of important implications. First, regulators should be aware that not only tournament incentives, but also the widespread use of rank incentives could accumulate (too much) risk in the financial sector. Second, the increased appetite for risk of underperforming professionals implies that regulating monetary tournament incentives might be ineffective as long as rank incentives trigger similar behavior. Third, and here the implications extend beyond regulation, competitive pressure in the finance industry ultimately originates from the customers if they directly or indirectly demand high abnormal returns, for example, via corresponding fund flows (see, among others, Sirri and Tufano, 1998; Kaniel and Parham, 2017). Hence, better financial literacy of customers could help to prevent unrealistic demands for outperformance. Fourth, our results shed new light on the claim that a higher number of female professionals would lower risk-taking and reduce the propensity of bubbles (Eckel and 
Füllbrunn, 2015). The aforementioned study used student samples, while we find no gender effects among financial professionals with regard to general risk-taking and rank-driven behavior. This could be an indication that professionals, who self-select into the financial industry and are subsequently exposed to the sector's own rules and norms, exhibit (partly) similar behavior across gender. Finally, from an employer's perspective, it is important to know that rank incentives can substitute for expensive bonuses, provided that increased risk-taking is a desirable strategy. Conversely, if increased risk-taking is not desired, companies might want to downplay rank incentives, particularly to limit risk-taking of underperformers.

The remainder of the paper is organized as follows: In Section I we introduce the experimental design and present the results of the investment experiment with professionals. In Section II we present data of the investment experiment with student subjects. In Section III we outline results of robustness check experiments with professionals investigating the role of identity importing and, finally, Section IV concludes.

\section{Investment Experiment with Professionals (PROF)}

We divided each lab-in-the-field and laboratory experiment into two parts. Participants played an investment game in the first and major part and participated in additional tasks eliciting risk attitudes, loss aversion, and personal characteristics in the second part.

\section{A The Investment Game}

Over eight periods, participants repeatedly made portfolio choices between a risk-free alternative and a risky asset. The investment game was inspired by, and resembles games of, Lohrenz et al. (2007), Ehm et al. (2014), Bradbury et al. (2015), and Huber et al. (2016). In each period, the risk-free asset yielded a return of $R F=0.015(1.5 \%)$ and the risky asset paid an expected return of $R E T \_A S S E T=0.036(3.6 \%)$ with a standard deviation of $15.9 \%$. As in Bradbury et al. (2015), we computed these numbers from time series of the 6-months EURIBOR for the risk-free rate (before 1999: FIBOR, Frankfurt Interbank Offered Rate) and from the DAX 30 for the risky asset. We calculated returns and standard deviations for a 20-year period from January 1, 1994 to December 31, 2013. The numbers reflect semi annual returns and standard deviations. Participants received information about the mean and standard deviation of the return distribution but no information about the origin of the underlying data (except that they were part of historical financial market data). In each period participants decided which fraction, RISK, of their current portfolio wealth, $W E A L T H_{t}$, to invest in the risky asset. Portfolio wealth is carried over from one period to the next. Participants were allowed to invest up to $200 \%$ of their portfolio wealth, meaning that the amount exceeding $W E A L T H_{t}$ was 
borrowed at the risk-free rate $R F .{ }^{4}$

In a between-subjects design, we randomly assigned participants to groups of six, which remained the same for the duration of the investment game. Each group played one of the three treatments described below. In Treatment TBASE participants faced linear incentives and allocated their portfolio in eight periods without peer feedback. They received an initial endowment of 90 euro and accumulated gains and losses depending on their investments over time. In line with Cohn et al. $(2014,2017)$ each participant received the payout of the investment game with a probability of $20 \%$ to facilitate high stakes. An increasing number of studies indicate that these commonly used payment schemes with random components do not bias risk-taking behavior in experiments (Starmer and Sugden, 1991; Cubitt et al., 1998; Hey and Lee, 2005; March et al., 2015). Recently, Charness et al. (2016) pointed out that the pay-one (or pay-asubset) method is either equal or even superior to the pay-all method in the majority of cases.

In Treatment TRANK participants received the same linear incentives as in TBASE, but after each period we showed them an anonymous league table, detailing all group members' current wealth levels, associated rank-RANK $\in\{1,2, \ldots, 6\}$ - and their own position in the ranking. This ranking was not incentivized and there was no public disclosure of the ranking in the end. ${ }^{5}$

Treatment TTOUR equals Treatment TRANK, the only difference being that the ranking was payout relevant. Participants who finished the investment experiment at ranks four to six received no payout. For the top three ranks the final wealth of all six participants was summed up and divided as follows. The winner received $1 / 2$, the second-best received $1 / 3$, and the third earned $1 / 6$ of the entire cake. This was done to ensure identical expected stake sizes across treatments. This treatment is an important extension in view of the prevalence of bonuses and tournament-like payments in the finance industry. It allows us disentangling rankdriven behavior rooted in non-monetary incentives in the ranking treatment from monetary rank incentives in the tournament treatment.

In the second part of the experiment, we administered two additional experimental tasks, one of which was paid out randomly, and survey questions. Part 2 of the instructions were handed

\footnotetext{
${ }^{4}$ Before the investment game started, participants had to sample 30 returns from the theoretical distribution with the above-mentioned first two moments of the distribution. The reason for this was to make them more familiar with the properties of the risky asset. As Kaufmann et al. (2013) and Bradbury et al. (2015) report, experience sampling increases decision commitment and confidence, while it can also decrease known biases such as overestimation of loss probabilities.

${ }^{5}$ The reason why, in addition to the ranking, we provided participants with information on their wealth is twofold. First, it made the experimental setup much more realistic, as finance professionals are used to having instantaneous access to wealth-related performance measures. Second, demoralization could have occurred once participants realized that their actual rank was below their desired rank but without any indication as to how much they had to catch up to reach their desired rank. When wealth is displayed along with rank, this demoralization effect is dampened - the associated mechanism is known as the path-goal model (House, 1971, 1996)-hence increasing motivation. See also Barankay (2015) regarding this approach of displaying performance along with rank in his field experiment. For theoretical contributions on the relation between relative wealth and risk-taking behavior see DeMarzo et al. (2004, 2007, 2008).
} 
out after all participants had completed Part 1. In the first task we measured risk-attitudes in a standard choice list setting (Bruhin et al., 2010; Abdellaoui et al., 2011). We also measured risk attitudes (on a Likert scale from 1 to 7 ) with a survey question from the German SocioEconomic Panel (SOEP; Dohmen et al., 2011). Participants answered the question: "How do you see yourself: Are you willing to take risks or try to avoid risks?" The answers were provided on a Likert scale from 1 (not at all willing to take risks) to 7 (very willing to take risks). We modified the scale with respect to Dohmen et al. (2011) to fit the other questions in the survey part. In the second task, we measured loss aversion using the procedure of Gächter et al. (2007). Participants earned 18 euro as a show-up fee for participating in the experiment, which covered the potential maximum loss in the loss aversion task. In the survey, we measured participants' attitudes toward social comparison with three questions on social status, financial success, and relative performance, taken from Cohn et al. (2014). Furthermore, we measured CRT scores (Cognitive Reflection Test; Frederick, 2005) with slightly modified questions (see Online Appendix E). Questions on demographics concluded the experiment. See Online Appendix C and D for instructions of all experiments of this paper. ${ }^{6}$

For Experiment PROF we recruited 252 professionals from major financial institutions in several OECD-countries. All professionals that participated in experiments in this paper are regularly confronted with competitive rankings, bonus incentives, and investment decisionsi.e., professionals from private banking, trading, investment banking, portfolio management, fund management, and wealth management. ${ }^{7}$ In Experiment PROF $88.9 \%$ of participants were male, their average age was 35.6 years, and they had been working in the finance industry for 11.7 years on average.

In all of our offline experiments with professionals we booked a conference room on location or in close proximity (for several organizations to participate simultaneously), set up our mobile laboratory and invited professionals to show up. Our mobile laboratory is virtually identical to the Innsbruck EconLab at the University of Innsbruck, where we ran the experiment with students (see pictures in the Online Appendix F). The mobile lab consists of laptops and partition walls on all sides for each participant, ensuring conditions as in regular experimental laboratories. We mainly recruited members of professional associations/societies, ensuring that most sessions were populated with professionals from different institutions. With this procedure

\footnotetext{
${ }^{6}$ In the standard choice list setting eliciting risk-preferences participants could choose between a risky option, paying either 0 or 24 euro with equal probability, or a safe payment, which differed between 3 and 21 euro in steps of 3 euro. In the task measuring loss aversion, participants had to decide whether to play a particular lottery or not. If they decided to play the lottery, participants either received, with equal probability, 15 euro or incur a loss of $\mathrm{X}$. The loss $\mathrm{X}$ varied from 3 to 18 euro in steps of 3 euro. If participants decided not to play a particular lottery, they received a payout of zero. We also elicited the 10-item Big-5 personality traits according to Rammstedt and John (2007) and socially undesirable personality traits such as narcissism, psychopathy, and machiavellianism (i.e., Dark Triad) using the 12-item test of Jonason and Webster (2010). The questions asked in the survey were programmed in a separate $\mathrm{z}$-Tree file, which will be provided upon request.

${ }^{7}$ We signed non disclosure agreements (NDA) for not disclosing the identity of the participating financial institutions.
} 
we achieved high comparability with the student sample as most professionals did not know, or barely knew, each other. In total, 78, 102, and 72 professionals participated in treatments TBASE, TRANK, and TTOUR, respectively. We programmed and conducted all experiments using z-Tree (Fischbacher, 2007).

Professionals received an average payout of 52 euro for both parts of Experiment PROF with a maximum payout of 600 euro and an average duration of 45 minutes per session. For participants who received money in the investment game, the average payout was 134 euro for a task of 20 minutes, ensuring salient incentives for professionals. In the questionnaire, professionals reported an average annual gross salary of 90,500 euro. Accordingly, the average (maximum) hourly payoff from the experiment amounted to roughly 2.7 times (31 times) the average professional's hourly wage after taxes. ${ }^{8}$ We therefore consider our monetary incentives to be substantial and are confident that they induced meaningful behavior. Finally, we administered the payout privately by handing out sealed envelopes containing the payout from the experiment.

\section{B Results}

Taking a first, descriptive look at average risk-taking across all periods and ranks, we find that the percentage invested in the risky asset is highest in Treatment TTOUR with $110.8 \%$, exceeding risk-taking in TBASE and TRANK by 14.9 and 11.8 percentage points, respectively (see Figure A1 in the Online Appendix). To investigate statistical significance of the variables of interest, we run random effects panel regressions with $\mathrm{AR}(1)$ disturbance with participant $i$ 's invested share $R I S K$ in period $t$ as the dependent variable. ${ }^{9}$ We account for asset- and portfolio-specific effects by including last period's asset return, $R E T_{-} A S S E T_{t-1}$, and the log-return of participant $i$ 's portfolio since the start, $R E T_{-} P F_{t-1}=\ln \left(W E A L T H_{t-1} / 90\right)$, where $W E A L T H_{t-1}$ is the portfolio wealth in euro in period $t-1$. (We henceforth refer to this econometric specifications as "baseline regression" and use it throughout the paper except where explicitly stated otherwise.)

\footnotetext{
${ }^{8}$ For this calculation, we assumed a working time of 45 hours/week for 47 weeks/year and $40 \%$ taxes to calculate an hourly net wage (26 euro). In our experiment, participants' average (maximum) hourly payment was $69(800)$ euro $(52 * 60 / 45$ and $600 * 60 / 45)$, resulting in $270 \%(3,116 \%)$ of their salary. Haigh and List (2005) report in footnote 6 that their average traders' payment for a 25 minutes task was 40 U.S. dollars, which translates to an hourly payment of 96 U.S. dollars. Given an exchange rate of about 1.32 at the time of the study, the payment in Haigh and List (2005) is equivalent to an average hourly wage of 73 euro. Note that monetary incentives in experiments with a representative sample of the general population are less accurate, because of the high heterogeneity in participants' salaries. In our case, the hourly payout of nearly three times the average applies to a sample with a more homogeneous salary distribution.

${ }^{9} \mathrm{~A}$ Hausman specification test indicates that the individual-level effects are adequately modelled with a random-effects model. Moreover, we prefer this method over, for instance, simple difference in means tests, because with this approach we can better control for the dynamics of the data set.
} 
Table 1: Ranks and Risk-Taking in Experiment PROF

Random effects panel regression with $\mathrm{AR}(1)$ disturbance, testing treatment differences of participants' (professionals') percentage invested in the risky asset, $R I S K . R E T_{-} P F_{t-1}$ is the log-return of participant $i$ 's portfolio since the start of the experiment and $R E T_{-} A S S E T_{t-1}$ is the preceding period's asset return. TRANK and TTOUR are dummy variables for the treatments with rank incentives and with tournament incentives, respectively, with TBASE as the baseline reference category. In Column 4 (ALL) treatment differences in risk-taking for the entire data set are displayed. In Columns 5 and 6 the data set is split into a sample of outperformers in each period (Ranks 1-3, HIGH) and a sample of underperformers in each period (Ranks 4-6, LOW). In Columns 7-9 the impact of last period's rank is investigated. Here, $R A N K_{t-1}$ indicates participant $i$ 's rank in the preceding period. Standard errors are provided in parentheses. $* * *, * *$, and * represent significance at the $1 \%, 5 \%$, and $10 \%$ levels, respectively.

\begin{tabular}{lcccccc}
\hline \hline Dep. variable: $R I S K$, & $(1)$ & $(2)$ & $(3)$ & $(4)$ & $(5)$ & $(6)$ \\
percentage risky asset & TBASE & TRANK & TTOUR & ALL & HIGH & LOW \\
\hline$\alpha$ & $97.065^{* * *}$ & $104.845^{* * *}$ & $113.971^{* * *}$ & $97.173^{* * *}$ & $106.765^{* * *}$ & $90.989^{* * *}$ \\
& $(5.583)$ & $(5.063)$ & $(6.308)$ & $(5.769)$ & $(6.560)$ & $(5.849)$ \\
$R E T \_P F_{t-1}$ & $-0.400^{* * *}$ & $-0.480^{* * *}$ & $-0.369^{* * *}$ & $-0.411^{* * *}$ & $-0.381^{* * *}$ & $-0.415^{* * *}$ \\
& $(0.076)$ & $(0.088)$ & $(0.082)$ & $(0.047)$ & $(0.084)$ & $(0.060)$ \\
$R E T \_A S S E T_{t-1}$ & -0.124 & -0.013 & $-0.464^{* * *}$ & $-0.180^{* *}$ & $-0.205^{*}$ & $-0.242^{* *}$ \\
& $(0.139)$ & $(0.129)$ & $(0.147)$ & $(0.080)$ & $(0.122)$ & $(0.116)$ \\
TRANK & & & & 7.658 & -12.337 & $23.872^{* * *}$ \\
& & & & $(7.664)$ & $(8.736)$ & $(7.865)$ \\
TTOUR & & & & $16.285^{* *}$ & -8.686 & $31.776^{* * *}$ \\
& & & & $(8.320)$ & $(9.587)$ & $(8.613)$ \\
\hline N & 546 & 714 & 504 & 1764 & 882 & 882 \\
R-squared & 0.094 & 0.099 & 0.111 & 0.109 & 0.002 & 0.301 \\
$\chi 2$ & 36.569 & 35.516 & 40.388 & 112.924 & 34.907 & 86.918 \\
Prob $>\chi 2$ & 0.000 & 0.000 & 0.000 & 0.000 & 0.000 & 0.000 \\
\hline \hline
\end{tabular}

\begin{tabular}{lccc}
\hline \hline Dep. variable: $R I S K$, & $(7)$ & $(8)$ & $(9)$ \\
percentage risky asset & TBASE & TRANK & TTOUR \\
\hline$\alpha$ & $109.336^{* * *}$ & $86.272^{* * *}$ & $86.661^{* * *}$ \\
& $(7.933)$ & $(7.635)$ & $(9.414)$ \\
$R E T_{-} P F_{t-1}$ & $-0.444^{* * *}$ & $-0.384^{* * *}$ & $-0.273^{* * *}$ \\
& $(0.079)$ & $(0.092)$ & $(0.085)$ \\
$R E T \_A S S E T_{t-1}$ & -0.096 & -0.067 & $-0.510^{* * *}$ \\
& $(0.140)$ & $(0.129)$ & $(0.146)$ \\
$R A N K_{t-1}$ & $-3.470^{* *}$ & $5.055^{* * *}$ & $7.764^{* * *}$ \\
& $(1.661)$ & $(1.566)$ & $(2.030)$ \\
\hline $\mathrm{N}$ & 546 & 714 & 504 \\
$\mathrm{R}-$-squared & 0.122 & 0.114 & 0.152 \\
$\chi 2$ & 41.706 & 46.438 & 56.405 \\
Prob $>\chi 2$ & 0.000 & 0.000 & 0.000 \\
\hline \hline
\end{tabular}


Table 1 reports the results of the baseline regression for each treatment separately (Columns 1 to 3), and for pooled data with dummies for treatments TRANK and TTOUR (Column 4, ALL). ${ }^{10}$ We find significantly higher levels of risk-taking in TTOUR compared to the baseline and no differences between TRANK and the baseline. A post-estimation Wald test also reports no difference between the coefficients of the dummies for TRANK and TTOUR either $(p=0.272)$. This result is in line with literature, arguing that tournament incentives increase risk-taking (Hvide, 2002; Rajan, 2006; Kleinlercher et al., 2014).

For a closer inspection of the effects of rank incentives, we split the data set in a sample of outperformers (ranks 1 to 3 ) and in a sample of underperformers (ranks 4 to 6 ) in each period. We find that risk-taking across treatments is statistically similar for outperformers (Column 5 , HIGH), but differs markedly for underperformers (Column 6, LOW). Here, significantly more risk is taken in TRANK and TTOUR compared to the baseline. ${ }^{11}$

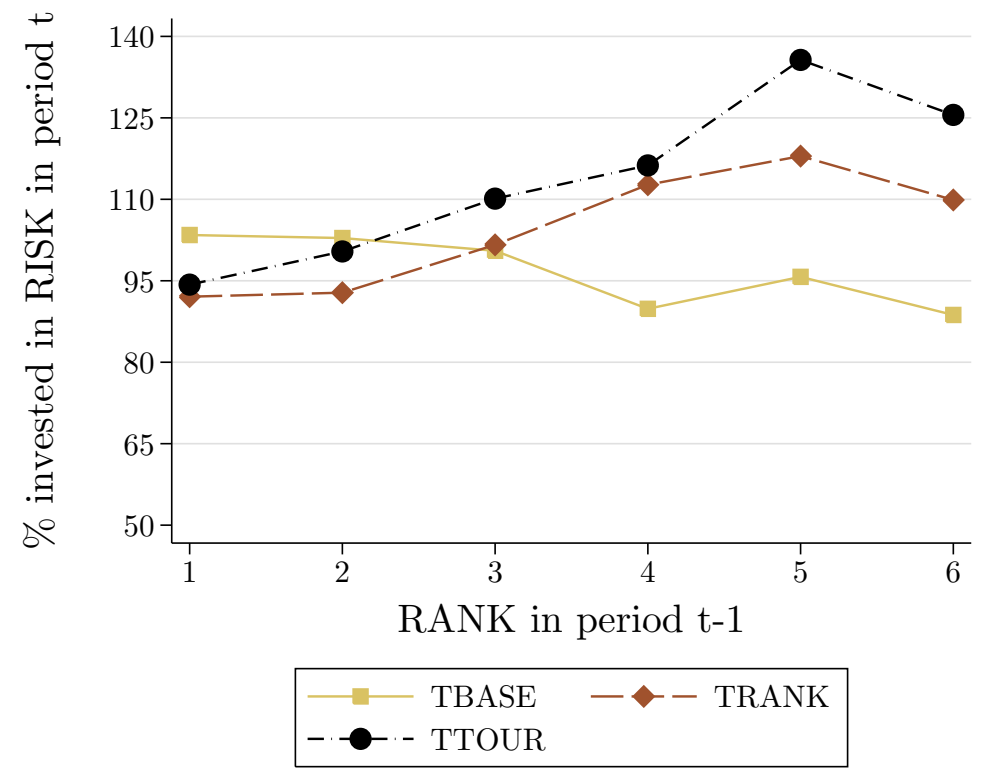

Figure 1: Ranks and Risk-Taking in Experiment PROF

Average percentage invested in the risky asset $(R I S K)$ in period $t$ conditional on rank in the previous period $\left(R A N K_{t-1}\right)$ across all treatments in the professional sample. $R A N K_{t-1}$ indicates the position in the ranking with higher numbers pointing at weaker relative performance.

Flanking the above results on rank-effects, Figure 1 shows professionals' risk-taking conditional on their rank in the previous period. ${ }^{12}$ We find that outperforming professionals, who

\footnotetext{
${ }^{10}$ For robustness we estimate all models in Table 1 without $\operatorname{AR}(1)$ disturbance. The results do not change qualitatively (see Table AI).

${ }^{11}$ A post-estimation Wald test reports no difference between the coefficients of TRANK and TTOUR among underperformers $(p=0.339)$.

${ }^{12}$ Here, we ran the baseline regressions (Columns 1 to 3 in Table 1) with dummy variables for each $R A N K$ in $t-1$ and without AR(1) disturbance. Figure 1 shows the sum of the intercept and the coefficient of each rank dummy, reflecting the rank-specific average of $R I S K$ after controlling for portfolio wealth and asset returns.
} 
were on first place in $t-1$, all invested relatively similarly in the risky asset across treatments, ranging from $92 \%$ in TRANK to $103 \%$ in the baseline. However, underperforming professionals in TRANK (ranks 4 to 6 ) clearly took on more risk and invested on average 112.7\%, 118.0\% and $109.9 \%$ of their current wealth in the risky asset, respectively. The differences in risk-taking of underperformers between treatments TRANK and TBASE are substantial, ranging from 21 to 23 percentage points. Figure 1 also shows that rank-dependent monetary incentives in TTOUR hardly change this rank-effect compared to the ranking treatment.

In Columns 7 to 9 of Table 1 we deepen the analyses of the rank-effect outlined in Figure 1 by including the variable $R A N K_{t-1}$, recording a professional's rank in portfolio wealth in the previous period. We find that the coefficient of $R A N K_{t-1}$ is positive and statistically highly significant in both the tournament and the ranking treatment. In TRANK, with anonymous rank feedback only, risk-taking among professionals increases by roughly 5.1 percentage points with each position further down the league table. Accordingly, the coefficient of $R A N K_{t-1}$ in the tournament treatment is close to the corresponding effect size in TRANK and statistically not different. ${ }^{13}$ In contrast, in the absence of rank information in the baseline treatment, risktaking decreases significantly in $R A N K_{t-1}$ (Column 7 ). In other words, risk-taking is lower in poorer ranks, which is expected as those who, on average, take more risks will end up higher in the ranking.

Next to the effects of ranking on risk-taking, we also observe a highly significant and consistent negative relationship between the portfolio return $R E T_{-} P F_{t-1}$ and participants' risktaking, indicating that professionals tend to decrease (increase) risk-taking in gains (losses). This behavior is related to the disposition effect (Weber and Camerer, 1998) and suggests a monetary reference point and/or nonlinear curvature in monetary incentives. ${ }^{14}$ To gain more insight into this investment behavior, we add a dummy variable for positive portfolio returns $\left(R E T_{-} P F_{t-1}^{P O S}\right)$. The results in Table AIV in the Online Appendix show that risk-taking is indeed negatively related to positive portfolio returns in most specifications. This is generally in line with the disposition effect as professionals seem to ride losses more than gains. We further report a negative and significant relationship between the last period's risky asset return $R E T_{\_} A S S E T_{t-1}$ and risk-taking in the tournament treatment and in the joint regressions in Columns 4 and 6 . This indicates that professionals do not consider the random draws to be independent. They rather exhibit behavior in line with the Gambler's Fallacy (Rabin, 2002).

One interesting aspect in this setting is the role of relative wealth concerns among professionals. Following DeMarzo et al. (2004) past or current relative wealth of others can influence one's own investment choices. In our setting relative wealth levels and ranks are correlated,

\footnotetext{
${ }^{13}$ We find no significant interaction effect for $R A N K_{t-1}$ and a dummy for TTOUR in a pooled sample with both treatments TRANK and TTOUR (unreported).

${ }^{14} \mathrm{We}$ acknowledge that it is not clear where such a monetary reference point would lie. A natural candidate could be the initial endowment, which we assume for the analysis below, but other references such as the compounded expected asset return are also possible.
} 
but relative wealth levels reveal additional information in terms of distance to peers. A clean separation of the role of pure rank information and pure relative wealth concerns would call for additional treatments that build on TRANK, but do not display relative wealth levels. We leave a clean separation of this issue for future research.

Results of this experiment suggest that anonymous rankings strongly increase risk-taking among underperformers. Although monetary tournament incentives increase risk-taking in general, non-monetary rank incentives seem to be a crucial force in shaping professionals' rankdependent investment behavior.

\section{Investment Experiment with Students (STUD)}

If concerns for relative performance are universal in framed investment decisions, one could expect that rank-driven behavior is equally strong among professionals and non-professionals. Students are perfectly suited for this analyses, because they do not have professional experience in investment decisions. Moreover, students represent the most prevalent, "classic" lab participant in experimental studies. We administered the same experiment to bachelor and master students from various disciplines at the University of Innsbruck (Austria). In total, 432 students took part, 144 in each treatment. To almost resemble the gender ratio of the professionals, we recruited $79.9 \%$ male participants. The average age was 23.9 years and $52.5 \%$ were economics or management students. All specifications were identical to the experiment with professionals except for the stake size. Similar to other studies (List and Haigh, 2005; Alevy et al., 2007; Cohn et al., 2014), we scaled down student stakes to $1 / 3$ of the professionals' payoffs in all parts of the experiment. Average earnings were 18 euro with a maximum payout of 323 euro.

We find that average risk-taking $(104.5 \%)$ is higher in the tournament treatment than in TRANK and TBASE with values of 76.9 and 74.0, respectively (see Figure A1 in the Online Appendix for an overview). This is supported by the panel regression in Table 2, showing that the coefficient of TTOUR in Columns 4 to 6 is positive and significant. This finding applies both for underperformers and outperformers, indicating that tournament incentives increase risk-taking among students on all levels. ${ }^{15}$

\footnotetext{
${ }^{15}$ A post-estimation Wald test also shows significant differences between the coefficients of TRANK and TTOUR ( $p=0.000$ for ALL and LOW; $p=0.015$ for HIGH).
} 
Table 2: Risk-Taking in Experiment STUD

Random effects panel regression with AR(1) disturbance, testing treatment differences of participants' (students') percentage invested in the risky asset, $R I S K . R E T_{-} P F_{t-1}$ is the log-return of participant $i$ 's portfolio since the start of the experiment and RET_ASSET $T_{t-1}$ is the preceding period's asset return. TRANK and TTOUR are dummy variables for the treatments with rank incentives and with tournament incentives, respectively, with TBASE as the baseline reference category. In Column 4 (ALL) treatment differences in risk-taking for the entire data set are displayed. In Columns 5 and 6 the data set is split into a sample of outperformers in each period (Ranks 1-3, HIGH) and a sample of underperformers in each period (Ranks 4-6, LOW). In Columns 7-9 the impact of last period's rank is investigated. Here, $R A N K_{t-1}$ indicates participant $i$ 's rank in the preceding period. Standard errors are provided in parentheses. ${ }^{* * *}, * *$, and $*$ represent significance at the $1 \%, 5 \%$, and $10 \%$ levels, respectively.

\begin{tabular}{|c|c|c|c|c|c|c|}
\hline $\begin{array}{l}\text { Dep. variable: } R I S K \text {, } \\
\text { percentage risky asset }\end{array}$ & $\begin{array}{c}(1) \\
\text { TBASE }\end{array}$ & $\begin{array}{c}(2) \\
\text { TRANK }\end{array}$ & $\begin{array}{c}(3) \\
\text { TTOUR }\end{array}$ & $\begin{array}{l}(4) \\
\text { ALL }\end{array}$ & $\begin{array}{c}(5) \\
\text { HIGH }\end{array}$ & $\begin{array}{c}(6) \\
\text { LOW }\end{array}$ \\
\hline$\alpha$ & $\begin{array}{c}73.560^{* * *} \\
(4.213)\end{array}$ & $\begin{array}{l}79.091^{* * *} \\
(4.418)\end{array}$ & $\begin{array}{c}106.806^{* * *} \\
(4.290)\end{array}$ & $\begin{array}{c}73.600^{* * *} \\
(4.303)\end{array}$ & $\begin{array}{c}73.646^{* * *} \\
(4.808)\end{array}$ & $\begin{array}{c}74.919^{* * *} \\
(4.872)\end{array}$ \\
\hline$R E T_{-} P F_{t-1}$ & $\begin{array}{c}-0.436^{* * *} \\
(0.063)\end{array}$ & $\begin{array}{c}-0.329 * * * \\
(0.070)\end{array}$ & $\begin{array}{c}-0.383^{* * *} \\
(0.073)\end{array}$ & $\begin{array}{c}-0.394^{* * *} \\
(0.040)\end{array}$ & $\begin{array}{c}-0.177^{* *} \\
(0.069)\end{array}$ & $\begin{array}{c}-0.468^{* * *} \\
(0.055)\end{array}$ \\
\hline$R E T_{-} A S S E T_{t-1}$ & $\begin{array}{l}-0.022 \\
(0.078)\end{array}$ & $\begin{array}{l}-0.071 \\
(0.093)\end{array}$ & $\begin{array}{l}-0.099 \\
(0.129)\end{array}$ & $\begin{array}{l}-0.056 \\
(0.057)\end{array}$ & $\begin{array}{l}-0.054 \\
(0.083)\end{array}$ & $\begin{array}{l}-0.133 \\
(0.087)\end{array}$ \\
\hline TRANK & & & & $\begin{array}{l}5.888 \\
(6.089)\end{array}$ & $\begin{array}{l}-0.023 \\
(6.623)\end{array}$ & $\begin{array}{l}7.006 \\
(6.678)\end{array}$ \\
\hline TTOUR & & & & $\begin{array}{c}33.069^{* * *} \\
(6.081)\end{array}$ & $\begin{array}{c}16.039^{* *} \\
(6.625)\end{array}$ & $\begin{array}{c}42.795^{* * *} \\
(6.681)\end{array}$ \\
\hline $\mathrm{N}$ & 1008 & 1008 & 1008 & 3024 & 1512 & 1512 \\
\hline R-squared & 0.098 & 0.046 & 0.040 & 0.097 & 0.000 & 0.243 \\
\hline$\chi 2$ & 54.791 & 31.039 & 35.075 & 153.791 & 17.853 & 146.822 \\
\hline Prob $>\chi 2$ & 0.000 & 0.000 & 0.000 & 0.000 & 0.003 & 0.000 \\
\hline
\end{tabular}

\begin{tabular}{lccc}
\hline \hline $\begin{array}{c}\text { Dep. variable: } R I S K, \\
\text { percentage risky asset }\end{array}$ & $(7)$ & $(8)$ & $(9)$ \\
\hline$\alpha$ & $70.189^{* * *}$ & $73.192^{* * *}$ & $70.271^{* * *}$ \\
& $(6.373)$ & $(6.569)$ & $(7.050)$ \\
$R E T_{-} P F_{t-1}$ & $-0.417^{* * *}$ & $-0.295^{* * *}$ & $-0.211^{* * *}$ \\
& $(0.068)$ & $(0.076)$ & $(0.077)$ \\
$R E T \_A S S E T_{t-1}$ & -0.029 & -0.090 & -0.204 \\
& $(0.079)$ & $(0.094)$ & $(0.128)$ \\
$R A N K_{t-1}$ & 0.972 & 1.630 & $10.458^{* * *}$ \\
& $(1.383)$ & $(1.343)$ & $(1.624)$ \\
\hline $\mathrm{N}$ & 1008 & 1008 & 1008 \\
$\mathrm{R}$-squared & 0.096 & 0.049 & 0.079 \\
$\chi 2$ & 55.346 & 32.607 & 77.920 \\
Prob $>\chi 2$ & 0.000 & 0.000 & 0.000 \\
\hline \hline
\end{tabular}




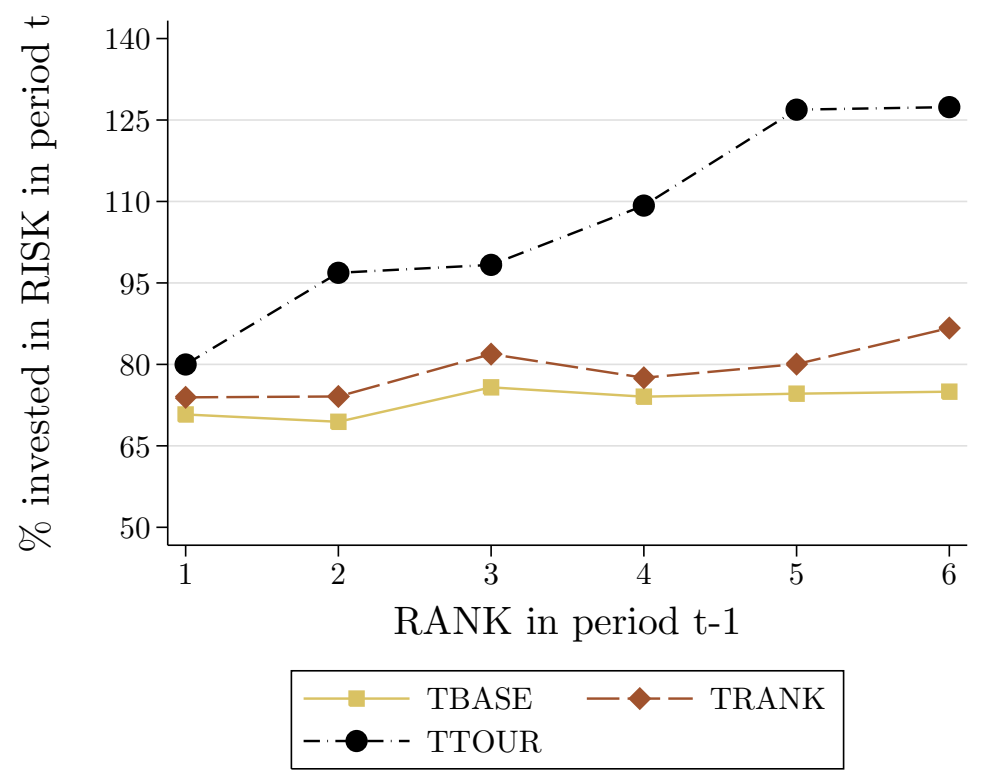

Figure 2: Ranks and Risk-Taking in Experiment STUD

Average percentage invested in the risky asset $(R I S K)$ in period $t$ conditional on rank in the previous period $\left(R A N K_{t-1}\right)$ across all treatments in the student sample. $R A N K_{t-1}$ indicates the position in the ranking with higher numbers pointing at weaker relative performance.

Moreover, in contrast to the professionals, students do not show any reaction to rank incentives, even when they underperform. Figure 2 documents the missing rank-effect in TRANK, outlining that underperformers do not increase risk-taking compared to outperformers. Column 8 in Table 2 provides statistical support as the coefficient of $R A N K_{t-1}$ in the ranking treatment is insignificant. ${ }^{16}$ These results stand in contrast to professionals, yet, once the ranking is payout relevant, we find that students' behavior is almost identical to professionals. Here, the coefficient of $R A N K_{t-1}$ in the tournament treatment (Column 9) is positive and highly significant with a value of 10.5 .

Turning to the control variables in Table 2, we find that the coefficients of portfolio returns, $R E T \_P F_{t-1}$, are significantly negative across all specifications. This is a similar pattern as in the professionals' sample, and indeed, when including an additional dummy for positive portfolio returns (Table AVIII in the Online Appendix) these patterns prevail. Note, however, that the effect is statistically and economically weaker with smaller coefficients and lower statistical significance. With regard to last period's asset return RET_ASSET $T_{t-1}$ and risk-taking, we find some differences between students and professionals, as students do not fall prey to the Gambler's Fallacy to a similar extent. ${ }^{17}$

\footnotetext{
${ }^{16}$ Note that this finding also rules out learning as a possible alternative explanation for the observed rank-effect in the sample of professionals. With feedback in Treatment TRANK, underperformers could learn that more risk-taking is rewarded with higher returns. However, as we observe no rank-effect in TRANK with students, learning does not hold as explanation.

${ }^{17}$ For robustness we estimate all models in Table 2 without $\operatorname{AR}(1)$ disturbance. The results do not change
} 
To investigate whether economics and management students already exhibit similar behavior compared to professionals, we split the student sample between econ/management students and students from other fields. In Table AIX in the Online Appendix we do not find marked differences in behavior between econ/management students and students from other fields. Most importantly, the interaction effects of $R A N K_{t-1} * E C O N$ are insignificant in treatments TRANK and TTOUR, indicating no differences in rank-driven behavior between both groups of students. ${ }^{18}$ These results suggest that the professional banking environment might at least partly drive risk-taking following underperformance.

Finally, in Table 3, we test whether rank-dependent behavior of professionals in Experiment PROF differs from students in Experiment STUD. We run the same regressions as in the first three and last three columns of tables 1 and 2 and add a dummy for professionals (PROFESSIONALS in Columns 1-3) as well as an interaction term with the rank in the previous period in Columns 4-6. The interaction term measures differences between professionals' and students' rank-dependent behavior. Although the experiments differed in stake sizes, which may limit the power of this comparison, the results in Table 3 corroborate our finding that rank-driven behavior, measured by $R A N K_{t-1}$, is significantly stronger in the professional sample than in the student sample in Treatment TRANK (Column 5), but does not differ once the ranking becomes payout-relevant in the tournament treatment (Column 6). ${ }^{19}$ Columns 1 and 2 also support earlier results that professionals exceed students' risk-taking in the baseline and in the ranking treatment, but not when tournament incentives are introduced (Column 3). ${ }^{20}$

Overall, our results indicate that rank-driven behavior in investment contexts is not universal and that professionals' behavior deviates markedly from students' behavior. It seems that non-incentivized and anonymous rankings already trigger professionals' preferences for relative performance, which results in increased risk-taking among underperformers. Tournament incentives, however, which translate ranks into monetary rewards, trigger similar behavior in both subject pools.

\footnotetext{
qualitatively (see Table AV).

${ }^{18}$ We only find marginally lower risk-taking (on a $10 \%$ level) of econ/management students in Treatment TTOUR. However, these results should be treated cautiously because splitting the student sample again into two groups lowers statistical power.

${ }^{19}$ Note that the interaction term is marginally significantly negative in Treatment TBASE, indicating that the difference in risk-taking between outperformers and underperformers among the professionals is significantly larger compared to the difference between both groups in the student sample.

${ }^{20}$ In Table AX we provide the same regressions as in tables 1 and 2, but with a dummy variable for professionals. Moreover, we run all regressions in tables 3 and $\mathrm{AX}$ with interaction terms of variables $R E T \quad P F_{t-1}$ and $R E T_{-} A S S E T_{t-1}$ with professionals, respectively. We find that all results essentially stay the same (unreported).
} 
Table 3: Ranks and Risk-Taking in Experiments PROF and STUD Testing for Differences Between Both Subject Pools

Random effects panel regression with $\mathrm{AR}(1)$ disturbance, testing treatment differences of participants' percentage invested in the risky asset, $R I S K$. RET $P F_{t-1}$ is the log-return of participant $i$ 's portfolio since the start of the experiment and RET_ASSET $T_{t-1}$ is the preceding period's asset return. PROFESSIONALS is a binary dummy variable indicating 1 for professionals, zero for students. In Columns 4-6 the impact of last period's rank is investigated. Here, $R A N K_{t-1}$ indicates participant $i$ 's rank in the preceding period and the interaction effect of treatment and past period rank (e.g., $R A N K_{t-1} *$ PROFESSIONALS) measures differences in rank-driven behavior of professionals with respect to students. Standard errors are provided in parentheses. ${ }^{* *},{ }^{* *}$, and ${ }^{*}$ represent significance at the $1 \%, 5 \%$, and $10 \%$ levels, respectively.

\begin{tabular}{lccc}
\hline \hline Dep. variable: $R I S K$, & $(1)$ & $(2)$ & $(3)$ \\
percentage risky asset & TBASE & TRANK & TTOUR \\
\hline$\alpha$ & $73.709^{* * *}$ & $79.430^{* * *}$ & $106.947^{* * *}$ \\
& $(4.174)$ & $(4.332)$ & $(4.359)$ \\
$R E T \_P F_{t-1}$ & $-0.421^{* * *}$ & $-0.386^{* * *}$ & $-0.386^{* * *}$ \\
& $(0.048)$ & $(0.055)$ & $(0.056)$ \\
RET_ASSET & -0.048 & -0.049 & $-0.220^{* *}$ \\
& $(0.069)$ & $(0.075)$ & $(0.099)$ \\
PROFESSIONALS & $23.208^{* * *}$ & $24.563^{* * *}$ & 6.494 \\
& $(7.039)$ & $(6.699)$ & $(7.545)$ \\
\hline $\mathrm{N}$ & 1554 & 1722 & 1512 \\
$\mathrm{R}$-squared & 0.116 & 0.090 & 0.062 \\
$\chi 2$ & 101.441 & 75.923 & 69.332 \\
Prob $>\chi 2$ & 0.000 & 0.000 & 0.000 \\
\hline \hline
\end{tabular}

\begin{tabular}{|c|c|c|c|}
\hline $\begin{array}{l}\text { Dep. variable: } R I S K \text {, } \\
\text { percentage risky asset }\end{array}$ & $\begin{array}{c}(4) \\
\text { TBASE }\end{array}$ & $\begin{array}{c}(5) \\
\text { TRANK }\end{array}$ & $\begin{array}{c}(6) \\
\text { TTOUR }\end{array}$ \\
\hline$\alpha$ & $\begin{array}{c}70.941^{* * *} \\
(6.343)\end{array}$ & $\begin{array}{l}74.518^{* * *} \\
(6.339)\end{array}$ & $\begin{array}{c}71.206^{* * *} \\
(6.783)\end{array}$ \\
\hline$R E T_{-} P F_{t-1}$ & $\begin{array}{c}-0.430^{* * *} \\
(0.050)\end{array}$ & $\begin{array}{c}-0.331^{* * *} \\
(0.059)\end{array}$ & $\begin{array}{c}-0.239^{* * *} \\
(0.059)\end{array}$ \\
\hline$R E T_{-} A S S E T_{t-1}$ & $\begin{array}{l}-0.043 \\
(0.070)\end{array}$ & $\begin{array}{l}-0.080 \\
(0.076)\end{array}$ & $\begin{array}{c}-0.303^{* * *} \\
(0.098)\end{array}$ \\
\hline PROFESSIONALS & $\begin{array}{c}36.769 * * * \\
(9.839)\end{array}$ & $\begin{array}{l}10.550 \\
(9.526)\end{array}$ & $\begin{array}{c}12.683 \\
(11.789)\end{array}$ \\
\hline$R A N K_{t-1}$ & $\begin{array}{c}0.787 \\
(1.391)\end{array}$ & $\begin{array}{l}1.312 \\
(1.299)\end{array}$ & $\begin{array}{c}10.223^{* * * *} \\
(1.513)\end{array}$ \\
\hline$R A N K_{t-1}{ }^{*} P R O F E S S I O N A L S$ & $\begin{array}{c}-3.861^{*} \\
(2.006) \\
\end{array}$ & $\begin{array}{c}3.950^{* *} \\
(1.946) \\
\end{array}$ & $\begin{array}{l}-1.827 \\
(2.633)\end{array}$ \\
\hline $\mathrm{N}$ & 1554 & 1722 & 1512 \\
\hline R-squared & 0.124 & 0.099 & 0.100 \\
\hline$\chi 2$ & 107.124 & 88.952 & 129.161 \\
\hline Prob $>\chi^{2}$ & 0.000 & 0.000 & 0.000 \\
\hline
\end{tabular}




\section{Additional Experiments Testing Identity Transfer}

Results so far raise the question about the origins and robustness of behavioral differences between financial professionals and student participants. One candidate explanation is that professionals' import their professional identity and experience from years in the industry to the laboratory and hence behavior in their private identity could differ. Following the literature on social identity theory (Akerlof and Kranton, 2000), decision makers have multiple social identities (e.g., gender, ethnicity, or occupation) prescribing how they behave when a certain identity is salient. For instance, studies by Cohn et al. $(2014,2017)$ show that industry professionals exhibit different behavior when their professional identity has been made less salient. Translated to our results this suggests that rank-driven behavior could be imported from professionals' experience in the industry where rankings, relative performance and tournament incentives are salient and important, while the rank-effect may be much weaker or even irrelevant in decisions that are less related to participants' professional identity. To gain deeper insights on the drivers of the rankeffect and its robustness, we follow this literature and provide survey evidence on professionals' preferences for relative performance in first step. In a second step, we run additional experiments addressing participants' professional identity and contrast it to their behavior when their private identity is more salient.

\section{A Survey Evidence on Preferences for Relative Performance}

To shed more light on potential "special" characteristics of professionals, we elicited preferences for financial success, relative performance, and social status and investigated their relation to behavior in the investment game. Following Cohn et al. (2014) we asked:

Q1 (SOCIAL_STATUS): How important is it for you what others think about you? (1: not important; 7: very important)

Q2 (FINANCIAL_SUCCESS): Social status is primarily defined by financial success. (1: completely disagree; 7: fully agree)

Q3 (RELATIVE_PERFORMANCE): How important is it for you to be the best at what you do? (1: not important; 7: very important)

Figure 3 and Table BI in the Online Appendix present results. We observe no differences between professionals and students in the average importance of financial success, but highly significant differences with regard to social status and relative performance. Social status is significantly more important for professionals than for students and relative performance is the most important trait. This result supports the notion that subject-pool-specific differences in attitudes toward relative performance can explain the differences in rank-dependent risktaking between professionals and students. In fact, economics and management students are 
closer to professionals in some of their attitudes than students with other majors (e.g., natural sciences, life sciences, humanities). When we split the student sample along these lines, we find that economics and management students consider social status and relative performance to be significantly more important than other students. Thus, it seems that part of this statusseeking behavior and attitudes toward relative performance are already present before entering the finance industry.
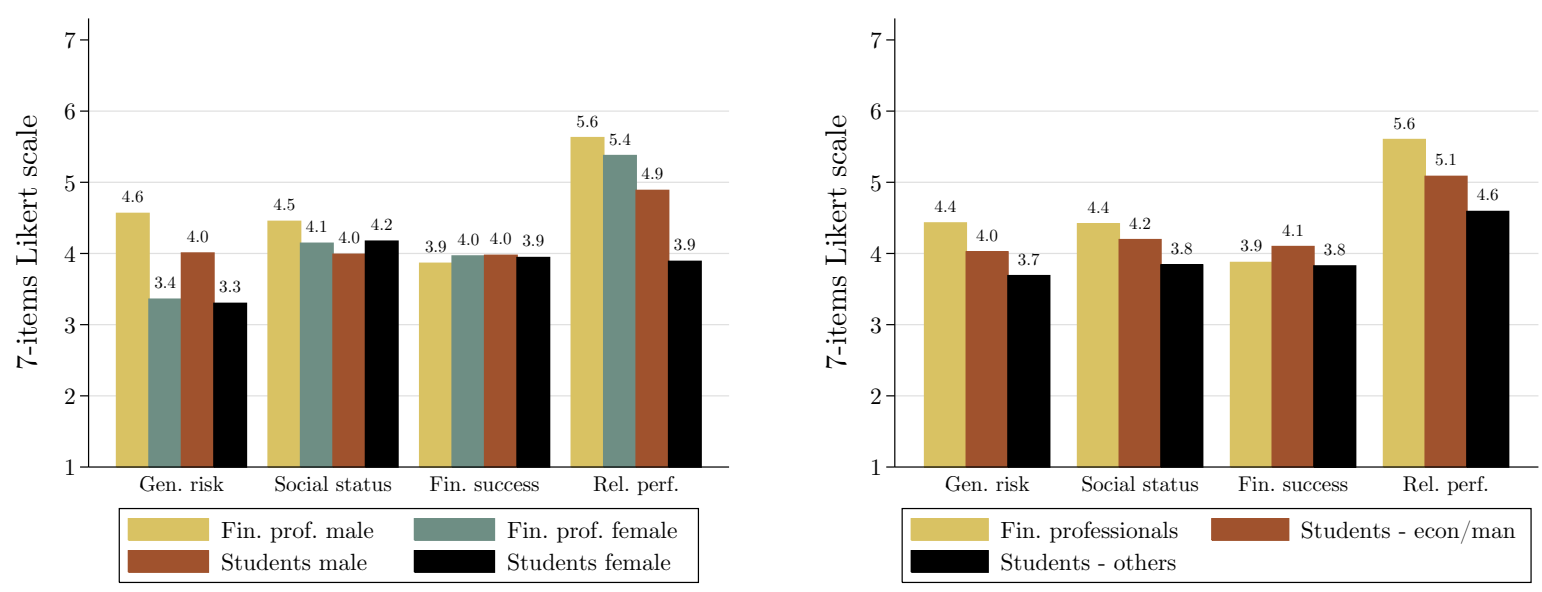

Figure 3: Preferences for Social Status, Financial Success, Relative Performance, and Risk-Taking, Separated by Gender (Left Panel) and Field of Study (Right Panel)

Average post-experimental survey responses on a 7-point Likert scale (higher values indicate stronger preferences) for the following variables: GENERAL_RISK, SOCIAL_STATUS, FINANCIAL_SUCCESS, and RELATIVE_PERFORMANCE. Risk attitudes ( $\overline{\left.G E N E R A L \_R I S K\right)}$ are measured with the German SOEP survey question with higher values indicating higher self-reported risk-taking in real life. Students - econ/man refers to economics and management students. Data is gathered from experiments PROF and STUD and split by subject pool and gender (left panel) and by field of studies for the student sample (right panel).

We also investigate whether professionals' concerns for relative performance and social status influence their behavior in the investment experiment. ${ }^{21}$ We find that professionals who consider relative performance to be important invest significantly more in the risky asset (probably in the hope of obtaining a high rank) than those who consider it less important, even when controlling for risk attitudes and loss aversion. In line with results on missing rank-effects in the student sample, individual preferences for relative performance fail to predict risk-taking behavior of students. See Online Appendix B for more details and further analyses regarding this section.

Taken together, for professionals, relative performance is more important than for students

\footnotetext{
${ }^{21}$ For this analysis, we run ordinary least squares regressions with a participant's average risk taken over all eight periods $(\overline{R I S K})$ as dependent variable and the answers to social status (Q1), financial success (Q2), and relative performance (Q3) as independent variables. We add loss aversion and general risk attitude as additional control variables and cluster standard errors at the group level. For loss aversion we include the normalized sum of accepted lotteries, LOSS_TOLERANCE, which takes on values from 0 (rejecting all gambles-highly loss averse) to 1 (accepting all gambles-loss seeking). For risk attitude we use the answer to the German SOEP survey question with higher values indicating more self-reported risk-taking in real life.
} 
and this attitude seems to affect risk-taking when professionals receive feedback on their ranking in investment decisions. Although students from economics and management show stronger preferences for relative performance than their peers from other fields, these preferences are not strong enough to exhibit rank-driven behavior in the investment game. Hence, this suggests that it is at least partly the professional banking environment that drives risk-taking following underperformance. This is what we are going to investigate in greater detail in the upcoming two sections - i.e., the impact of professionals' professional identity on rank-driven behavior.

\section{B Treatments TRANK ${ }^{\mathrm{LOT}}$ and TRANK ${ }^{\mathrm{FAM}}$}

In Treatment TRANK ${ }^{\mathrm{LOT}}$ we build on the work of Cooper et al. (1999) and re-frame Treatment TRANK in abstract lottery terms without any references to real investment decisions. Following Cohn et al. (2014, 2017) we could expect different behavior, because participants' professional identity as investment managers becomes less salient in this task. In particular, we kept everything identical to Treatment TRANK, but re-framed all investment-related terms to abstract terms, for example, from "return" to "number", "wealth" to "points", "stock index" to "alternative B" and "risk-free rate" to "alternative A" (see Online Appendix C for details).

One concern could be that framing the experiment in abstract lottery terms is too weak as professionals might recognize the investment features behind the abstract frame. Therefore, we administered the additional Treatment TRANK ${ }^{\mathrm{FAM}}$ in which we let professionals invest (partly) for a family member to activate professionals' family identity by highlighting the family payoff dimension of the decisions taken. This treatment is identical to Treatment TRANK with the only difference that a professional invests 90 euro for herself and 90 euro for a self-selected family member with the same portfolio. At the beginning of the experiment, professionals have to identify the family member they want to invest for. We paid out the family member via bank transfer after the experiment. Importantly, the fact that professionals invested for one family member was made very salient in the instructions and on the investment screen mentioning terms like "your family member's current wealth". In addition, professionals had to answer three questions about the self-selected family member just before the investment game started. ${ }^{22}$ This was done to increase the salience of the family member in professionals' thought processes. For treatments TRANK ${ }^{\mathrm{LOT}}$ and TRANK ${ }^{\mathrm{FAM}}$ we recruited another 54 and 48 professionals each. $81.4 \%$ were male, their average age was 33.5 years, and they had been working in the finance industry for 7.9 years on average. If both treatments exhibit similar rank-driven behavior like Treatment TRANK, this would be a strong hint for preferences for relative performance among professionals even outside the finance domain.

\footnotetext{
${ }^{22}$ See the instructions in Online Appendix C for further details. The questions regarding the family member were: "What do you think will the chosen family member do with the money?"; "How many hours per week do you spend time with the selected family member on average?"; "How do you see your selected family member: Is he/she willing to take risks or try to avoid risks?".
} 


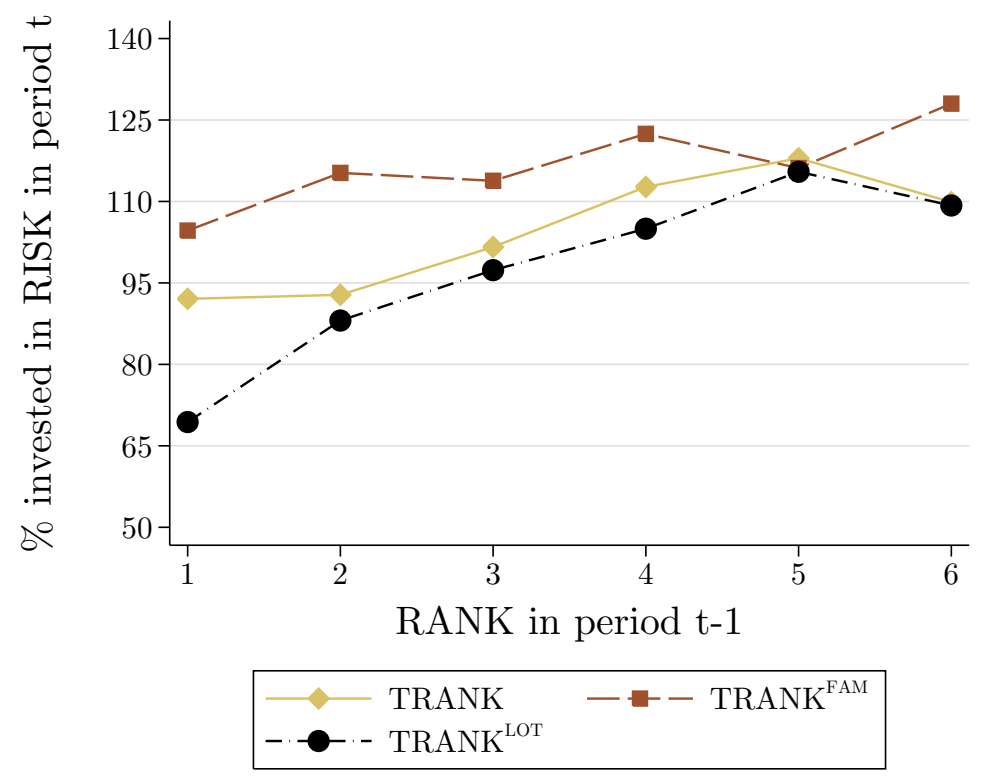

Figure 4: Ranks and Risk-Taking in Treatments TRANK, TRANK ${ }^{\mathrm{LOT}}$, and TRANK ${ }^{\text {FAM }}$ in the Professional Sample

Average percentage invested in the risky asset $(R I S K)$ in period $t$ conditional on participant's rank in the previous period $\left(R A N K_{t-1}\right)$ across all included treatments. $R A N K_{t-1}$ indicates the position in the ranking with higher numbers pointing at weaker relative performance.

Figure 4 and Table 4 outline the results. We find that all major results essentially stay the same. We observe that rank-driven behavior is strong in Treatment TRANK ${ }^{\mathrm{LOT}}$ (Column 5) with a coefficient value of $R A N K_{t-1}$ of 7.1. Moreover, the rank-effect remains significant and is close to the $5 \%$ level $(p=0.053)$ when concerns for family members are activated in Treatment TRANK $^{\text {FAM }}$ (Column 6). However, it is worth noting that the coefficient is lower at 3.5. This indicates that even when professionals invest for a family member they still take more risk after underperformance, but the effect is less pronounced (although insignificantly so) than in a more professional environment. ${ }^{23}$

\footnotetext{
${ }^{23}$ To be sure whether the family treatment already moderates the rank-effect (i.e., to find a rank-effect that is significantly weaker than in the other treatments with rank information), we would clearly need more data. We leave this open for future research.
} 
Table 4: Ranks and Risk-Taking in Treatments TRANK ${ }^{\mathrm{LOT}}$ and TRANK ${ }^{\mathrm{FAM}}$ in the Professional Sample

Random effects panel regressions with $\mathrm{AR}(1)$ disturbance, testing rank-driven behavior in treatments TRANK ${ }^{\mathrm{LOT}}$ and TRANK ${ }^{\mathrm{FAM}}$. RET $P F_{t-1}$ is the log-return of participant $i$ 's portfolio since the start of the experiment and RET_ASSET $T_{t-1}$ is the preceding period's asset return. In Columns 3-7 the impact of last period's rank is investigated in each treatment. Here, $R A N K_{t-1}$ indicates participant $i$ 's rank in the preceding period. Standard errors are provided in parentheses. ${ }^{* * *}, * *$, and $*$ represent significance at the $1 \%, 5 \%$, and $10 \%$ levels, respectively.

\begin{tabular}{|c|c|c|}
\hline $\begin{array}{l}\text { Dep. variable: } R I S K \text {, } \\
\text { percentage risky asset }\end{array}$ & $\begin{array}{c}(1) \\
\text { TRANK }^{\mathrm{LOT}}\end{array}$ & $\begin{array}{c}(2) \\
\text { TRANK }^{\text {FAM }}\end{array}$ \\
\hline$\alpha$ & $\begin{array}{c}95.764^{* * *} \\
(6.480)\end{array}$ & $\begin{array}{c}116.318^{* * *} \\
(8.449)\end{array}$ \\
\hline$R E T_{-} P F_{t-1}$ & $\begin{array}{c}-0.589^{* * *} \\
(0.093)\end{array}$ & $\begin{array}{c}-0.161^{* *} \\
(0.072)\end{array}$ \\
\hline$R E T_{-} A S S E T_{t-1}$ & $\begin{array}{c}0.212 \\
(0.132)\end{array}$ & $\begin{array}{c}-0.503^{* * *} \\
(0.159)\end{array}$ \\
\hline $\mathrm{N}$ & 378 & 336 \\
\hline R-squared & 0.274 & 0.080 \\
\hline$\chi 2$ & 42.447 & 19.989 \\
\hline Prob $>\chi 2$ & 0.000 & 0.000 \\
\hline
\end{tabular}

\begin{tabular}{|c|c|c|c|c|c|}
\hline $\begin{array}{l}\text { Dep. variable: } R I S K \text {, } \\
\text { percentage risky asset }\end{array}$ & $\begin{array}{c}(3) \\
\text { TBASE }\end{array}$ & $\begin{array}{c}(4) \\
\text { TRANK }\end{array}$ & $\begin{array}{c}(5) \\
\text { TRANK }^{\text {LOT }}\end{array}$ & $\begin{array}{c}(6) \\
\text { TRANK }^{\text {FAM }}\end{array}$ & $\begin{array}{c}(7) \\
\text { TTOUR }\end{array}$ \\
\hline$\alpha$ & $\begin{array}{c}109.336^{* * *} \\
(7.933)\end{array}$ & $\begin{array}{c}86.272^{* * *} \\
(7.635)\end{array}$ & $\begin{array}{c}72.751^{* * *} \\
(8.184)\end{array}$ & $\begin{array}{c}104.466^{* * *} \\
(10.367)\end{array}$ & $\begin{array}{c}86.661^{* * *} \\
(9.414)\end{array}$ \\
\hline$R E T_{-} P F_{t-1}$ & $\begin{array}{c}-0.444^{* * *} \\
(0.079)\end{array}$ & $\begin{array}{c}-0.384^{* * *} \\
(0.092)\end{array}$ & $\begin{array}{c}-0.460 * * * \\
(0.097)\end{array}$ & $\begin{array}{c}-0.133^{*} \\
(0.073)\end{array}$ & $\begin{array}{c}-0.273^{* * *} \\
(0.085)\end{array}$ \\
\hline$R E T_{-} A S S E T_{t-1}$ & $\begin{array}{l}-0.096 \\
(0.140)\end{array}$ & $\begin{array}{l}-0.067 \\
(0.129)\end{array}$ & $\begin{array}{c}0.129 \\
(0.133)\end{array}$ & $\begin{array}{c}-0.519^{* * *} \\
(0.159)\end{array}$ & $\begin{array}{c}-0.510^{* * *} \\
(0.146)\end{array}$ \\
\hline$R A N K_{t-1}$ & $\begin{array}{c}-3.470^{* *} \\
(1.661)\end{array}$ & $\begin{array}{c}5.055^{* * *} \\
(1.566)\end{array}$ & $\begin{array}{c}7.104^{* * *} \\
(1.740)\end{array}$ & $\begin{array}{l}3.477^{*} \\
(1.797)\end{array}$ & $\begin{array}{c}7.764^{* * *} \\
(2.030)\end{array}$ \\
\hline $\mathrm{N}$ & 546 & 714 & 378 & 336 & 504 \\
\hline R-squared & 0.122 & 0.114 & 0.359 & 0.099 & 0.152 \\
\hline$\chi 2$ & 41.706 & 46.438 & 64.241 & 23.913 & 56.405 \\
\hline Prob $>\chi 2$ & 0.000 & 0.000 & 0.000 & 0.000 & 0.000 \\
\hline
\end{tabular}


Although the absolute level of risk-taking in Treatment TRANK ${ }^{\text {FAM }}$ seems to be the highest, it is not statistically different from all other treatments containing rank incentives - TRANK and TRANK ${ }^{\mathrm{LOT}}$ —in the paper (see Table AXI in the Online Appendix). In addition, we observe similar patterns for variable $R E T_{-} P F_{t-1}$ compared to all treatments in Experiment PROF. The coefficients of portfolio returns are significantly negative in both treatments indicating that professionals decrease (increase) risk-taking after high (low) portfolio returns when investing in an abstract lottery frame or when investing for a family member. Further, also in line with previous results, we observe indications for Gambler's Fallacy (Rabin, 2002) in the family treatment, where the coefficient of last period's asset return is significantly negative.

Taken together, these results suggest that professionals' rank-driven behavior is robust and concerns for relative performance are not significantly changed by a neutral experimental frame or by activating family concerns.

\section{Online Experiment PROF ${ }^{\text {ONLINE }}$}

One critical issue of treatments TRANK ${ }^{\mathrm{LOT}}$ and TRANK ${ }^{\mathrm{FAM}}$ is that it is not entirely clear whether participants' professional identity was sufficiently de-activated or less salient even when the frame was abstract or family concerns were addressed. The critique centers around the fact that the lab-in-the-field experiments were run in the institutional environment in which the professionals were working. Importantly, professionals saw and knew that they played against other professionals which could override the abstract lottery frame and possible family concerns. Therefore, it could be that professionals' professional identity was still (partly) activated. To circumvent this problem we designed the online experiment PROF ${ }^{\text {ONLINE }}$ with two treatments: one in which we (i) primed professionals on their private identity and (ii) let them play against people from the general population, and another one where we (i) primed professionals on their professional identity and (ii) let them play against other professionals. With this design we provide an institutionally cleaner task with a clear distinction between private and professional settings.

For the investment task we designed a modified version of Kuziemko et al. (2014) which is sufficiently simple for an online task and framed in abstract lottery terms. In each group of six the computer randomly assigned each player a rank in the distribution of initial wealth in euro $\{54.0,49.5,45.0,40.5,36.0,31.5\} .{ }^{24}$ In both treatments the league-table of initial wealth is common knowledge and displayed. Professionals can decide between two alternatives: They can either go for 2.25 euro with $100 \%$ probability or for a lottery paying out 9 euro with $75 \%$ probability or -18 euro with $25 \%$ probability. After each period, all random draws were independently and separately drawn for each player and the new league table with the final

\footnotetext{
${ }^{24}$ The instructions for the online experiment in Online Appendix D are in USD, which we also quoted for convenvience for some of the participants. At the time of the experiment the euro and USD were practically on par.
} 
wealth of this period was displayed. The final wealth was computed by adding 2.25 euro to the initial wealth, in case the safe option was chosen, and by either adding 9 or subtracting 18 euro if the lottery was chosen. For the next period the professionals were randomly selected into another group of six and re-randomized to the same $\{54.0,$. . ., 31.5\} distribution of initial wealth levels. Each online session consisted of three independent periods. Like in the other experiments in this paper, the final wealth (including the loss aversion task from Experiment PROF) was paid out with $20 \%$ probability. One important feature of this design is that the safe payment is always equal to half the difference between ranks (2.25 euro) and therefore, ceteris paribus, does not improve one's position. The positive lottery outcome equals the difference of two ranks above the decision maker (9 euro) and the negative lottery outcome the difference of four ranks below her (-18 euro). Note that the final wealth was always above zero and that both options (safe and lottery) had the same expected value under risk-neutrality. Following related literature, participants in the lab have been shown to exhibit diminishing absolute risk aversion and risk-taking is believed to increase in initial wealth levels (see, among others, Levy, 1994; Holt and Laury, 2002). This means that, purely based on wealth levels, the player with the worst rank (rank 6) would be the least likely to choose the lottery (Kuziemko et al., 2014). Hence, our design takes a conservative position, because - in order to be observable - rank-effects would have to work against a possible decrease of risk aversion in wealth.

In Treatment TRANK ${ }^{\text {PRIV }}$ we took care to activate professionals' private identity. We, first, primed professionals on their private identity before the investment task with the protocol of Cohn et al. $(2014,2017)$ and, second, we let them play against people from the general population. This was common knowledge ex ante and highlighted in the task by adding to the league table depersonalized information about participants' last vacation and two preferred leisure activities with family and friends. ${ }^{25}$ The information was extracted from the initial priming questions and displayed alongside each participant's rank and initial (final) wealth on the decision (results) screen, making the non-professional identity of the other players in the group very salient. Similarly, in Treatment TRANK ${ }^{\text {FIN }}$ we, first, made participants' professional identity salient before the investment task with the protocol of Cohn et al. $(2014,2017) .{ }^{26}$

\footnotetext{
${ }^{25}$ See Online Appendix D for details on the priming procedure. In particular, we asked the following 7 priming

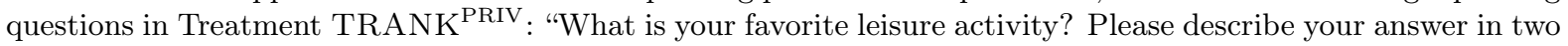
to three sentences."; "Which three opportunities for leisure activities would you most like in your area?"; "How many hours per week on average do you watch TV?"; "Where did you spend your last vacation?"; "Which three things did you like most about your last vacation?"; "Are you actively involved or have you ever been involved in a club?"; "Which three leisure activities do you enjoy most with your friends or family?".

${ }^{26}$ We asked the following 7 priming questions in Treatment TRANK ${ }^{\text {FIN }}$ : "At which financial institution are you presently employed?"; "What is your function at this financial institution?"; "For how many years have you been working in the financial sector? (Please enter full years; can be in different organizations and/or functions)"; "Why did you decide to become an employee in the financial sector? Please describe your answer in two to three sentences."; "What are, in your opinion, the three major advantages of your occupation as an employee in the financial sector?"; "Which three characteristics of your personality do you think are typical for an employee in the financial sector?"; "What are the three most important things you learned in your occupation as an employee in the financial sector?".
} 
Second, we let them play against other professionals and displayed depersonalized information on job function, years of experience in the finance industry, and on what participants regarded as the most important personality characteristic for an employee in the finance industry. Again, this information was extracted from the answers in the priming task and displayed in the league table alongside each professional's rank and wealth. ${ }^{27}$

For this experiment we recruited another 303 professionals, selected with the same criteria as in the other experiments with professionals. $53.8 \%$ of the sample were men and the average age was 40.2 years with 12.8 years of working experience in the finance industry. We consciously recruited a similar number of male and female professionals to address questions about gender differences among financial professionals. For the online experiments we had a larger pool of participants which allows us to investigate this issue with more statistical power.

In Figure 5 we present a first overview on professionals' choices for the risky lottery as a function of rank. In Table 5 we show probit estimations of professionals' likelihood to invest in the lottery $(R I S K)$ conditional on rank at the beginning of the period. We find clear and highly significant evidence for rank-driven behavior no matter whether professionals' private or professional identity was activated and no matter whether male or female professionals decided in both primes. In particular, variable $R A N K$, indicating professional's rank according to initial wealth, is highly significant at the $1 \%$ level for both primes (Columns 1 and 2). Again, like in all other experiments in this paper, underperforming professionals increase risk-taking markedly. Moreover, the variable FEMALE and its interaction term with rank, FEMALE* $R A N K$, are insignificant in both primes, indicating no gender differences in risk-taking and no gender differences regarding rank-driven behavior (Columns 3 and 4). ${ }^{28}$ In general, we find no differences in the overall level of risk-taking and in the rank-effect across both primes for the aggregate data (Column 5). Here, the dummy variable for TRANK ${ }^{\text {FIN }}$ and the interaction term $\mathrm{TRANK}^{\mathrm{FIN}} * R A N K$ are insignificant. In Columns 6 and 7 we show robustness checks for the aggregate data by including a dummy for each rank according to initial wealth $(R A N K=\{2$. . ., 6\}, with the first rank serving as base category). Again, professionals that are down in the ranking increase risk-taking significantly in both primes.

\footnotetext{
${ }^{27}$ Similar to Cohn et al. (2014) we collected data on the other players in a pilot group ex ante and imported the data into both treatments. Only the characteristics of the pilot group were shown to others (depersonalized) after their explicit consent.

${ }^{28}$ To provide a broader picture on gender differences among professionals, we investigate whether the behavior of male and female professionals differs in the investment experiments PROF and STUD. Note that results have to be treated with caution as sample size among female professionals is rather low. We find that risk taking is indifferent between male and female professionals when we re-run the tests in Table 1 with gender dummies (see Table AIII in the Online Appendix A). Results for the student sample are different as risk taking in the pooled analyses for all treatments appears to be significantly lower among female students compared to their male counterparts (see Table AVII in the Online Appendix A).
} 

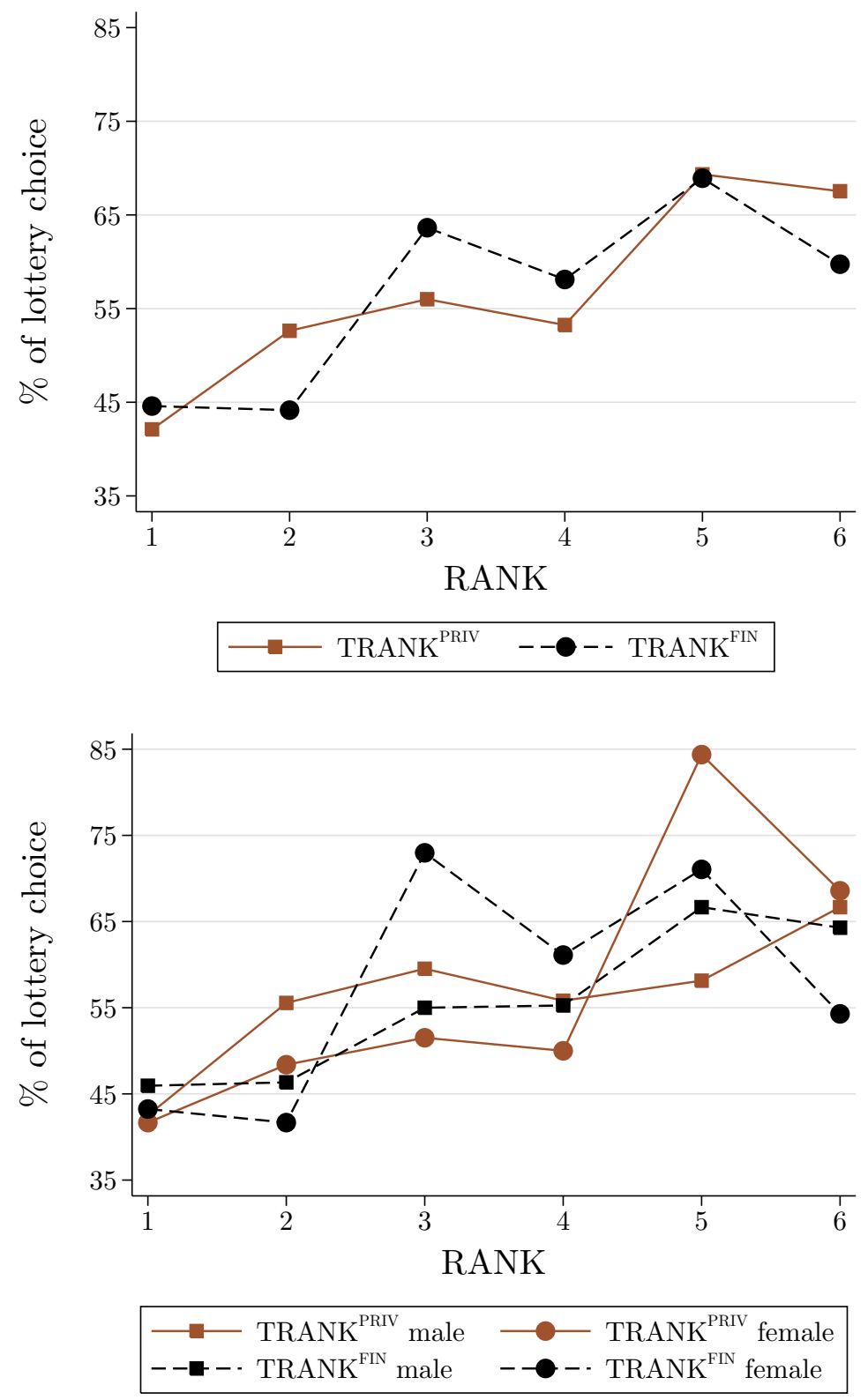

Figure 5: Ranks and Risk-Taking in Treatments TRANK ${ }^{\mathrm{PRIV}}$ and TRANK $^{\mathrm{FIN}}$ in the Online Experiment PROF ${ }^{\text {ONLINE }}$

Fraction of choices for investment in the risky lottery conditional on professionals' rank at the beginning of the period, by prime (top panel) and by gender and prime (bottom panel). RANK indicates the position in the ranking with higher numbers pointing at lower initial wealth levels. 
Table 5: Ranks and Risk-Taking in Treatments TRANK ${ }^{\text {PRIV }}$ and TRANK ${ }^{\text {FIN }}$ in the Online Experiment PROF ${ }^{\text {ONLINE }}$

Probit estimations of professionals' likelihood to invest in the lottery $(R I S K)$ as a function of rank at the beginning of the period. RISK is a binary dummy indicating 1 if a participant selects the lottery, zero otherwise (i.e., choosing the fixed payment). RANK indicates participant $i$ 's rank at the beginning of the period according to initial wealth. FEM ALE is a dummy for gender effects. $R A N K=\{2, \ldots, 6\}$ are dummies for the respective rank. Standard errors are provided in parentheses and are clustered on a participant level. ***, **, and * represent significance at the $1 \%, 5 \%$, and $10 \%$ levels, respectively.

\begin{tabular}{|c|c|c|c|c|c|}
\hline $\begin{array}{l}\text { Dep. variable: RISK, } \\
\text { choice of lottery }\end{array}$ & $\begin{array}{c}(1) \\
\text { TRANK }^{\text {PRIV }}\end{array}$ & $\begin{array}{c}(2) \\
\text { TRANK }^{\text {FIN }}\end{array}$ & $\begin{array}{c}(3) \\
\text { TRANK }^{\text {PRIV }}\end{array}$ & $\begin{array}{c}(4) \\
\text { TRANK }^{\text {FIN }}\end{array}$ & $\begin{array}{l}(5) \\
\text { ALL }\end{array}$ \\
\hline$\alpha$ & $\begin{array}{c}-0.274^{* *} \\
(0.134)\end{array}$ & $\begin{array}{l}-0.200 \\
(0.127)\end{array}$ & $\begin{array}{l}-0.149 \\
(0.184)\end{array}$ & $\begin{array}{l}-0.248 \\
(0.170)\end{array}$ & $\begin{array}{c}-0.274^{* *} \\
(0.134)\end{array}$ \\
\hline$R A N K$ & $\begin{array}{c}0.128^{* * *} \\
(0.033)\end{array}$ & $\begin{array}{c}0.105^{* * *} \\
(0.031)\end{array}$ & $\begin{array}{l}0.089^{* *} \\
(0.045)\end{array}$ & $\begin{array}{c}0.111^{* * *} \\
(0.039)\end{array}$ & $\begin{array}{c}0.128^{* * *} \\
(0.033)\end{array}$ \\
\hline$F E M A L E$ & & & $\begin{array}{l}-0.280 \\
(0.268)\end{array}$ & $\begin{array}{c}0.097 \\
(0.255)\end{array}$ & \\
\hline$F E M A L E * R A N K$ & & & $\begin{array}{c}0.088 \\
(0.066)\end{array}$ & $\begin{array}{l}-0.013 \\
(0.061)\end{array}$ & \\
\hline TRANK $^{\text {FIN }}$ & & & & & $\begin{array}{c}0.074 \\
(0.185)\end{array}$ \\
\hline $\mathrm{TRANK}^{\mathrm{FIN}} * R A N K$ & & & & & $\begin{array}{l}-0.024 \\
(0.045)\end{array}$ \\
\hline $\mathrm{N}$ & 456 & 453 & 456 & 453 & 909 \\
\hline Clusters & 152 & 151 & 152 & 151 & 303 \\
\hline Pseudo R-squared & 0.0218 & 0.0146 & 0.0243 & 0.0150 & 0.0182 \\
\hline$\chi 2$ & 15.089 & 11.748 & 17.345 & 12.533 & 26.938 \\
\hline Prob $>\chi 2$ & 0.000 & 0.001 & 0.001 & 0.006 & 0.000 \\
\hline
\end{tabular}

\begin{tabular}{lcc}
\hline \hline $\begin{array}{c}\text { Dep. variable: } R I S K, \\
\text { choice of lottery }\end{array}$ & $\begin{array}{c}(6) \\
\text { TRANK }\end{array}$ & $(7)$ \\
\hline$\alpha$ & -0.199 & -0.136 \\
& $(0.145)$ & $(0.147)$ \\
$R A N K=2$ & 0.265 & -0.011 \\
& $(0.205)$ & $(0.205)$ \\
$R A N K=3$ & $0.350^{*}$ & $0.485^{* * *}$ \\
& $(0.190)$ & $(0.185)$ \\
$R A N K=4$ & 0.281 & $0.341^{*}$ \\
& $(0.185)$ & $(0.193)$ \\
$R A N K=5$ & $0.705^{* * *}$ & $0.629^{* * *}$ \\
& $(0.204)$ & $(0.212)$ \\
$R A N K=6$ & $0.654^{* * *}$ & $0.383^{* *}$ \\
& $(0.202)$ & $(0.173)$ \\
\hline N & 456 & 453 \\
Clusters & 152 & 151 \\
Pseudo R-squared & 0.0261 & 0.0254 \\
$\chi 2$ & 18.202 & 18.599 \\
Prob $>\chi 2$ & 0.003 & 0.002 \\
\hline \hline
\end{tabular}


To analyze whether the priming was successful, we used the experimental protocol of Cohn et al. $(2014,2017)$ for a manipulation check. Directly after the investment task we ran a word completion task with six words of which four could either be completed in a finance-related or a non-finance-related way. For instance, "..ock" could either be complemented as "clock" or "stock" (see Figure A2 in Online Appendix A for details on these four words). We find that in three out of four relevant words the frequency of finance-related completes is significantly higher when participants were primed with their professional identity compared to having been primed with their private identity $(p<0.010, \mathrm{MW}$ U-tests). This provides confidence that the priming was successful and that professionals acted under different social identities in the two treatments.

We thus conclude that professionals' rank-driven behavior and their concerns for relative performance are robust to changes in the experimental frame (investment frame versus abstract lottery frame), changes in the payoff consequences (own return versus family return), changes in the identity with which professionals are primed (private identity versus professional identity), and to professionals' gender (no difference between male and female professionals).

\section{Conclusion}

In this paper we run lab-in-the-field and online experiments with 657 financial professionals and laboratory experiments with 432 student participants to investigate whether the competition for rank among financial professionals influences risk-taking in investment decisions.

First, we find that professionals care about relative performance. In particular, we observe that underperformers take more risk when an anonymous and non-incentivized ranking is displayed compared to a baseline setting without rank revelation. The observed effect of rank incentives is remarkable given that we applied a mild version with anonymous ranking instead of public disclosure of identities. Moreover, we report that monetary incentives in the tournament treatment increase risk-taking in general, but hardly change rank-dependent investment behavior as observed in the ranking treatment: in both treatments underperformers take more risk than outperformers.

Second, to check for the universality of this effect we re-run the experiment with student participants and find that their investment behavior is not driven by rankings. Only payoutrelevant rankings in the tournament treatment increase students' risk-taking similarly to that of professionals in the ranking treatment. This suggests that professionals care more about relative performance and gain a higher utility from rank incentives.

Third, to analyze drivers and the robustness of professionals' rank-driven behavior, we provide survey evidence showing stronger preferences for relative performance among professionals compared to students. Moreover, in additional lab-in-the-field and online experiments we find that the rank-effect is robust to changes in the experimental frame (investment frame versus abstract lottery frame), changes in the payoff consequences (own return versus family return), 
changes in the identity with which professionals are primed (private identity versus professional identity), and to professionals' gender (no difference between male and female professionals).

Following the literature on social identity theory (Akerlof and Kranton, 2000), the import of professional's professional identity from a closely related environment outside the lab (where rankings and tournament incentives are important) can potentially influence their rank-driven behavior (Cohn et al., 2014, 2017). In our experiments this identity importing effect is less clear-cut. We even find that professionals show rank-driven behavior outside their professional environment as well, raising the question of the origins of this rank-effect. First, it could be that highly competitive individuals self-select into the industry. Second, the strong focus on relative performance among professionals may have been (additionally) shaped by the business culture of the finance industry where rankings and relative performance are pervasive features which potentially improve a professionals' self-image (Maslow, 1943; Bénabou and Tirole, 2003; Köszegi, 2006) or public status (Frank, 1985; Moldovanu et al., 2007). In addition, monetary tournament incentives as a typical feature of the finance industry could "train" professionals on the importance of outperforming others. For instance, professional fund managers in the experiment may have been acting based on their real-world experience in which a top rank means a higher net fund inflow and thus a higher income. This is supported by empirical findings showing that fund flows chase top performers (Sirri and Tufano, 1998; Kaniel and Parham, 2017). However, we believe that a clean separation of the effects of self-selection and business culture would require a longitudinal study, starting at adolescence (or earlier).

Our findings provide suggestions for professionals' decision making outside the laboratory. First, regulators should be aware that rank incentives and tournament incentives have the power to increase risk-taking (particularly among underperformers) which could accumulate to unwarranted levels in the financial sector. Our results are supported by studies on fund manager performance showing that it is generally the poorly performing fund managers who boost risk over the next evaluation period (e.g., Brown et al., 1996; Goetzmann et al., 2003). However, this strand of literature cannot disentangle between the impact of rank incentives and tournament incentives. We, however, provide evidence that rank incentives alone have the power to increase risk-taking among underperformers.

Second, from a regulatory perspective, the increased appetite for risk of underperforming professionals implies that regulating monetary tournament incentives might be ineffective as long as rank incentives trigger similar behavior.

Third, from a legislatory perspective, the question concerning the origins of rank-driven risktaking has to be raised. One potential reason of competitive pressure in the finance industry could be rooted in the customers themselves, often claiming high abnormal returns; directly or indirectly through fund flows (Sirri and Tufano, 1998; Kaniel and Parham, 2017). Here, better financial literacy of customers in investment-related matters could help, particularly regarding the well-known finding that consistently outperforming the market is almost impossible. 
Fourth, the claim that a higher fraction of female professionals would lower risk-taking and the propensity of bubbles (Eckel and Füllbrunn, 2015) warrants some discussion. While the aforementioned study tests male and female students, we find no differences in risk-taking and in rank-driven behavior between male and female professionals. Our results suggest that financial professionals, no matter what gender and whether they operate under a private or professional identity, show similar concerns for relative performance. This indicates that male and female professionals that self-select into the industry show similar behavior. Therefore, increasing the ratio of women without changing the business culture might be ineffective.

Fifth, from an employer's perspective, it is important to know that rank incentives can substitute for expensive bonuses, provided that increased risk-taking is desirable. Note that this substitution is limited if there is strong competition for talent, leading to excessive pay for top performers (Bénabou and Tirole, 2016). If tasks of particular professionals do not contain a riskcomponent, rank incentives could be promoted as they probably increase effort in general (Azmat and Iriberri, 2010; Blanes-i-Vidal and Nossol, 2011; Tran and Zeckhauser, 2012; Bandiera et al., 2013; Delfgaauw et al., 2013), but have the downside of unethical behavior (Charness et al., 2014). In contrast, if increased risk-taking is not desirable, companies might want to limit or downplay rank incentives. This particularly applies to underperformers, because this group of investors (who are more likely to experience losses) might increase risk-taking the most.

The importance of these implications calls for future research to further disentangle the underlying mechanisms for the distortions in risk-taking due to rankings and the origins of financial professionals' motivation for relative performance. 


\section{References}

Abdellaoui, Mohammed, Aurélien Baillon, Laetitia Placido, Peter P. Wakker. 2011. The rich domain of uncertainty: Source functions and their experimental implementation. American Economic Review 101(2) 695-723.

Abdellaoui, Mohammed, Han Bleichrodt, Hilda Kammoun. 2013. Do financial professionals behave according to prospect theory? An experimental study. Theory and Decision $\mathbf{7 4}(3)$ 411-429.

Akerlof, George, Rachel Kranton. 2000. Economics and identity. Quarterly Journal of Economics 115(3) 715-753.

Alevy, Jonathan E., Michael S. Haigh, John A. List. 2007. Information cascades: Evidence from a field experiment with financial market professionals. Journal of Finance 62(1) 151-180.

Azmat, Ghazala, Nagore Iriberri. 2010. The importance of relative performance feedback information: Evidence from a natural experiment using high school students. Journal of Public Economics 94(7-8) 435-452.

Bandiera, Oriana, Iwan Barankay, Imran Rasul. 2013. Team incentives: Evidence from a firm level experiment. Journal of the European Economic Association 11(5) 1079-1114.

Barankay, Iwan. 2015. Rank incentives: Evidence from a randomized workplace experiment. Working Paper.

Bebchuk, Lucian, Holger Spamann. 2010. Regulating bankers' pay. Georgetown Law Journal 98(2) 247-287.

Bénabou, Roland, Jean Tirole. 2003. Intrinsic and extrinsic motivation. Review of Economic Studies 70(3) 489-520.

Bénabou, Roland, Jean Tirole. 2006. Incentives and Prosocial Behavior. American Economic Review 96(5) 1652-1678.

Bénabou, Roland, Jean Tirole. 2016. Bonus culture: competitive pay, screening, and multitasking. Journal of Political Economy 124(2) 305-370.

Blanes-i-Vidal, Jordi, Mareike Nossol. 2011. Tournaments without prizes: Evidence from personnel records. Management Science 57(10) 1721-1736.

Bradbury, Meike, Thorsten Hens, Stefan Zeisberger. 2015. Improving investment decisions with simulated experience. Review of Finance 19(3) 1019-1052. 
Brown, Keith C., W.V. Harlow, Laura T. Starks. 1996. Of tournaments and temptations: An analysis of managerial incentives in the mutual fund industry. Journal of Finance 51(1) $85-110$.

Bruhin, Adrian, Helga Fehr-Duda, Thomas Epper. 2010. Risk and rationality: Uncovering heterogeneity in probability distortion. Econometrica 78(4) 1375-1412.

Charness, Gary, Uri Gneezy, Brianna Halladay. 2016. Experimental methods: pay one or pay all. Journal of Economic Behavior and Organization 131 141-150.

Charness, Gary, David Masclet, Marie Claire Villeval. 2014. The dark side of competition for status. Management Science 60(1) 38-55.

Cipriani, Marco, Antonio Guarino. 2009. Herd behavior in financial markets: An experiment with financial market professionals. Journal of the European Economic Association 7(1) 206233.

Cohn, Alain, Ernst Fehr, Michel André Maréchal. 2014. Business culture and dishonesty in the banking industry. Nature $\mathbf{5 1 6} 86-89$.

Cohn, Alain, Ernst Fehr, Michel André Maréchal. 2017. Do professional norms in the banking industry favor risk-taking? Review of Financial Studies forthcoming.

Cooper, David J., John H. Kagel, Wei Lo, Qing Liang Gu. 1999. Gaming against managers in incentive systems: Experimental results with chinese students and chinese managers. American Economic Review 89(4) 781-804.

Crawford, Vincent. 1998. A survey of experiments on communication via cheap talk. Journal of Economic Theory 78(2) 286-298.

Cubitt, Robin P., Chris Starmer, Robert Sugden. 1998. On the validity of the random lottery incentive system. Experimental Economics 1(2) 115-131.

Delfgaauw, Josse, Robert Dur, Joeri Sol, Willem Verbeke. 2013. Tournament incentives in the field: Gender differences in the workplace. Journal of Labor Economics 31(2) 305-326.

DeMarzo, Peter M., Ron Kaniel, Ilan Kremer. 2004. Diversification as a public good: Community effects in portfolio choice. Journal of Finance 59(4) 1677-1715.

DeMarzo, Peter M., Ron Kaniel, Ilan Kremer. 2007. Technological innovation and real investment booms and busts. Journal of Financial Economics 85(3) 735-754.

DeMarzo, Peter M., Ron Kaniel, Ilan Kremer. 2008. Relative Wealth Concerns and Financial Bubbles. Review of Financial Studies 21(1) 19-50. 
Dewatripont, Mathias, Xavier Freixas. 2012. Bank resolution: Lessons from the crisis. London: Centre for Economic Policy Research.

Diamond, Douglas W., Raghuram G. Rajan. 2009. The credit crisis: Conjectures about causes and remedies. American Economic Review 99(2) 606-610.

Dijk, Oege, Martin Holmen, Michael Kirchler. 2014. Rank matters - The impact of social competition on portfolio choice. European Economic Review 66 97-110.

Dohmen, Thomas J., Armin Falk, David Huffman, Juergen Schupp, Uwe Sunde, Gert Wagner. 2011. Individual risk attitudes: Measurement, determinants, and behavioral consequences. Journal of the European Economic Association 9(3) 522-550.

Eckel, Catherine C., Sascha Füllbrunn. 2015. Thar she blows? gender, competition, and bubbles in experimental asset markets. American Economic Review 105(2) 906-920.

Ehm, Christian, Christine Kaufmann, Martin Weber. 2014. Volatility inadaptability: Investors care about risk, but can't cope with volatility. Review of Finance 18 1387-1423.

Festinger, Leon. 1954. A theory of social comparison processes. Human Relations 7 117-140.

Financial Crisis Inquiry Commission. 2011. The Financial Crisis Inquiry Report: The Final Report of the National Commission on the Causes of the Financial and Economic Crisis in the United States Including Dissenting Views. Cosimo, Inc.

Fischbacher, Urs. 2007. z-tree: Zurich toolbox for ready-made economic experiments. Experimental Economics 10(2) 171-178.

Frank, Robert H. 1985. Choosing the right pond: Human behavior and the quest for status. Oxford University Press.

Frederick, Shane. 2005. Cognitive reflection and decision making. Journal of Economic Perspectives 19(4) 25-42.

Frydman, Cary. 2016. Relative wealth concerns in portfolio choice: neural and behavioral evidence. Working Paper.

Gächter, Simon, E. J. Johnson, A. Hermann. 2007. Individual-level loss aversion in riskless and risky choices. CeDEx Discussion Paper No. 2007-02.

Goetzmann, William N., Jonathan E. Ingersoll, Stephen A. Ross. 2003. High-water marks and hedge fund management contracts. Journal of Finance 58(4) 1685-1718.

Haigh, Michael S., John A. List. 2005. Do professional traders exhibit myopic loss aversion? An experimental analysis. Journal of Finance 60(1) 523-534. 
Hey, John D., Jinkwon Lee. 2005. Do subjects separate (or are they sophisticated)? Experimental Economics 8(3) 233-265.

Holt, Charles A., Susan K. Laury. 2002. Risk aversion and incentive effects. American Economic Review 92(5) 1644-1655.

House, Robert J. 1971. A path-goal theory of leader effectiveness. Administrative Science Quarterly 16(3) 321-339.

House, Robert J. 1996. Path-goal theory of leadership: Lessons, legacy, and a reformulated theory. Leadership Quarterly 7(3) 323-352.

Huber, Jürgen, Michael Kirchler, Thomas Stöckl. 2016. The influence of investment experience on market prices: Laboratory evidence. Experimental Economics 19(2) 394-411.

Hvide, Hans K. 2002. Tournament rewards and risk taking. Journal of Labor Economics 20(4) 877-898.

Jonason, Peter K., Gregory D. Webster. 2010. The dirty dozen: A concise measure of the dark triad. Psychological Assessment 22(2) 420-432.

Kaniel, Ron, Robert Parham. 2017. Wsj category kings - the impact of media attention on consumer and mutual fund investment decisions. Journal of Financial Economics 123(2) 337-356.

Kaufmann, Christine, Martin Weber, Emily Celia Haisley. 2013. The role of experience sampling and graphical displays on one's investment risk appetite. Management Science 59(2) 323-340.

Kleinlercher, Daniel, Jürgen Huber, Michael Kirchler. 2014. The impact of different incentive schemes on asset prices. European Economic Review 68 137-150.

Köszegi, Botond. 2006. Ego utility, overconfidence, and task choice. Journal of the European Economic Association 4(4) 673-707.

Kuziemko, Ilyana, Ryan Buell, Taly Reich, Michael I. Norton. 2014. "Last-place aversion": Evidence and redistributive implications. Quarterly Journal of Economics 129(1) 105-149.

Levy, Haim. 1994. Absolute and relative risk aversion: An experimental study. Journal of Risk and Uncertainty 8 289-307.

List, John A., Michael S. Haigh. 2005. A simple test of expected utility theory using professional traders. Proceedings of the National Academy of Science 102(3) 945-948.

Lohrenz, Terry, Kevin McCabe, Colin F. Camerer, Read Montague. 2007. Neural signature of fictive learning signals in a sequential investment task. Proceedings of the National Academy of Science 104(22) 9493-9498. 
March, Christoph, Anthony Ziegelmeyer, Ben Greiner, René Cyranek. 2015. Monetary incentives in large-scale experiments: A case study of risk aversion. Working Paper.

Maslow, Abraham H. 1943. A theory of human motivation. Psychological Review 50(4) 370-396.

Moldovanu, Benny, Aner Sela, Xianwen Shi. 2007. Contests for status. Journal of Political Economy 115(2) 338-363.

Rabin, Matthew. 2002. Inference by believers in the law of small numbers. Quarterly Journal of Economics 117(3) 775-816.

Rajan, Raghuram G. 2006. Has finance made the world riskier? European Financial Management $12(4)$ 499-533.

Rammstedt, Beatrice, Oliver P. John. 2007. Measuring personality in one minute or less: A 10-item short version of the big five inventory in english and german. Journal of Research in Personality 41(1) 203-212.

Roussanov, Nikolai. 2010. Diversification and its discontents: Idiosyncratic and entrepreneurial risk in the quest for social status. Journal of Finance 65(5) 1755-1788.

Sirri, Erik R., Peter Tufano. 1998. Costly search and mutual fund flows. Journal of Finance 53(5) 1589-1622.

Starmer, Chris, Robert Sugden. 1991. Does the random-lottery incentive system elicit true preferences? An experimental investigation. American Economic Review 81(4) 971-978.

Tran, Anh, Richard Zeckhauser. 2012. Rank as an inherent incentive: Evidence from a field experiment. Journal of Public Economics 96(9-10) 645-650.

Veblen, Thorstein. 1899. The theory of the leisure class: An economic study of institutions. Macmillan.

Weber, Martin, Colin F. Camerer. 1998. The disposition effect in securities trading: an experimental analysis. Journal of Economic Behavior \& Organization 33(2) 167-184. 


\section{Online Appendix \\ Rankings and Risk-Taking in the Finance Industry \\ Michael Kirchler, Florian Lindner, and Utz Weitzel}

\section{A Additional Figures and Tables}

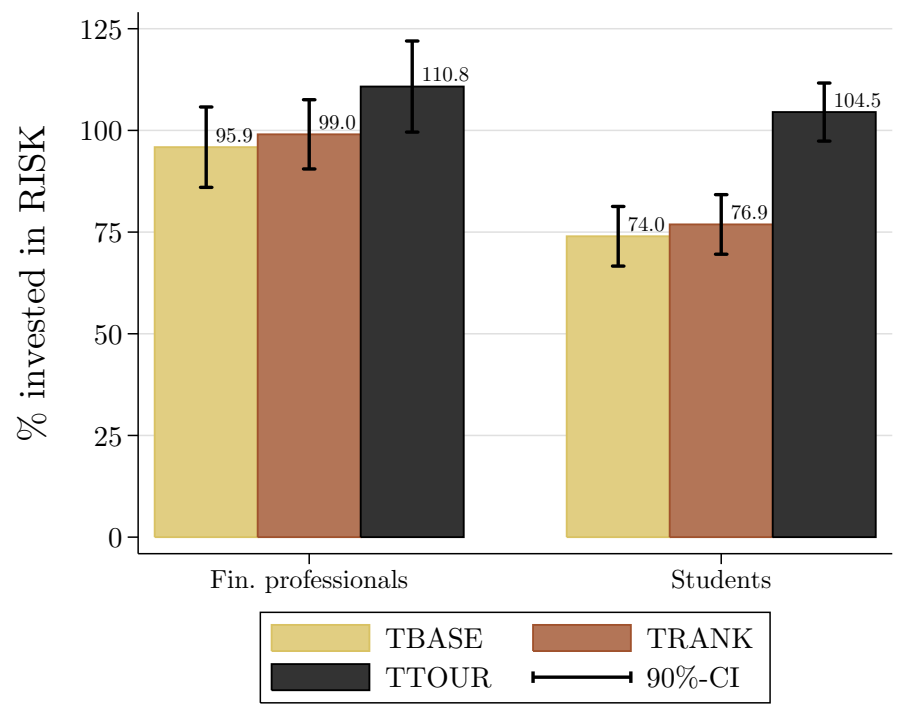

Figure A1: Risk-Taking in Experiments PROF and STUD

Average percentage invested in the risky asset $(R I S K)$ across treatments by experiment: professionals (PROF) and students (STUD). For each treatment the $90 \%$ confidence bounds are displayed.

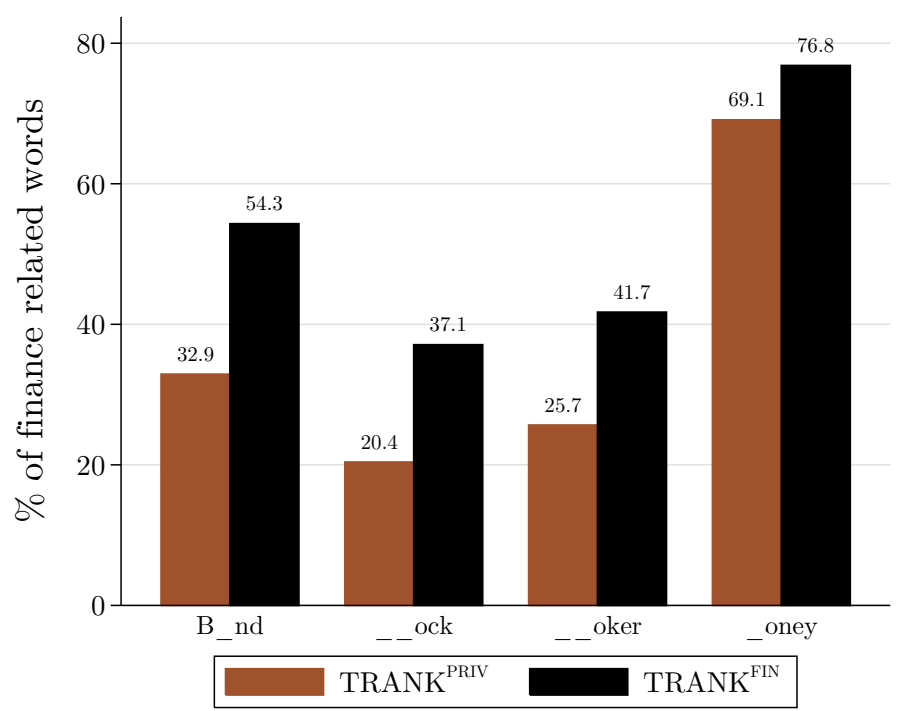

Figure A2: Manipulation check of Online Experiment PROF ${ }^{\text {ONLINE }}$

Average percentage of finance-related answers (words) for treatments TRANK ${ }^{\text {PRIV }}$ and TRANK ${ }^{\text {FIN }}$. 


\section{Table AI: Ranks and Risk-Taking in Experiment PROF}

Random effects panel regression without $\mathrm{AR}(1)$ disturbance, testing treatment differences of participants' percentage invested in the risky asset, $R I S K . R E T_{-} P F_{t-1}$ is the log-return of participant $i$ 's portfolio since the start of the experiment and RET_ASSET $T_{t-1}$ is the preceding period's asset return. TRANK and TTOUR are dummy variables for the treatments with rank incentives and with tournament incentives, respectively, with TBASE as the baseline reference category. In Column 4 (ALL) treatment differences in risk-taking for the entire data set are displayed. In Columns 5 and 6 the data set is split into a sample of outperformers in each period (Ranks 1-3, HIGH) and a sample of underperformers in each period (Ranks 4-6, LOW). In Columns 7-9 the impact of last period's rank is investigated. Here, $R A N K_{t-1}$ indicates participant $i$ 's rank in the preceding period. Standard errors are clustered at the group level and are provided in parentheses. ${ }^{* * *}$, ${ }^{* *}$, and ${ }^{*}$ represent significance at the $1 \%, 5 \%$, and $10 \%$ levels, respectively.

\begin{tabular}{|c|c|c|c|c|c|c|}
\hline $\begin{array}{l}\text { Dep. variable: } R I S K \text {, } \\
\text { percentage risky asset }\end{array}$ & $\begin{array}{c}(1) \\
\text { TBASE }\end{array}$ & $\begin{array}{c}(2) \\
\text { TRANK }\end{array}$ & $\begin{array}{c}(3) \\
\text { TTOUR }\end{array}$ & $\begin{array}{l}(4) \\
\text { ALL }\end{array}$ & $\begin{array}{c}(5) \\
\text { HIGH }\end{array}$ & $\begin{array}{c}(6) \\
\text { LOW }\end{array}$ \\
\hline$\alpha$ & $\begin{array}{c}96.761^{* * *} \\
(6.274)\end{array}$ & $\begin{array}{c}105.308^{* * *} \\
\quad(6.260)\end{array}$ & $\begin{array}{c}113.831^{* * *} \\
(8.339)\end{array}$ & $\begin{array}{c}97.091^{* * *} \\
(6.082)\end{array}$ & $\begin{array}{c}106.390^{* * *} \\
(7.265)\end{array}$ & $\begin{array}{c}91.455^{* * *} \\
(7.040)\end{array}$ \\
\hline$R E T_{-} P F_{t-1}$ & $\begin{array}{c}-0.390^{* * *} \\
(0.122)\end{array}$ & $\begin{array}{c}-0.444^{* * *} \\
(0.160)\end{array}$ & $\begin{array}{c}-0.356^{* * *} \\
(0.114)\end{array}$ & $\begin{array}{c}-0.388^{* * *} \\
(0.075)\end{array}$ & $\begin{array}{c}-0.417^{* * *} \\
(0.120)\end{array}$ & $\begin{array}{c}-0.319^{* * *} \\
(0.071)\end{array}$ \\
\hline$R E T_{-} A S S E T_{t-1}$ & $\begin{array}{l}-0.129 \\
(0.165)\end{array}$ & $\begin{array}{l}-0.121 \\
(0.142)\end{array}$ & $\begin{array}{l}-0.502^{*} \\
(0.269)\end{array}$ & $\begin{array}{c}-0.248^{* *} \\
(0.112)\end{array}$ & $\begin{array}{l}-0.131 \\
(0.167)\end{array}$ & $\begin{array}{c}-0.374^{* *} \\
(0.170)\end{array}$ \\
\hline TRANK & & & & $\begin{array}{l}8.163 \\
(8.767)\end{array}$ & $\begin{array}{r}-10.940 \\
(9.265)\end{array}$ & $\begin{array}{r}23.998^{* *} \\
(10.447)\end{array}$ \\
\hline TTOUR & & & & $\begin{array}{c}16.054 \\
(10.329)\end{array}$ & $\begin{array}{c}-7.814 \\
(13.692)\end{array}$ & $\begin{array}{c}31.422^{* * *} \\
(10.766)\end{array}$ \\
\hline $\mathrm{N}$ & 546 & 714 & 504 & 1764 & 882 & 882 \\
\hline Clusters & 13 & 17 & 12 & 42 & 42 & 42 \\
\hline R-squared & 0.094 & 0.099 & 0.110 & 0.108 & 0.002 & 0.294 \\
\hline$\chi 2$ & 17.324 & 16.182 & 12.902 & 52.567 & 15.885 & 47.095 \\
\hline Prob $>\chi^{2}$ & 0.000 & 0.000 & 0.002 & 0.000 & 0.003 & 0.000 \\
\hline
\end{tabular}

\begin{tabular}{lccc}
\hline \hline $\begin{array}{c}\text { Dep. variable: } R I S K, \\
\text { percentage risky asset }\end{array}$ & $(7)$ & $(8)$ & $(9)$ \\
\hline$\alpha$ & $107.944^{* * *}$ & $87.317^{* * *}$ & $87.068^{* * *}$ \\
& $(9.224)$ & $(9.090)$ & $(11.301)$ \\
$R E T_{-} P F_{t-1}$ & $-0.425^{* * *}$ & $-0.357^{* * *}$ & $-0.263^{* *}$ \\
& $(0.137)$ & $(0.138)$ & $(0.106)$ \\
$R E T \_A S S E T_{t-1}$ & -0.102 & -0.174 & $-0.542^{* *}$ \\
& $(0.168)$ & $(0.131)$ & $(0.266)$ \\
$R A N K_{t-1}$ & $-3.169^{*}$ & $4.919^{* *}$ & $7.613^{* * *}$ \\
& $(1.618)$ & $(1.991)$ & $(2.027)$ \\
\hline $\mathrm{N}$ & 546 & 714 & 504 \\
Clusters & 13 & 17 & 12 \\
$\mathrm{R}$-squared & 0.121 & 0.115 & 0.151 \\
$\chi 2$ & 16.764 & 21.966 & 34.798 \\
Prob $>\chi 2$ & 0.001 & 0.000 & 0.000 \\
\hline \hline
\end{tabular}


Table AII: Ranks and Risk-Taking Among Male Participants in Experiment PROF

Random effects panel regression with $\mathrm{AR}(1)$ disturbance, testing treatment differences of only males' percentage invested in the risky asset, $R I S K . R E T_{-} P F_{t-1}$ is the log-return of participant $i$ 's portfolio since the start of the experiment and RET_ASSET $T_{t-1}$ is the preceding period's asset return. TRANK and TTOUR are dummy variables for the treatments with rank incentives and with tournament incentives, respectively, with TBASE as the baseline reference category. In Column 4 (ALL) treatment differences in risk-taking for the entire data set are displayed. In Columns 5 and 6 the data set is split into a sample of outperformers in each period (Ranks 1-3, HIGH) and a sample of underperformers in each period (Ranks 4-6, LOW). In Columns 7-9 the impact of last period's rank is investigated. Here, $R A N K_{t-1}$ indicates participant $i$ 's rank in the preceding period. Standard errors are provided in parentheses. ${ }^{* * *},{ }^{* *}$, and $*$ represent significance at the $1 \%, 5 \%$, and $10 \%$ levels, respectively.

\begin{tabular}{lcccccc}
\hline \hline Dep. variable: $R I S K$, & $(1)$ & $(2)$ & $(3)$ & $(4)$ & $(5)$ & $(6)$ \\
percentage risky asset & TBASE & TRANK & TTOUR & ALL & HIGH & LOW \\
\hline$\alpha$ & $98.296^{* * *}$ & $106.386^{* * *}$ & $113.654^{* * *}$ & $98.532^{* * *}$ & $109.025^{* * *}$ & $93.078^{* * *}$ \\
& $(5.834)$ & $(5.623)$ & $(6.503)$ & $(6.009)$ & $(6.882)$ & $(6.181)$ \\
$R E T \_P F_{t-1}$ & $-0.379^{* * *}$ & $-0.513^{* * *}$ & $-0.402^{* * *}$ & $-0.417^{* * *}$ & $-0.424^{* * *}$ & $-0.414^{* * *}$ \\
& $(0.077)$ & $(0.098)$ & $(0.089)$ & $(0.050)$ & $(0.090)$ & $(0.064)$ \\
$R E T \_A S S E T_{t-1}$ & -0.114 & -0.058 & $-0.487^{* * *}$ & $-0.211^{* *}$ & $-0.225^{*}$ & $-0.275^{* *}$ \\
& $(0.143)$ & $(0.148)$ & $(0.157)$ & $(0.087)$ & $(0.131)$ & $(0.128)$ \\
TRANK & & & & 7.599 & -14.149 & $25.146^{* * *}$ \\
& & & & $(8.191)$ & $(9.360)$ & $(8.584)$ \\
TTOUR & & & & $14.532^{*}$ & -11.070 & $31.045^{* * *}$ \\
& & & & $(8.713)$ & $(10.108)$ & $(9.129)$ \\
\hline N & 511 & 595 & 462 & 1568 & 786 & 782 \\
R-squared & 0.095 & 0.120 & 0.129 & 0.117 & 0.007 & 0.300 \\
$\chi 2$ & 32.126 & 34.562 & 40.489 & 105.680 & 37.441 & 78.338 \\
Prob $>\chi 2$ & 0.000 & 0.000 & 0.000 & 0.000 & 0.000 & 0.000 \\
\hline \hline
\end{tabular}

\begin{tabular}{lccc}
\hline \hline Dep. variable: $R I S K$, & $(7)$ & $(8)$ & $(9)$ \\
percentage risky asset & TBASE & TRANK & TTOUR \\
\hline$\alpha$ & $110.503^{* * *}$ & $88.830^{* * *}$ & $85.416^{* * *}$ \\
& $(8.274)$ & $(8.383)$ & $(9.954)$ \\
$R E T_{-} P F_{t-1}$ & $-0.423^{* * *}$ & $-0.417^{* * *}$ & $-0.306^{* * *}$ \\
& $(0.079)$ & $(0.104)$ & $(0.091)$ \\
$R E T \_A S S E T_{t-1}$ & -0.090 & -0.117 & $-0.539^{* * *}$ \\
& $(0.144)$ & $(0.149)$ & $(0.156)$ \\
$R A N K_{t-1}$ & $-3.422^{* *}$ & $4.901^{* * *}$ & $7.929^{* * *}$ \\
& $(1.720)$ & $(1.774)$ & $(2.174)$ \\
\hline $\mathrm{N}$ & 511 & 595 & 462 \\
$\mathrm{R}-$-squared & 0.124 & 0.152 & 0.176 \\
$\chi 2$ & 36.879 & 43.215 & 55.317 \\
Prob $>\chi 2$ & 0.000 & 0.000 & 0.000 \\
\hline \hline
\end{tabular}




\section{Table AIII: Ranks and Risk-Taking in Experiment PROF Including a Dummy for}

FEMALE

Random effects panel regression with $\mathrm{AR}(1)$ disturbance, testing treatment differences of participants' percentage invested in the risky asset, $R I S K . R E T_{-} P F_{t-1}$ is the log-return of participant $i$ 's portfolio since the start of the experiment and $R E T_{-} A S S E T_{t-1}$ is the preceding period's asset return. FEMALE is a binary dummy variable indicating 1 for female professionals, zero otherwise. TRANK and TTOUR are dummy variables for the treatments with rank incentives and with tournament incentives, respectively, with TBASE as the baseline reference category. In Column 4 (ALL) treatment differences in risk-taking for the entire data set are displayed. In Columns 5 and 6 the data set is split into a sample of outperformers in each period (Ranks 1-3, HIGH) and a sample of underperformers in each period (Ranks 4-6, LOW). In Columns 7-9 the impact of last period's rank is investigated. Here, $R A N K_{t-1}$ indicates participant $i$ 's rank in the preceding period. Standard errors are provided in parentheses. ${ }^{* * *},{ }^{* *}$, and $*$ represent significance at the $1 \%, 5 \%$, and $10 \%$ levels, respectively.

\begin{tabular}{lcccccc}
\hline \hline Dep. variable: $R I S K$, & $(1)$ & $(2)$ & $(3)$ & $(4)$ & $(5)$ & $(6)$ \\
percentage risky asset & TBASE & TRANK & TTOUR & ALL & HIGH & LOW \\
\hline$\alpha$ & $98.407^{* * *}$ & $105.869^{* * *}$ & $113.500^{* * *}$ & $97.572^{* * *}$ & $106.849^{* * *}$ & $92.251^{* * *}$ \\
& $(5.744)$ & $(5.503)$ & $(6.593)$ & $(5.805)$ & $(6.618)$ & $(5.851)$ \\
$R E T_{-} P F_{t-1}$ & $-0.398^{* * *}$ & $-0.477^{* * *}$ & $-0.369^{* * *}$ & $-0.410^{* * *}$ & $-0.380^{* * *}$ & $-0.414^{* * *}$ \\
& $(0.076)$ & $(0.088)$ & $(0.082)$ & $(0.047)$ & $(0.084)$ & $(0.060)$ \\
$R E T \_A S S E T_{t-1}$ & -0.125 & -0.013 & $-0.464^{* * *}$ & $-0.180^{* *}$ & $-0.205^{*}$ & $-0.247^{* *}$ \\
& $(0.139)$ & $(0.129)$ & $(0.147)$ & $(0.080)$ & $(0.123)$ & $(0.116)$ \\
$F E M A L E$ & -21.057 & -6.360 & 5.618 & -6.292 & -1.171 & $-18.954^{*}$ \\
& $(22.655)$ & $(13.366)$ & $(22.790)$ & $(10.321)$ & $(11.749)$ & $(10.312)$ \\
TRANK & & & & 8.296 & -12.236 & $26.279^{* * *}$ \\
& & & & $(7.734)$ & $(8.799)$ & $(7.913)$ \\
TTOUR & & & & $16.407^{* *}$ & -8.661 & $32.098^{* * *}$ \\
& & & & $(8.320)$ & $(9.596)$ & $(8.554)$ \\
\hline N & 546 & 714 & 504 & 1764 & 882 & 882 \\
R-squared & 0.098 & 0.100 & 0.112 & 0.109 & 0.002 & 0.310 \\
$\chi 2$ & 37.480 & 35.706 & 40.378 & 113.277 & 34.884 & 91.952 \\
Prob $>\chi 2$ & 0.000 & 0.000 & 0.000 & 0.000 & 0.000 & 0.000 \\
\hline \hline
\end{tabular}

\begin{tabular}{lccc}
\hline \hline Dep. variable: $R I S K$, & $(7)$ & $(8)$ & $(9)$ \\
percentage risky asset & TBASE & TRANK & TTOUR \\
\hline$\alpha$ & $111.078^{* * *}$ & $87.487^{* * *}$ & $85.640^{* * *}$ \\
& $(8.063)$ & $(7.836)$ & $(9.675)$ \\
$R E T \_P F_{t-1}$ & $-0.443^{* * *}$ & $-0.379^{* * *}$ & $-0.272^{* * *}$ \\
& $(0.078)$ & $(0.093)$ & $(0.085)$ \\
$R E T \_A S S E T_{t-1}$ & -0.096 & -0.068 & $-0.510^{* * *}$ \\
& $(0.140)$ & $(0.130)$ & $(0.146)$ \\
$F E M A L E$ & -22.614 & -9.129 & 10.079 \\
& $(21.604)$ & $(13.261)$ & $(22.170)$ \\
$R A N K_{t-1}$ & $-3.555^{* *}$ & $5.125^{* * *}$ & $7.814^{* * *}$ \\
& $(1.662)$ & $(1.570)$ & $(2.034)$ \\
\hline $\mathrm{N}$ & 546 & 714 & 504 \\
$\mathrm{R}$-squared & 0.126 & 0.116 & 0.154 \\
$\chi 2$ & 42.979 & 46.898 & 56.552 \\
Prob $>\chi 2$ & 0.000 & 0.000 & 0.000 \\
\hline \hline
\end{tabular}




\section{Table AIV: Ranks and Risk-Taking in Experiment PROF With Dummy For Positive}

Portfolio Returns

Random effects panel regression with $\mathrm{AR}(1)$ disturbance, testing treatment differences of participants' percentage invested in the risky asset, $R I S K . R E T_{-} P F_{t-1}$ is the log-return of participant $i$ 's portfolio since the start of the experiment. $R E T T_{-} P F_{t-1}^{P O S}$ is a dummy variable for positive portfolio returns, and $R E T_{-} A S S E T_{t-1}$ is the preceding period's asset return. TRANK and TTOUR are dummy variables for the treatments with rank incentives and with tournament incentives, respectively, with TBASE as the baseline reference category. In Column 4 (ALL) treatment differences in risk-taking for the entire data set are displayed. In Columns 5 and 6 the data set is split into a sample of outperformers in each period (Ranks 1-3, HIGH) and a sample of underperformers in each period (Ranks 4-6, LOW). In Columns 7-9 the impact of last period's rank is investigated. Here, $R A N K_{t-1}$ indicates participant $i$ 's rank in the preceding period. Standard errors are provided in parentheses. $* * *, * *$, and $*$ represent significance at the $1 \%, 5 \%$, and $10 \%$ levels, respectively.

\begin{tabular}{|c|c|c|c|c|c|c|}
\hline $\begin{array}{l}\text { Dep. variable: } R I S K \text {, } \\
\text { percentage risky asset }\end{array}$ & $\begin{array}{c}(1) \\
\text { TBASE }\end{array}$ & $\begin{array}{c}(2) \\
\text { TRANK }\end{array}$ & $\begin{array}{c}(3) \\
\text { TTOUR }\end{array}$ & $\begin{array}{l}(4) \\
\text { ALL }\end{array}$ & $\begin{array}{c}(5) \\
\text { HIGH }\end{array}$ & $\begin{array}{c}(6) \\
\mathrm{LOW}\end{array}$ \\
\hline$\alpha$ & $\begin{array}{c}104.856^{* * *} \\
(7.568)\end{array}$ & $\begin{array}{c}115.116^{* * *} \\
(6.038)\end{array}$ & $\begin{array}{c}135.077^{* * *} \\
(7.136)\end{array}$ & $\begin{array}{c}111.677^{* * *} \\
(6.213)\end{array}$ & $\begin{array}{c}111.629^{* * *} \\
(7.646)\end{array}$ & $\begin{array}{l}119.538^{* * *} \\
(6.755)\end{array}$ \\
\hline$R E T_{-} P F_{t-1}$ & $\begin{array}{c}-0.349^{* * *} \\
(0.083)\end{array}$ & $\begin{array}{c}-0.323^{* * *} \\
(0.102)\end{array}$ & $\begin{array}{l}-0.143 \\
(0.091)\end{array}$ & $\begin{array}{c}-0.287^{* * *} \\
(0.052)\end{array}$ & $\begin{array}{c}-0.324^{* * *} \\
(0.094)\end{array}$ & $\begin{array}{c}-0.207^{* * *} \\
(0.066)\end{array}$ \\
\hline$R E T_{-} P F_{t-1}^{P O S}$ & $\begin{array}{l}-11.630 \\
(7.762)\end{array}$ & $\begin{array}{c}-19.201^{* * *} \\
(6.480)\end{array}$ & $\begin{array}{c}-38.766^{* * *} \\
(7.691)\end{array}$ & $\begin{array}{c}-21.729^{* * *} \\
(4.144)\end{array}$ & $\begin{array}{l}-7.725 \\
(6.331)\end{array}$ & $\begin{array}{c}-42.973^{* * *} \\
(5.937)\end{array}$ \\
\hline$R E T_{-} A S S E T_{t-1}$ & $\begin{array}{l}-0.055 \\
(0.147)\end{array}$ & $\begin{array}{c}0.088 \\
(0.134)\end{array}$ & $\begin{array}{c}-0.323^{* *} \\
(0.148)\end{array}$ & $\begin{array}{l}-0.065 \\
(0.083)\end{array}$ & $\begin{array}{l}-0.161 \\
(0.128)\end{array}$ & $\begin{array}{l}-0.068 \\
(0.117)\end{array}$ \\
\hline TRANK & & & & $\begin{array}{l}5.395 \\
(7.403)\end{array}$ & $\begin{array}{r}-12.848 \\
(8.655)\end{array}$ & $\begin{array}{c}19.926^{* * *} \\
(7.355)\end{array}$ \\
\hline TTOUR & & & & $\begin{array}{l}13.546^{*} \\
(8.039)\end{array}$ & $\begin{array}{l}-9.044 \\
(9.494) \\
\end{array}$ & $\begin{array}{c}25.298^{* * *} \\
(8.081)\end{array}$ \\
\hline $\mathrm{N}$ & 546 & 714 & 504 & 1764 & 882 & 882 \\
\hline R-squared & 0.109 & 0.127 & 0.194 & 0.144 & 0.005 & 0.387 \\
\hline$\chi 2$ & 39.162 & 45.324 & 68.868 & 144.493 & 35.724 & 156.106 \\
\hline Prob $>\chi 2$ & 0.000 & 0.000 & 0.000 & 0.000 & 0.000 & 0.000 \\
\hline
\end{tabular}

\begin{tabular}{lccc}
\hline \hline Dep. variable: $R I S K$, & $(7)$ & $(8)$ & $(9)$ \\
percentage risky asset & TBASE & TRANK & TTOUR \\
\hline$\alpha$ & $118.563^{* * *}$ & $96.646^{* * *}$ & $109.528^{* * *}$ \\
& $(9.606)$ & $(8.307)$ & $(10.128)$ \\
$R E T_{-} P F_{t-1}$ & $-0.389^{* * *}$ & $-0.233^{* *}$ & -0.069 \\
& $(0.085)$ & $(0.105)$ & $(0.092)$ \\
$R E T \_P F_{t-1}^{P O S}$ & $-12.846^{*}$ & $-18.835^{* * *}$ & $-36.631^{* * *}$ \\
& $(7.760)$ & $(6.442)$ & $(7.647)$ \\
$R E T \_A S S E T_{t-1}$ & -0.018 & 0.033 & $-0.372^{* *}$ \\
& $(0.148)$ & $(0.134)$ & $(0.147)$ \\
$R A N K_{t-1}$ & $-3.647^{* *}$ & $4.976^{* * *}$ & $6.931^{* * *}$ \\
& $(1.661)$ & $(1.556)$ & $(1.979)$ \\
\hline $\mathrm{N}$ & 546 & 714 & 504 \\
$\mathrm{R}$-squared & 0.138 & 0.143 & 0.229 \\
$\chi 2$ & 44.928 & 56.233 & 83.692 \\
Prob $>\chi 2$ & 0.000 & 0.000 & 0.000 \\
\hline \hline
\end{tabular}




\section{Table AV: Risk-Taking in Experiment STUD}

Random effects panel regression without $\mathrm{AR}(1)$ disturbance, testing treatment differences of participants' percentage invested in the risky asset, $R I S K . R E T_{-} P F_{t-1}$ is the log-return of participant $i$ 's portfolio since the start of the experiment, and $R E T \_A S S E T_{t-1}$ is the preceding asset return. TRANK and TTOUR are dummy variables for the treatments with rank incentives and with tournament incentives, respectively, with TBASE as the baseline reference category. In Column 4 (ALL) treatment differences in risk-taking for the entire data set are displayed. In Columns 5 and 6 the data set is split into a sample of outperformers in each period (Ranks 1-3, $\mathrm{HIGH}$ ) and a sample of underperformers in each period (Ranks 4-6, LOW). In Columns 7-9 the impact of last period's rank is investigated. Here, $R A N K_{t-1}$ indicates participant $i$ 's rank in the preceding period. Standard errors are clustered on the group level and are provided in parentheses. ${ }^{* * *},{ }^{* *}$, and ${ }^{*}$ represent significance at the $1 \%, 5 \%$, and $10 \%$ levels, respectively.

\begin{tabular}{lcccccc}
\hline \hline Dep. variable: $R I S K$, & $(1)$ & $(2)$ & $(3)$ & $(4)$ & $(5)$ & $(6)$ \\
percentage risky asset & TBASE & TRANK & TTOUR & ALL & HIGH & LOW \\
\hline$\alpha$ & $73.242^{* * *}$ & $79.295^{* * *}$ & $106.393^{* * *}$ & $73.418^{* * *}$ & $74.800^{* * *}$ & $75.969^{* * *}$ \\
& $(5.118)$ & $(5.012)$ & $(5.581)$ & $(4.985)$ & $(6.336)$ & $(6.076)$ \\
$R E T_{-} P F_{t-1}$ & $-0.436^{* * *}$ & $-0.323^{* * *}$ & $-0.361^{* * *}$ & $-0.382^{* * *}$ & $-0.287^{* *}$ & $-0.415^{* * *}$ \\
& $(0.103)$ & $(0.107)$ & $(0.106)$ & $(0.063)$ & $(0.112)$ & $(0.081)$ \\
$R E T_{-} A S S E T_{t-1}$ & -0.067 & -0.104 & -0.221 & $-0.116^{*}$ & -0.013 & $-0.325^{* * *}$ \\
& $(0.092)$ & $(0.078)$ & $(0.179)$ & $(0.065)$ & $(0.080)$ & $(0.114)$ \\
TRANK & & & & 6.406 & 0.740 & 6.911 \\
& & & & $(7.055)$ & $(9.375)$ & $(8.853)$ \\
TTOUR & & & & $32.774^{* * *}$ & $16.571^{*}$ & $42.403^{* * *}$ \\
& 1008 & 1008 & 1008 & 3024 & 1512 & 1512 \\
N & 24 & 24 & 24 & 72 & 72 & 72 \\
Clusters & 0.098 & 0.046 & 0.040 & 0.097 & 0.001 & 0.246 \\
R-squared & 28.437 & 11.231 & 17.927 & 78.641 & 11.996 & 101.626 \\
$\chi 2$ & 0.000 & 0.004 & 0.000 & 0.000 & 0.017 & 0.000 \\
Prob $>2$ & & & & & & \\
\hline \hline
\end{tabular}

\begin{tabular}{lccc}
\hline \hline $\begin{array}{c}\text { Dep. variable: } R I S K, \\
\text { percentage risky asset }\end{array}$ & TBASE & TRANK & TTOUR \\
\hline$\alpha$ & $70.200^{* * *}$ & $71.625^{* * *}$ & $72.372^{* * *}$ \\
& $(9.370)$ & $(7.613)$ & $(10.493)$ \\
$R E T_{-} P F_{t-1}$ & $-0.419^{* * *}$ & $-0.280^{* * *}$ & $-0.209^{*}$ \\
& $(0.111)$ & $(0.106)$ & $(0.109)$ \\
$R E T_{-} A S S E T_{t-1}$ & -0.073 & $-0.129^{*}$ & $-0.318^{*}$ \\
& $(0.091)$ & $(0.074)$ & $(0.177)$ \\
$R A N K_{t-1}$ & 0.877 & 2.122 & $9.737^{* * *}$ \\
& $(1.791)$ & $(1.436)$ & $(2.155)$ \\
\hline $\mathrm{N}$ & 1008 & 1008 & 1008 \\
Clusters & 24 & 24 & 24 \\
$\mathrm{R}$-squared & 0.096 & 0.049 & 0.079 \\
$\chi 2$ & 32.220 & 17.977 & 66.224 \\
Prob $>\chi 2$ & 0.000 & 0.000 & 0.000 \\
\hline \hline
\end{tabular}


Table AVI: Ranks and Risk-Taking Among Male Participants in Experiment STUD

Random effects panel regression with $\mathrm{AR}(1)$ disturbance, testing treatment differences of only males' percentage percentage invested in the risky asset, $R I S K . R E T_{-} P F_{t-1}$ is the log-return of participant $i$ 's portfolio since the start of the experiment, and $R E T_{-} A S S E T_{t-1}$ is the preceding asset return. TRANK and TTOUR are dummy variables for the treatments with rank incentives and with tournament incentives, respectively, with TBASE as the baseline reference category. In Column 4 (ALL) treatment differences in risk-taking for the entire data set are displayed. In Columns 5 and 6 the data set is split into a sample of outperformers in each period (Ranks 1-3, HIGH) and a sample of underperformers in each period (Ranks 4-6, LOW). In Columns 7-9 the impact of last period's rank is investigated. Here, $R A N K_{t-1}$ indicates participant $i$ 's rank in the preceding period. Standard errors are provided in parentheses. Standard errors are provided in parentheses. ${ }^{* * *}$, ${ }^{* *}$, and * represent significance at the $1 \%, 5 \%$, and $10 \%$ levels, respectively.

\begin{tabular}{lcccccc}
\hline \hline Dep. variable: RISK, & $(1)$ & $(2)$ & $(3)$ & $(4)$ & $(5)$ & $(6)$ \\
percentage risky asset & TBASE & TRANK & TTOUR & ALL & HIGH & LOW \\
\hline$\alpha$ & $77.029^{* * *}$ & $82.615^{* * *}$ & $107.774^{* * *}$ & $76.760^{* * *}$ & $75.515^{* * *}$ & $78.341^{* * *}$ \\
& $(4.970)$ & $(5.421)$ & $(4.457)$ & $(5.104)$ & $(5.674)$ & $(5.768)$ \\
$R E T_{-} P F_{t-1}$ & $-0.538^{* * *}$ & $-0.354^{* * *}$ & $-0.377^{* * *}$ & $-0.424^{* * *}$ & $-0.191^{* *}$ & $-0.473^{* * *}$ \\
& $(0.076)$ & $(0.083)$ & $(0.075)$ & $(0.046)$ & $(0.077)$ & $(0.064)$ \\
$R E T \_A S S E T_{t-1}$ & -0.040 & $-0.231^{*}$ & -0.118 & $-0.127^{*}$ & -0.094 & $-0.241^{* *}$ \\
& $(0.098)$ & $(0.124)$ & $(0.136)$ & $(0.070)$ & $(0.099)$ & $(0.109)$ \\
TRANK & & & & 5.954 & -0.221 & 8.320 \\
& & & & $(7.279)$ & $(7.801)$ & $(8.176)$ \\
TTOUR & & & & $31.010^{* * *}$ & $14.073^{*}$ & $41.197^{* * *}$ \\
& & & & $(6.826)$ & $(7.347)$ & $(7.598)$ \\
\hline N & 749 & 721 & 945 & 2415 & 1231 & 1184 \\
R-squared & 0.129 & 0.057 & 0.042 & 0.103 & 0.000 & 0.252 \\
$\chi 2$ & 58.771 & 34.201 & 33.248 & 143.786 & 15.871 & 123.070 \\
Prob $>\chi 2$ & 0.000 & 0.000 & 0.000 & 0.000 & 0.007 & 0.000 \\
\hline \hline
\end{tabular}

\begin{tabular}{lccc}
\hline \hline Dep. variable: $R I S K$, & $(7)$ & $(8)$ & $(9)$ \\
percentage risky asset & TBASE & TRANK & TTOUR \\
\hline$\alpha$ & $71.881^{* * *}$ & $77.065^{* * *}$ & $68.396^{* * *}$ \\
& $(7.593)$ & $(8.131)$ & $(7.313)$ \\
$R E T_{-} P F_{t-1}$ & $-0.508^{* * *}$ & $-0.324^{* * *}$ & $-0.189^{* *}$ \\
& $(0.083)$ & $(0.089)$ & $(0.078)$ \\
$R E T_{-} A S S E T_{t-1}$ & -0.051 & $-0.248^{* *}$ & $-0.221^{*}$ \\
& $(0.098)$ & $(0.126)$ & $(0.134)$ \\
$R A N K_{t-1}$ & 1.426 & 1.596 & $11.298^{* * *}$ \\
& $(1.604)$ & $(1.747)$ & $(1.693)$ \\
\hline $\mathrm{N}$ & 749 & 721 & 945 \\
$\mathrm{R}-$ squared & 0.122 & 0.061 & 0.088 \\
$\chi 2$ & 59.861 & 35.103 & 79.308 \\
Prob $>\chi 2$ & 0.000 & 0.000 & 0.000 \\
\hline \hline
\end{tabular}


Table AVII: Ranks and Risk-Taking in Experiment STUD Including a Dummy for FEMALE

Random effects panel regression with $\mathrm{AR}(1)$ disturbance, testing treatment differences of participants' percentage invested in the risky asset, $R I S K . R E T_{-} P F_{t-1}$ is the log-return of participant $i$ 's portfolio since the start of the experiment and $R E T_{-} A S S E T_{t-1}$ is the preceding period's asset return. FEMALE is a binary dummy variable indicating 1 for female professionals, zero otherwise. TRANK and TTOUR are dummy variables for the treatments with rank incentives and with tournament incentives, respectively, with TBASE as the baseline reference category. In Column 4 (ALL) treatment differences in risk-taking for the entire data set are displayed. In Columns 5 and 6 the data set is split into a sample of outperformers in each period (Ranks 1-3, HIGH) and a sample of underperformers in each period (Ranks 4-6, LOW). In Columns 7-9 the impact of last period's rank is investigated. Here, $R A N K_{t-1}$ indicates participant $i$ 's rank in the preceding period. Standard errors are provided in parentheses. ${ }^{* * *},{ }^{* *}$, and $*$ represent significance at the $1 \%, 5 \%$, and $10 \%$ levels, respectively.

\begin{tabular}{lcccccc}
\hline \hline Dep. variable: $R I S K$, & $(1)$ & $(2)$ & $(3)$ & $(4)$ & $(5)$ & $(6)$ \\
percentage risky asset & TBASE & TRANK & TTOUR & ALL & HIGH & LOW \\
\hline$\alpha$ & $76.558^{* * *}$ & $81.785^{* * *}$ & $107.745^{* * *}$ & $76.369^{* * *}$ & $74.632^{* * *}$ & $78.392^{* * *}$ \\
& $(4.864)$ & $(5.198)$ & $(4.424)$ & $(4.591)$ & $(5.163)$ & $(5.111)$ \\
$R E T_{-} P F_{t-1}$ & $-0.446^{* * *}$ & $-0.329^{* * *}$ & $-0.384^{* * *}$ & $-0.398^{* * *}$ & $-0.181^{* * *}$ & $-0.473^{* * *}$ \\
& $(0.063)$ & $(0.070)$ & $(0.073)$ & $(0.040)$ & $(0.070)$ & $(0.055)$ \\
$R E T \_A S S E T_{t-1}$ & -0.020 & -0.071 & -0.101 & -0.056 & -0.054 & -0.134 \\
& $(0.078)$ & $(0.093)$ & $(0.129)$ & $(0.057)$ & $(0.083)$ & $(0.087)$ \\
$F E M A L E$ & -11.702 & -9.463 & -14.968 & $-10.788^{*}$ & -3.703 & $-14.477^{* *}$ \\
& $(9.650)$ & $(9.692)$ & $(17.675)$ & $(6.376)$ & $(7.019)$ & $(6.757)$ \\
TRANK & & & & 6.216 & 0.087 & 8.325 \\
& & & & $(6.074)$ & $(6.624)$ & $(6.653)$ \\
TTOUR & & & & $30.976^{* * *}$ & $15.323^{* *}$ & $40.306^{* * *}$ \\
& & & & $(6.187)$ & $(6.761)$ & $(6.735)$ \\
\hline N & 1008 & 1008 & 1008 & 3024 & 1512 & 1512 \\
R-squared & 0.105 & 0.050 & 0.043 & 0.101 & 0.000 & 0.250 \\
$\chi 2$ & 56.437 & 32.014 & 35.783 & 157.047 & 18.084 & 154.085 \\
Prob $>\chi 2$ & 0.000 & 0.000 & 0.000 & 0.000 & 0.006 & 0.000 \\
\hline \hline
\end{tabular}

\begin{tabular}{lccc}
\hline \hline Dep. variable: $R I S K$, & $(7)$ & $(8)$ & $(9)$ \\
percentage risky asset & TBASE & TRANK & TTOUR \\
\hline$\alpha$ & $73.551^{* * *}$ & $75.777^{* * *}$ & $71.234^{* * *}$ \\
& $(6.950)$ & $(7.001)$ & $(7.113)$ \\
$R E T_{-} P F_{t-1}$ & $-0.430^{* * *}$ & $-0.293^{* * *}$ & $-0.210^{* * *}$ \\
& $(0.069)$ & $(0.076)$ & $(0.077)$ \\
$R E T_{-} A S S E T_{t-1}$ & -0.026 & -0.091 & -0.207 \\
& $(0.079)$ & $(0.094)$ & $(0.128)$ \\
$F E M A L E$ & -11.274 & -10.256 & -16.670 \\
& $(9.617)$ & $(9.699)$ & $(17.234)$ \\
$R A N K_{t-1}$ & 0.835 & 1.722 & $10.481^{* * *}$ \\
& $(1.386)$ & $(1.346)$ & $(1.624)$ \\
\hline $\mathrm{N}$ & 1008 & 1008 & 1008 \\
$\mathrm{R}-$ squared & 0.102 & 0.053 & 0.082 \\
$\chi 2$ & 56.942 & 33.761 & 78.863 \\
Prob $>\chi 2$ & 0.000 & 0.000 & 0.000 \\
\hline \hline
\end{tabular}




\section{Table AVIII: Ranks and Risk-Taking in Experiment STUD With Dummy For Positive}

Portfolio Returns

Random effects panel regression with $\mathrm{AR}(1)$ disturbance, testing treatment differences of participants' percentage invested in the risky asset, $R I S K . R E T_{-} P F_{t-1}$ is the log-return of participant $i$ 's portfolio since the start of the experiment. $R E T T_{-} P F_{t-1}^{P O S}$ is a dummy variable for positive portfolio returns, and $R E T_{-} A S S E T_{t-1}$ is the preceding period's asset return. TRANK and TTOUR are dummy variables for the treatments with rank incentives and with tournament incentives, respectively, with TBASE as the baseline reference category. In Column 4 (ALL) treatment differences in risk-taking for the entire data set are displayed. In Columns 5 and 6 the data set is split into a sample of outperformers in each period (Ranks 1-3, HIGH) and a sample of underperformers in each period (Ranks 4-6, LOW). In Columns 7-9 the impact of last period's rank is investigated. Here, $R A N K_{t-1}$ indicates participant $i$ 's rank in the preceding period. Standard errors are provided in parentheses. $* * *, * *$, and $*$ represent significance at the $1 \%, 5 \%$, and $10 \%$ levels, respectively.

\begin{tabular}{|c|c|c|c|c|c|c|}
\hline $\begin{array}{l}\text { Dep. variable: } R I S K \text {, } \\
\text { percentage risky asset }\end{array}$ & $\begin{array}{c}(1) \\
\text { TBASE }\end{array}$ & $\begin{array}{c}(2) \\
\text { TRANK }\end{array}$ & $\begin{array}{c}(3) \\
\text { TTOUR }\end{array}$ & $\begin{array}{l}(4) \\
\text { ALL }\end{array}$ & $\begin{array}{c}(5) \\
\text { HIGH }\end{array}$ & $\begin{array}{c}(6) \\
\text { LOW }\end{array}$ \\
\hline$\alpha$ & $\begin{array}{c}77.882^{* * * *} \\
(5.070)\end{array}$ & $\begin{array}{c}86.923^{* * *} \\
(5.246)\end{array}$ & $\begin{array}{c}113.122^{* * *} \\
(5.507)\end{array}$ & $\begin{array}{c}79.855^{* * *} \\
(4.612)\end{array}$ & $\begin{array}{c}76.304^{* * *} \\
(5.456)\end{array}$ & $\begin{array}{c}89.623^{* * *} \\
(5.497)\end{array}$ \\
\hline$R E T_{-} P F_{t-1}$ & $\begin{array}{c}-0.394^{* * *} \\
(0.069)\end{array}$ & $\begin{array}{c}-0.252^{* * *} \\
(0.077)\end{array}$ & $\begin{array}{c}-0.310^{* * *} \\
(0.083)\end{array}$ & $\begin{array}{c}-0.324^{* * *} \\
(0.045)\end{array}$ & $\begin{array}{c}-0.147^{* *} \\
(0.075)\end{array}$ & $\begin{array}{c}-0.323^{* * *} \\
(0.061)\end{array}$ \\
\hline$R E T_{-} P F_{t-1}^{P O S}$ & $\begin{array}{l}-7.569 \\
(5.022)\end{array}$ & $\begin{array}{c}-12.401^{* *} \\
(5.022)\end{array}$ & $\begin{array}{c}-11.278^{*} \\
(6.143)\end{array}$ & $\begin{array}{c}-10.999^{* * *} \\
(3.144)\end{array}$ & $\begin{array}{l}-4.662 \\
(4.506)\end{array}$ & $\begin{array}{c}-25.852^{* * *} \\
(4.829)\end{array}$ \\
\hline$R E T_{-} A S S E T_{t-1}$ & $\begin{array}{c}0.011 \\
(0.081)\end{array}$ & $\begin{array}{l}-0.008 \\
(0.097)\end{array}$ & $\begin{array}{l}-0.026 \\
(0.136)\end{array}$ & $\begin{array}{c}0.001 \\
(0.060)\end{array}$ & $\begin{array}{l}-0.032 \\
(0.086)\end{array}$ & $\begin{array}{l}-0.020 \\
(0.090)\end{array}$ \\
\hline TRANK & & & & $\begin{array}{c}6.559 \\
(6.019)\end{array}$ & $\begin{array}{c}0.511 \\
(6.632)\end{array}$ & $\begin{array}{c}7.439 \\
(6.498)\end{array}$ \\
\hline TTOUR & & & & $\begin{array}{c}33.016^{* * *} \\
(6.008)\end{array}$ & $\begin{array}{c}16.104^{* *} \\
(6.613)\end{array}$ & $\begin{array}{c}42.671^{* * *} \\
(6.500)\end{array}$ \\
\hline $\mathrm{N}$ & 1008 & 1008 & 1008 & 3024 & 1512 & 1512 \\
\hline R-squared & 0.105 & 0.073 & 0.044 & 0.107 & 0.000 & 0.275 \\
\hline$\chi^{2}$ & 57.308 & 37.790 & 38.674 & 167.924 & 18.812 & 185.207 \\
\hline Prob $>\chi^{2}$ & 0.000 & 0.000 & 0.000 & 0.000 & 0.004 & 0.000 \\
\hline
\end{tabular}

\begin{tabular}{lccc}
\hline \hline Dep. variable: $R I S K$, & $(7)$ & $(8)$ & $(9)$ \\
percentage risky asset & TBASE & TRANK & TTOUR \\
\hline$\alpha$ & $74.894^{* * *}$ & $82.371^{* * *}$ & $75.760^{* * *}$ \\
& $(7.101)$ & $(7.567)$ & $(7.982)$ \\
$R E T_{-} P F_{t-1}$ & $-0.379^{* * *}$ & $-0.232^{* * *}$ & $-0.157^{*}$ \\
& $(0.073)$ & $(0.080)$ & $(0.085)$ \\
$R E T_{-} P F_{t-1}^{P O S}$ & -7.397 & $-11.711^{* *}$ & -8.759 \\
& $(5.034)$ & $(5.090)$ & $(6.042)$ \\
$R E T_{-} A S S E T_{t-1}$ & 0.004 & -0.026 & -0.146 \\
& $(0.082)$ & $(0.099)$ & $(0.134)$ \\
$R A N K_{t-1}$ & 0.833 & 1.137 & $10.290^{* * *}$ \\
& $(1.384)$ & $(1.361)$ & $(1.624)$ \\
\hline $\mathrm{N}$ & 1008 & 1008 & 1008 \\
$\mathrm{R}-$ squared & 0.102 & 0.074 & 0.082 \\
$\chi 2$ & 57.723 & 38.547 & 80.166 \\
Prob $>\chi 2$ & 0.000 & 0.000 & 0.000 \\
\hline \hline
\end{tabular}


Table AIX: Ranks and Risk-Taking in Experiment STUD With Dummy For Economics and Management Students

Random effects panel regression with $\mathrm{AR}(1)$ disturbance, testing treatment differences of participants' percentage invested in the risky asset, RISK. RET $P F_{t-1}$ is the log-return of participant $i$ 's portfolio since the start of the experiment and $R E T T_{-} A S S E T_{t-1}$ is the preceding period's asset return. ECON is a binary dummy variable indicating 1 for economics and management students, zero for other fields. TRANK and TTOUR are dummy variables for the treatments with rank incentives and with tournament incentives, respectively, with TBASE as the baseline reference category. In Column 4 (ALL) treatment differences in risk-taking for the entire data set are displayed. In Columns 5 and 6 the data set is split into a sample of outperformers in each period (Ranks 1-3, HIGH) and a sample of underperformers in each period (Ranks 4-6, LOW). In Columns 7-9 the impact of last period's rank is investigated. Here, $R A N K_{t-1}$ indicates participant $i$ 's rank in the preceding period. Standard errors are provided in parentheses. ${ }^{* * *},{ }^{* *}$, and ${ }^{*}$ represent significance at the $1 \%, 5 \%$, and $10 \%$ levels, respectively.

\begin{tabular}{|c|c|c|c|c|c|c|}
\hline $\begin{array}{l}\text { Dep. variable: } R I S K \text {, } \\
\text { percentage risky asset }\end{array}$ & $\begin{array}{c}(1) \\
\text { TBASE }\end{array}$ & $\begin{array}{c}(2) \\
\text { TRANK }\end{array}$ & $\begin{array}{c}(3) \\
\text { TTOUR }\end{array}$ & $\begin{array}{l}(4) \\
\text { ALL }\end{array}$ & $\begin{array}{l}(5) \\
\text { HIGH }\end{array}$ & $\begin{array}{c}(6) \\
\text { LOW }\end{array}$ \\
\hline$\alpha$ & $\begin{array}{c}66.243^{* * *} \\
(5.770)\end{array}$ & $\begin{array}{c}79.990^{* * *} \\
(6.895)\end{array}$ & $\begin{array}{l}111.081^{* * * *} \\
(6.094)\end{array}$ & $\begin{array}{c}66.281^{* * *} \\
(5.935)\end{array}$ & $\begin{array}{c}68.752^{* * *} \\
(6.783)\end{array}$ & $\begin{array}{c}64.959^{* * *} \\
(6.493)\end{array}$ \\
\hline$R E T_{-} P F_{t-1}$ & $\begin{array}{c}-0.437^{* * *} \\
(0.063)\end{array}$ & $\begin{array}{c}-0.330^{* * *} \\
(0.070)\end{array}$ & $\begin{array}{c}-0.381^{* * *} \\
(0.073)\end{array}$ & $\begin{array}{c}-0.394^{* * *} \\
(0.040)\end{array}$ & $\begin{array}{c}-0.178^{* *} \\
(0.070)\end{array}$ & $\begin{array}{c}-0.463^{* * *} \\
(0.055)\end{array}$ \\
\hline$R E T_{-} A S S E T_{t-1}$ & $\begin{array}{l}-0.020 \\
(0.078)\end{array}$ & $\begin{array}{l}-0.071 \\
(0.093)\end{array}$ & $\begin{array}{l}-0.103 \\
(0.129)\end{array}$ & $\begin{array}{l}-0.056 \\
(0.057)\end{array}$ & $\begin{array}{l}-0.053 \\
(0.083)\end{array}$ & $\begin{array}{l}-0.137 \\
(0.087)\end{array}$ \\
\hline$E C O N$ & $\begin{array}{l}15.261^{*} \\
(8.328)\end{array}$ & $\begin{array}{l}-1.517 \\
(8.930)\end{array}$ & $\begin{array}{l}-8.424 \\
(8.553)\end{array}$ & $\begin{array}{l}15.274^{*} \\
(8.570)\end{array}$ & $\begin{array}{l}9.564 \\
(9.436)\end{array}$ & $\begin{array}{l}21.903 \\
(9.542)\end{array}$ \\
\hline TRANK & & & & $\begin{array}{l}14.379 \\
(8.952)\end{array}$ & $\begin{array}{c}6.475 \\
(10.072)\end{array}$ & $\begin{array}{l}16.927^{*} \\
(9.519)\end{array}$ \\
\hline $\mathrm{TRANK}^{*} E C O N$ & & & & $\begin{array}{l}-17.263 \\
(12.218)\end{array}$ & $\begin{array}{l}-12.186 \\
(13.400)\end{array}$ & $\begin{array}{l}-21.766 \\
(13.278)\end{array}$ \\
\hline TTOUR & & & & $\begin{array}{c}44.606^{* * *} \\
(8.506)\end{array}$ & $\begin{array}{l}18.365^{*} \\
(9.721)\end{array}$ & $\begin{array}{c}58.569^{* * *} \\
(9.111)\end{array}$ \\
\hline${ }^{*} E C O N$ & & & & $\begin{array}{l}-23.595^{*} \\
(12.115)\end{array}$ & $\begin{array}{c}-4.952 \\
(13.304)\end{array}$ & $\begin{array}{c}-33.754^{* *} \\
(13.303)\end{array}$ \\
\hline $\mathrm{N}$ & 1008 & 1008 & 1008 & 3024 & 1512 & 1512 \\
\hline R-squared & 0.112 & 0.046 & 0.044 & 0.102 & 0.001 & 0.251 \\
\hline$\chi 2$ & 58.553 & 31.039 & 36.046 & 158.468 & 19.066 & 156.436 \\
\hline Prob $>\chi 2$ & 0.000 & 0.000 & 0.000 & 0.000 & 0.015 & 0.000 \\
\hline
\end{tabular}

\begin{tabular}{lccc}
\hline \hline Dep. variable: $R I S K$, & $(7)$ & $(8)$ & $(9)$ \\
percentage risky asset & TBASE & TRANK & TTOUR \\
\hline$\alpha$ & $68.493^{* * *}$ & $72.117^{* * *}$ & $70.657^{* * *}$ \\
& $(8.811)$ & $(10.332)$ & $(10.231)$ \\
$R E T_{-} P F_{t-1}$ & $-0.410^{* * *}$ & $-0.296^{* * *}$ & $-0.207^{* * *}$ \\
& $(0.068)$ & $(0.076)$ & $(0.077)$ \\
$R E T \_A S S E T_{t-1}$ & -0.026 & -0.091 & -0.208 \\
& $(0.079)$ & $(0.094)$ & $(0.128)$ \\
$E C O N$ & 3.932 & 1.721 & -0.835 \\
& $(12.176)$ & $(12.751)$ & $(13.541)$ \\
$R A N K_{t-1}$ & -0.614 & 2.065 & $11.165^{* * *}$ \\
& $(1.875)$ & $(2.056)$ & $(2.299)$ \\
$R A N K_{t-1}{ }^{*} E C O N$ & 3.287 & -0.730 & -1.436 \\
& $(2.553)$ & $(2.559)$ & $(3.053)$ \\
\hline $\mathrm{N}$ & 1008 & 1008 & 1008 \\
$\mathrm{R}-$ squared & 0.113 & 0.04945 & 0.083 \\
$\chi 2$ & 60.943 & 32.639 & 78.598 \\
Prob $>\chi 2$ & 0.000 & 0.000 & 0.000 \\
\hline \hline
\end{tabular}


Table AX: Ranks and Risk-Taking in Experiment PROF and STUD Including a Dummy for PROFESSIONALS

Random effects panel regression with $\mathrm{AR}(1)$ disturbance, testing treatment differences of participants' percentage invested in the risky asset, $R I S K$. $R E T_{-} P F_{t-1}$ is the log-return of participant $i$ 's portfolio since the start of the experiment and RET_ASSET $T_{t-1}$ is the preceding period's asset return. PROFESSIONALS is a binary dummy variable indicating 1 for professionals, zero for students. TRANK and TTOUR are dummy variables for the treatments with rank incentives and with tournament incentives, respectively, with TBASE as the baseline reference category. In Column 4 (ALL) treatment differences in risk-taking for the entire data set are displayed. In Columns 5 and 6 the data set is split into a sample of outperformers in each period (Ranks 1-3, HIGH) and a sample of underperformers in each period (Ranks 4-6, LOW). In Columns 7-9 the impact of last period's rank is investigated. Here, $R A N K_{t-1}$ indicates participant $i$ 's rank in the preceding period. Standard errors are provided in parentheses. ${ }^{* * *},{ }^{* *}$, and $*$ represent significance at the $1 \%, 5 \%$, and $10 \%$ levels, respectively.

\begin{tabular}{lcccccc}
\hline \hline Dep. variable: $R I S K$, & $(1)$ & $(2)$ & $(3)$ & $(4)$ & $(5)$ & $(6)$ \\
percentage risky asset & TBASE & TRANK & TTOUR & ALL & HIGH & LOW \\
\hline$\alpha$ & $73.709^{* * *}$ & $79.430^{* * *}$ & $106.947^{* * *}$ & $75.310^{* * *}$ & $79.882^{* * *}$ & $74.135^{* * *}$ \\
& $(4.174)$ & $(4.332)$ & $(4.359)$ & $(3.751)$ & $(4.285)$ & $(4.138)$ \\
$R E T_{-} P F_{t-1}$ & $-0.421^{* * *}$ & $-0.386^{* * *}$ & $-0.386^{* * *}$ & $-0.402^{* * *}$ & $-0.275^{* * *}$ & $-0.448^{* * *}$ \\
& $(0.048)$ & $(0.055)$ & $(0.056)$ & $(0.031)$ & $(0.054)$ & $(0.041)$ \\
RET_ASSET $T_{t-1}$ & -0.048 & -0.049 & $-0.220^{* *}$ & $-0.094^{* *}$ & -0.097 & $-0.166^{* *}$ \\
& $(0.069)$ & $(0.075)$ & $(0.099)$ & $(0.046)$ & $(0.068)$ & $(0.070)$ \\
PROFESSIONALS & $23.208^{* * *}$ & $24.563^{* * *}$ & 6.494 & $18.637^{* * *}$ & $17.303^{* * *}$ & $18.550^{* * *}$ \\
& $(7.039)$ & $(6.699)$ & $(7.545)$ & $(4.100)$ & $(4.572)$ & $(4.396)$ \\
TRANK & & & & 6.871 & -4.612 & $13.659^{* * *}$ \\
& & & & $(4.787)$ & $(5.340)$ & $(5.146)$ \\
TTOUR & & & & $27.376^{* * *}$ & 7.241 & $39.229^{* * *}$ \\
& & & & $(4.930)$ & $(5.527)$ & $(5.323)$ \\
\hline N & 1554 & 1722 & 1512 & 4788 & 2394 & 2394 \\
R-squared & 0.116 & 0.090 & 0.062 & 0.108 & 0.002 & 0.263 \\
$\chi 2$ & 101.441 & 75.923 & 69.332 & 274.114 & 57.117 & 232.433 \\
Prob $>\chi 2$ & 0.000 & 0.000 & 0.000 & 0.000 & 0.000 & 0.000 \\
\hline \hline
\end{tabular}

\begin{tabular}{lccc}
\hline \hline Dep. variable: RISK, & $(7)$ & $(8)$ & $(9)$ \\
percentage risky asset & TBASE & TRANK & TTOUR \\
\hline$\alpha$ & $77.024^{* * *}$ & $68.786^{* * *}$ & $73.153^{* * *}$ \\
& $(5.505)$ & $(5.685)$ & $(6.179)$ \\
$R E T_{-} P F_{t-1}$ & $-0.436^{* * *}$ & $-0.327^{* * *}$ & $-0.239^{* * *}$ \\
& $(0.050)$ & $(0.059)$ & $(0.059)$ \\
$R E T \_A S S E T_{t-1}$ & -0.041 & -0.083 & $-0.303^{* * *}$ \\
& $(0.070)$ & $(0.076)$ & $(0.098)$ \\
PROFESSIONALS & $23.287^{* * *}$ & $24.364^{* * *}$ & 6.291 \\
& $(6.942)$ & $(6.680)$ & $(7.352)$ \\
RANK $K_{t-1}$ & -0.955 & $2.944^{* * *}$ & $9.666^{* * *}$ \\
& $(1.053)$ & $(1.022)$ & $(1.284)$ \\
\hline $\mathrm{N}$ & 1554 & 1722 & 1512 \\
$\mathrm{R}-$ squared & 0.120 & 0.096 & 0.100 \\
$\chi 2$ & 103.063 & 84.716 & 128.739 \\
Prob $>\chi 2$ & 0.000 & 0.000 & 0.000 \\
\hline \hline
\end{tabular}


Table AXI: Ranks and Risk-Taking in Treatments TRANK, TRANK ${ }^{\mathrm{LOT}}$, and TRANK ${ }^{\text {FAM }}$ in the Professional Sample

Random effects panel regressions with $\mathrm{AR}(1)$ disturbance, testing rank-driven behavior in treatments TRANK, TRANK ${ }^{\mathrm{LOT}}$, and TRANK ${ }^{\mathrm{FAM}}$. RET $P F_{t-1}$ is the log-return of participant $i$ 's portfolio since the start of the experiment and RET ASSET $T_{t-1}$ is the preceding period's asset return. TRANK (dummy) and TRANK ${ }^{\mathrm{LOT}}$ (dummy) are dummy variables for the treatments with rank incentives and with rank incentives in an abstract lottery frame, respectively. Treatment TRANK ${ }^{\text {FAM }}$ (with rank incentives when investing for a family member) serves as the reference category. In Column 1 treatment differences in risk-taking for the entire data set are displayed. In Columns 2 and 3 the data set is split into a sample of outperformers in each period (Column 2 - HIGH) and a sample of underperformers in each period (Column 3-LOW). Standard errors are provided in parentheses. ${ }^{* * *},{ }^{* *}$, and $*$ represent significance at the $1 \%, 5 \%$, and $10 \%$ levels, respectively.

\begin{tabular}{lccc}
\hline \hline $\begin{array}{c}\text { Dep. variable: } R I S K, \\
\text { percentage risky asset }\end{array}$ & ALL & HIGH & LOW \\
\hline$\alpha$ & $113.564^{* * *}$ & $100.668^{* * *}$ & $115.399^{* * *}$ \\
& $(7.484)$ & $(8.669)$ & $(8.225)$ \\
$R E T \_P F_{t-1}$ & $-0.404^{* * *}$ & $-0.285^{* * *}$ & $-0.378^{* * *}$ \\
& $(0.051)$ & $(0.097)$ & $(0.062)$ \\
$R E T \_A S S E T_{t-1}$ & -0.067 & -0.096 & -0.069 \\
& $(0.082)$ & $(0.126)$ & $(0.108)$ \\
TRANK & -9.378 & -8.511 & -1.777 \\
& $(9.116)$ & $(10.567)$ & $(9.885)$ \\
TRANKLOT & -15.491 & -19.521 & 2.613 \\
& $(10.257)$ & $(11.946)$ & $(11.254)$ \\
\hline N & 1428 & 714 & 714 \\
R-squared & 0.134 & 0.006 & 0.268 \\
$\chi 2$ & 83.701 & 14.434 & 51.594 \\
Prob $>\chi 2$ & 0.000 & 0.013 & 0.000 \\
\hline \hline
\end{tabular}




\section{B Survey Evidence on Preferences for Relative Performance, Com- petitiveness and Risk}

Our findings raise the question about "special" characteristics of professionals, which may help to explain the observed differences in rank-dependent behavior when compared with students. It is unclear, however, which group, professionals or students, is special with respect to these characteristics and to which extent. To shed more light on the role that professionals' and students' individual characteristics may play, we, elicited preferences for relative performance and social status and investigated their relation to observed behavior in the investment game of the experiments PROF and STUD.

Given the performance-oriented business culture in the financial industry and the possibility that very competitive individuals self-select into this sector and are also shaped by it, financial professionals might differ from other groups in their preferences for relative performance and competitiveness. Moreover, they might also have different risk attitudes and loss tolerance, both of which could explain risk-taking in the investment task in general. In addition to the above mentioned experimental tasks on risk attitudes and loss aversion, we therefore administered a slightly modified version of the classical CRT by Frederick (2005, see Online Appendix E), the Big 5, the Dark Triad personality traits, survey questions measuring risk attitudes according to the German SOEP (Dohmen et al., 2011) and attitudes toward social status, financial success, and relative performance like in Cohn et al. (2014). Regarding the latter we asked:

Q1 (Social Status): How important is it for you what others think about you? (1: not important; 7: very important)

Q2 (Financial Success): Social status is primarily defined by financial success. (1: completely disagree; 7: fully agree)

Q3 (Relative Performance): How important is it for you to be the best at what you do? (1: not important; 7 : very important)

Figure B1 and Table BI present descriptive results from experiments PROF and STUD. In this section we only use data of these two experiments because they are identical in all tasks (except stake sizes). ${ }^{29}$ We observe no differences between professionals and students in the average importance of financial success, but highly significant differences with regard to social status and relative performance. Social status is significantly more important for professionals than for students and relative performance is the most important trait. ${ }^{30}$ This result supports the notion that subject-pool-specific differences in attitudes toward relative performance can

\footnotetext{
${ }^{29}$ For instance, in the online experiment we had to forgo some of the additional tasks for time reasons.

${ }^{30}$ All participants answered questions on social status and financial success, Q1 and Q2 respectively. After collecting some observations, we additionally asked the question on relative performance (Q3). For analyses regarding the latter we therefore use the corresponding sub sample with $N=342$.
} 
explain the differences in rank-dependent risk-taking between professionals and students. In fact, economics and management students are closer to professionals in some of their attitudes than students with other majors (e.g., natural sciences, life sciences, humanities). When we split the student sample along these lines, we find that economics and management students consider social status and relative performance to be significantly more important than other students. Thus, it seems that part of this status-seeking behavior and attitudes towards relative performance are already present before entering the finance industry.
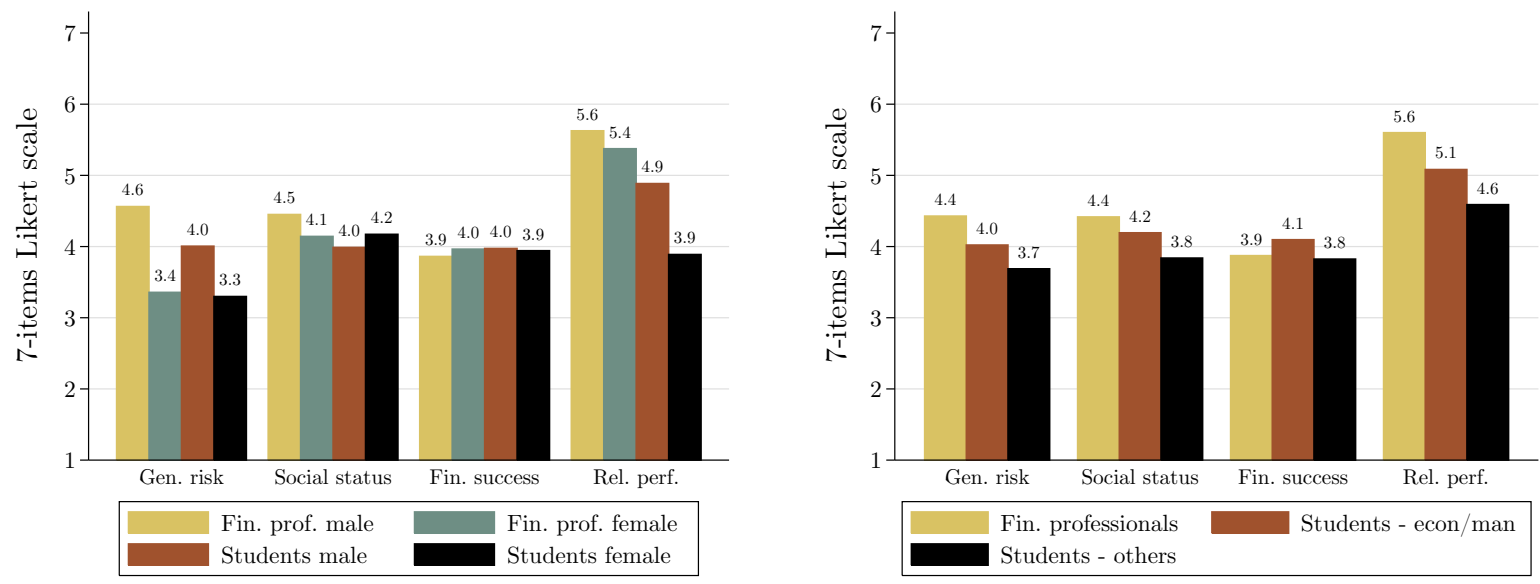

Figure B1: Preferences for Status, Financial Success, Relative Performance, and Risk-Taking, Separated by Gender (Left Panel) and Field of Study (Right Panel)

Average post-experimental survey responses on a 7-point Likert scale (higher values indicate stronger preferences) for the following variables: GENERAL_RISK, SOCIAL_STATUS, FINANCIAL_SUCCESS, and RELATIVE_PERFORMANCE. Students-econ/man refers to economics and management students. Data is gathered from experiments PROF and STUD and split by subject pool and gender (left) and by field of studies for the student sample (right panel). 
Table BI: Univariate Analysis of Preferences for Status, Financial Success, Relative Performance, and Cognitive Reflection Test Scores

Univariate Analysis of post-experimental responses, separated by subject pool, gender and field of studies (for the student sample). SOCIAL_STATUS, FINANCIAL_SUCCESS, and RELATIVE_PERFORMANCE represent the answers to corresponding survey questions on a 7-point Likert scale (higher values indicate stronger preferences). GENERAL_RISK is the self-reported willingness to take risks (7-point Likert scale; higher values indicate stronger preferences). RISK_TOLERANCE is a lottery-based measure of risk attitudes (normalized from 0 to 1; lower values indicate higher risk aversion; a value of 0.50 stands for risk neutrality). LOSS_TOLERANCE is a lottery-based measure of loss attitudes (normalized from 0 to 1 ; higher values indicate lower loss aversion). $C R T \_S C O R E$ is the test score on a slightly modified version of the CRT by Frederick (2005) ranging from 0 (no correct answer) to 3 (all answers correct). Econ/Man and Stud E/M refer to economics and management students. ${ }^{* * *},{ }^{* *}$, and ${ }^{*}$ represent significance at the $1 \%, 5 \%$, and $10 \%$ levels of double-sided Mann-Whitney U-tests, respectively. The data is gathered from experiments PROF and STUD.

\begin{tabular}{lccc}
\hline \hline & & Professionals \\
Variable & ALL & Male & Female \\
\hline SOCIAL_STATUS (7 items) & 4.42 & 4.45 & 4.14 \\
FINANCIAL_SUCCESS (7 items) & 3.87 & 3.86 & 3.96 \\
RELATIVE_PERFORMANCE (7 items) & 5.60 & 5.63 & 5.38 \\
GENERAL_RISK (7 items) & 4.43 & 4.56 & 3.36 \\
RISK_TOLERANCE (lottery-based) & 0.43 & 0.43 & 0.43 \\
LOSS_TOLERANCE (lottery-based) & 0.49 & 0.49 & 0.49 \\
CRT_SCORE (from 0 to 3) & 1.81 & 1.84 & 1.54 \\
\hline N & 252 & 224 & 28 \\
Percentage FEMALE & 11.11 & & \\
\hline \hline
\end{tabular}

\begin{tabular}{|c|c|c|c|c|c|}
\hline Variable & ALL & Male & $\begin{array}{r}\text { Students } \\
\text { Female }\end{array}$ & Econ/Man & Others \\
\hline SOCIAL_STATUS (7 items) & 4.03 & 4.17 & 4.00 & 4.19 & 3.84 \\
\hline FINANCIAL_SUCCESS (7 items) & 3.97 & 3.94 & 3.97 & 4.10 & 3.82 \\
\hline RELATIVE_ $\bar{P} E R F O R M A N C E$ (7 items) & 4.84 & 4.89 & 3.89 & 5.08 & 4.59 \\
\hline GENERAL_RISK (7 items) & 3.86 & 4.01 & 3.30 & 4.02 & 3.69 \\
\hline RISK_TOEERANCE (lottery-based) & 0.41 & 0.41 & 0.39 & 0.41 & 0.41 \\
\hline LOSS_TOLERANCE (lottery-based) & 0.35 & 0.36 & 0.31 & 0.34 & 0.36 \\
\hline$C R T \_S C O R E$ (from 0 to 3 ) & 1.69 & 1.81 & 1.21 & 1.67 & 1.71 \\
\hline $\mathrm{N}$ & 432 & 345 & 87 & 227 & 205 \\
\hline Percentage $F E M A L E$ & 20.14 & & & & \\
\hline
\end{tabular}

\begin{tabular}{|c|c|c|c|c|}
\hline \multirow[b]{2}{*}{ Variable } & \multicolumn{4}{|c|}{ MW-U tests (|Z-values $\mid)$} \\
\hline & $\begin{array}{l}\text { Prof v } \\
\text { Stud }\end{array}$ & $\begin{array}{l}\text { Prof Male v } \\
\text { Prof Fem }\end{array}$ & $\begin{array}{l}\text { Stud Male v } \\
\text { Stud Fem }\end{array}$ & $\begin{array}{l}\text { Stud E/M v } \\
\text { Stud Others }\end{array}$ \\
\hline$S O C I A L \_S T A T U S$ (7 items) & $3.338^{* * *}$ & 0.996 & 1.066 & $2.437^{* *}$ \\
\hline FINANCIAL_SUCCESS (7 items) & 0.838 & 0.061 & 0.256 & $1.731^{*}$ \\
\hline RELATIVE_ $\bar{P} E R F O R M A N C E$ (7 items) & $5.289 * * *$ & 0.216 & 1.391 & $2.703^{* * *}$ \\
\hline GENERAL_RISK (7 items) & $4.548^{* * *}$ & $3.686^{* * *}$ & $4.060 * * *$ & $2.500^{* *}$ \\
\hline RISK_TOLERANCE (lottery-based) & $2.767^{* * *}$ & 0.171 & 1.419 & 0.181 \\
\hline LOSS_TOLERANCE (lottery-based) & $8.682^{* * *}$ & 0.011 & 1.940 & 0.845 \\
\hline$C R T \_\bar{S} C O R E$ (from 0 to 3 ) & 1.374 & 1.574 & $4.594^{* * *}$ & 0.336 \\
\hline
\end{tabular}


In Table BI we also report differences between both subject pools regarding preferences for risk and loss. Univariate analyses show that professionals are less risk averse than students in both the self-reported measure referring to risks in real life (German SOEP-question) and in the lottery task. Moreover, professionals have a significantly higher tolerance for losses than students. ${ }^{31}$ All differences are significant at the $1 \%$ level. By splitting the student sample, we find that students in economics and management exhibit significantly higher levels of selfreported risk-taking compared to their peers from other fields (German SOEP-question), but no differences in the lottery-based experiments on risk aversion and loss aversion. Regarding CRT we do not find differences across subject pools: both populations show relatively high values of 1.81 (professionals) and 1.69 (students) compared to extant scores in the literature (Frederick, 2005). We also test for differences in personality traits as measured by the Big 5 and the Dark Triad, but do not find systematic differences across subject pools.

Another important aspect investigated in Table BI is whether male and female professionals differ regarding preferences for relative performance, social status, financial success, risk, and loss. Although the total sample size of professionals in Experiment PROF is large, the number of female professionals is low and varies between 35 and 47 depending on the variable tested. Therefore, the following results have to be treated with caution. Interestingly, we find that male and female professionals do not differ in the abstract lottery-based measures of risk aversion and of loss aversion. This is also confirmed when we re-run the tests in Table 1 with gender dummies, which show no clear nor significant relationship with risk taken in Experiment PROF (see Table AIII). ${ }^{32}$ Female professionals are, however, significantly more risk-averse in their selfreported risk-taking as measured by the German SOEP-question. It seems that, although female professionals self-report higher levels of general risk aversion, they do not differ from their male colleagues when it comes to more specific lottery tasks and risk-taking in experimental investment decisions. For all other variables in Table BI, we do not find any differences between male and female professionals. This also applies to the student population with the only exception that male students show significantly higher CRT scores than their female counterparts.

In a next step we investigate whether professionals' concern for relative performance and social status influence their behavior in the investment experiment. For this, we use the data of experiments PROF and STUD to run ordinary least squares regressions with a participant's average risk taken over all eight periods $(\overline{R I S K})$ as dependent variable and the answers to social status (Q1), financial success (Q2), and relative performance (Q3) as independent variables. We add loss aversion and general risk attitude as additional control variables and cluster standard

\footnotetext{
${ }^{31}$ The difference of 0.14 of the normalized loss aversion measure is very pronounced. Professionals accept $49 \%$ of the mixed gambles, while students only accept $35 \%$ of the mixed gambles. Professionals are nevertheless slightly averse to losses as they, on average, switch to rejecting the lottery when potential losses are between 9 and 12 euro (for an equally probable gain of 15 euro).

${ }^{32}$ See Table AVII for corresponding regressions with gender dummies in the student sample. For robustness of our previous results we re-run the tests in tables 1 and 2 with the male sub sample only and find very similar results (see Table AII and AVI in the Online Appendix).
} 
errors at the group level. For loss aversion we include the normalized sum of accepted lotteries, LOSS_TOLERANCE, which takes on values from 0 (rejecting all gambles - highly loss averse) to 1 (accepting all gambles - loss seeking). For risk attitude we use the answer to the German SOEP survey question with higher values indicating more self-reported risk-taking in real life. Faced with a choice between alternative risk measurements we find that the SOEP measure has less multi-collinearity and more explanatory power. ${ }^{33}$

\section{Table BII: Individual Preferences and Investments in the Risky Asset}

Ordinary least squares regression of participants' average amount invested in the risky asset, $\overline{R I S K}$. SOCIAL_STATUS, FINANCIAL_SUCCESS, and RELATIVE_PERFORMANCE represent the answers to corresponding survey questions on a 7 -point Likert scale (higher values indicate stronger preferences). LOSS TOLERANCE is a measure of loss attitudes (from 0 to 1 ; higher values indicate lower loss aversion) and GENERAL_RISK is the self-reported willingness to take risks (7-point Likert scale). Standard errors are provided in parentheses. $* * *, * *$, and $*$ represent significance at the $1 \%, 5 \%$, and $10 \%$ levels, respectively. The data is gathered from experiments PROF and STUD.

\begin{tabular}{lcc}
\hline \hline Dep. variable: $\overline{R I S K}$, mean & & \\
percentage invested in risky asset & PROF & STUD \\
\hline$\alpha$ & 14.910 & $35.814^{*}$ \\
& $(24.114)$ & $(17.958)$ \\
SOCIAL_STATUS & -3.242 & -2.800 \\
& $(3.162)$ & $(2.286)$ \\
FINANCIAL_SUCCESS & -1.554 & 0.905 \\
& $(2.986)$ & $(2.449)$ \\
RELATIVE_PERFORMANCE & $9.886^{* * *}$ & -1.271 \\
& $(2.179)$ & $(2.981)$ \\
GENERAL_RISK & $8.312^{* * *}$ & $14.083^{* * *}$ \\
& $(2.449)$ & $(1.680)$ \\
LOSS_TOLERANCE & $38.677^{*}$ & $52.210^{* * *}$ \\
& $(20.100)$ & $(17.943)$ \\
\hline N & 150 & 192 \\
Clusters & 25 & 32 \\
R-squared & 0.149 & 0.227 \\
$F$ & 7.956 & 29.978 \\
Prob $>F$ & 0.000 & 0.000 \\
\hline \hline
\end{tabular}

Table BII reports the results for the sub-sample with non-missing answers to the question on relative performance (Q3). ${ }^{34}$ Remarkably, we find that attitudes toward relative performance

\footnotetext{
${ }^{33}$ In Experiment PROF the pairwise correlation between the lottery risk measure and loss aversion is 0.30 , while the pairwise correlation between the SOEP risk measure and loss aversion is 0.17 . The explanatory power (measured with R-squared) of all reported regressions is higher when using the SOEP measure for risk attitude. The results for all three questions on social status, financial success and relative performance remain very similar if we include the lottery measure for risk aversion (see Table BIV).

${ }^{34}$ Table BIII reports more extensive regressions results for both the sub-sample and the total sample.
} 
(RELATIVE_PERFORMANCE) are a predictor for professionals' risk-taking in Experiment PROF. ${ }^{35}$ Professionals who consider relative performance to be important invest significantly more in the risky asset (probably in the hope of obtaining a high rank) than those who consider it less important, even when controlling for risk aversion and loss aversion. Interestingly, and in line with earlier results on missing rank-effects in the student sample, individual preferences for relative performance fail to predict risk-taking behavior of students, as shown in the regression of Experiment STUD in Table BII and, per treatment, in Table BIV. Turning to possible other explanatory variables we do not observe a consistent or statistically significant pattern in the effects of self-reported attitudes toward social status and financial success. In line with intuition, participants who are more tolerant to losses and particularly to risk in general, take more risks in the investment experiment. This applies to both professionals and students. ${ }^{36}$ Note that the results at treatment level in Table BIV should be treated with caution, because of a relatively low sample size in most treatments. However, the aggregated results per experiment show strong support for the impact of preferences for relative performance on risk-taking among professionals.

\footnotetext{
${ }^{35}$ This also holds per treatment when we run the same regressions with PROF and the SOEP risk measure (see Table BIV).

${ }^{36}$ The reported results remain very similar when controlling for $C R T \_S C O R E$ and personality traits $(B I G-5$ and DARK_TRIAD)—see Table BIII.
} 
Table BIII: Preferences for Relative Performance, Status, Financial Success and RiskTaking

Ordinary least squares regression of participants' average amount invested in the risky asset, $\overline{R I S K}$. SOCIAL_STATUS, FINANCIAL_SUCCESS, and RELATIVE_PERFORMANCE represent the answers to corresponding survey questions on a 7-point Likert scale (higher values indicate stronger preferences). LOSS_TOLERANCE is a measure of loss attitudes (from 0 to 1 ; higher values indicate lower loss aversion) and GENERAL_RISK is the self-reported willingness to take risks (7-point Likert scale). Model 1 (Model 4) contains the total sample, Model 2 (Model 5) the sub-sample with non-missing Q3, and Model 3 (Model 6) controls additionally for $C R T \_S C O R E, B I G-5$ and $D A R K \_T R I A D$ in the sub-sample. Standard errors are clustered at the group level and are provided in parentheses. ${ }^{* * *}, * *$, and $*$ represent significance at the $1 \%, 5 \%$, and $10 \%$ levels, respectively.

\begin{tabular}{lccc}
\hline \hline Dep. variable: $\overline{\overline{R I S K}}$, mean & \multicolumn{3}{c}{ Experiment PROF } \\
percentage risky asset & $(1)$ & $(2)$ & $(3)$ \\
\hline$\alpha$ & $47.680^{* * *}$ & 14.910 & 13.457 \\
& $(16.036)$ & $(24.114)$ & $(54.484)$ \\
SOCIAL_ST ATUS & -3.141 & -3.242 & -2.114 \\
& $(2.377)$ & $(3.162)$ & $(3.127)$ \\
FINANCIAL_SUCCESS & -0.524 & -1.554 & -0.553 \\
& $(2.203)$ & $(2.986)$ & $(3.211)$ \\
GENERAL_RISK & $11.398^{* * *}$ & $8.312^{* * *}$ & $9.530^{* * *}$ \\
& $(1.862)$ & $(2.449)$ & $(2.595)$ \\
LOSS_TOLERANCE & $38.783^{* *}$ & $38.677^{*}$ & 34.036 \\
& $(14.563)$ & $(20.100)$ & $(20.894)$ \\
RELATIVE_PERFORMANCE & & $9.886^{* * *}$ & $9.366^{* * *}$ \\
& & $(2.179)$ & $(2.739)$ \\
CRT_SCORE & & & 7.490 \\
& & & $(4.595)$ \\
BIG - 5 & no & no & yes \\
DARK_TRIAD & no & no & yes \\
\hline N & 252 & 150 & 150 \\
Clusters & 42 & 25 & 25 \\
R-squared & 0.163 & 0.149 & 0.202 \\
Prob > F & 16.774 & 7.956 & 4.954 \\
\hline \hline & 0.000 & 0.000 & 0.000 \\
\hline
\end{tabular}

\begin{tabular}{|c|c|c|c|}
\hline \multirow{2}{*}{$\begin{array}{l}\text { Dep. variable: } \overline{R I S K} \text {, mean } \\
\text { percentage invested in risky asset }\end{array}$} & \multicolumn{3}{|c|}{ Experiment STUD } \\
\hline & (4) & $(5)$ & $(6)$ \\
\hline$\alpha$ & $\begin{array}{c}21.236^{* *} \\
(9.099)\end{array}$ & $\begin{array}{l}35.814^{*} \\
(17.958)\end{array}$ & $\begin{array}{c}31.309 \\
(52.421)\end{array}$ \\
\hline$S O C I A L \_S T A T U S$ & $\begin{array}{l}-1.298 \\
(1.695)\end{array}$ & $\begin{array}{l}-2.800 \\
(2.286)\end{array}$ & $\begin{array}{l}-1.698 \\
(2.685)\end{array}$ \\
\hline FINANCIAL_SUCCESS & $\begin{array}{c}0.814 \\
(1.483)\end{array}$ & $\begin{array}{c}0.905 \\
(2.449)\end{array}$ & $\begin{array}{c}0.920 \\
(2.605)\end{array}$ \\
\hline$G E N E R A L_{-} R I S K$ & $\begin{array}{c}12.454^{* * *} \\
(1.586)\end{array}$ & $\begin{array}{c}14.083^{* * *} \\
(1.680)\end{array}$ & $\begin{array}{c}14.415^{* * * *} \\
(1.981)\end{array}$ \\
\hline$L O S S \_T O L E R A N C E$ & $\begin{array}{c}50.328^{* * *} \\
(15.866)\end{array}$ & $\begin{array}{c}52.210^{* * *} \\
(17.943)\end{array}$ & $\begin{array}{c}51.253^{* * *} \\
(18.102)\end{array}$ \\
\hline RELATIVE_PERFORMANCE & & $\begin{array}{l}-1.271 \\
(2.981)\end{array}$ & $\begin{array}{c}0.472 \\
(3.098)\end{array}$ \\
\hline CRT_SCORE & & & $\begin{array}{c}2.186 \\
(4.058)\end{array}$ \\
\hline$B I G-5$ & no & no & yes \\
\hline$D A R K_{-} T R I A D$ & no & no & yes \\
\hline $\mathrm{N}$ & 432 & 192 & 192 \\
\hline Clusters & 72 & 32 & 32 \\
\hline R-squared & 0.184 & 0.227 & 0.269 \\
\hline$F$ & 21.959 & 29.978 & 14.497 \\
\hline Prob $>F$ & 0.000 & 0.000 & 0.000 \\
\hline
\end{tabular}


Table BIV: Preferences for Relative Performance, Status, Financial Success and RiskTaking (Self-Reported) per Treatment

Ordinary least squares regression on participants' average amount invested in the risky asset, $\overline{R I S K}$. SOCIAL_STATUS, FINANCIAL_SUCCESS, and RELATIVE_PERFORMANCE represent the answers to corresponding survey questions on a 7 -point Likert scale (higher values indicate stronger preferences). LOSS_TOLERANCE is a measure of loss attitudes (from 0 to 1 ; higher values indicate lower loss aversion) and GENERAL_RISK is the self-reported willingness to take risks (7-point Likert scale). Standard errors are clustered at the group level and are provided in parentheses. $* * *, * *$, and $*$ represent significance at the $1 \%, 5 \%$, and $10 \%$ levels, respectively. The data is gathered from experiments PROF and STUD.

\begin{tabular}{lccc}
\hline \hline \multirow{2}{*}{ Dep. variable: $\overline{R I S K}$, mean } & \multicolumn{3}{c}{ Experiment PROF } \\
percentage risky asset & TBASE & TRANK & TTOUR \\
\hline$\alpha$ & -35.723 & 50.676 & -24.346 \\
& $(57.580)$ & $(32.770)$ & $(37.497)$ \\
SOCIAL_STATUS & 1.855 & -6.735 & -1.616 \\
& $(4.928)$ & $(5.335)$ & $(4.837)$ \\
FINANCIAL_SUCCESS & -8.715 & 2.032 & -2.021 \\
& $(5.639)$ & $(4.727)$ & $(5.209)$ \\
RELATIVE_PERFORMANCE & $17.783^{* *}$ & $6.966^{* *}$ & $13.853^{* *}$ \\
& $(5.261)$ & $(2.904)$ & $(5.532)$ \\
GENERAL_RISK & 4.372 & 7.709 & $8.859^{* *}$ \\
& $(4.228)$ & $(5.230)$ & $(3.350)$ \\
LOSS_TOLERANCE & $90.931^{* *}$ & -5.397 & $64.417^{*}$ \\
& $(22.679)$ & $(21.161)$ & $(30.549)$ \\
\hline N & 30 & 48 & 72 \\
Clusters & 5 & 8 & 12 \\
R-squared & 0.394 & 0.142 & 0.167 \\
$F$ &. & 3.982 & 4.967 \\
Prob > F &. & 0.050 & 0.013 \\
\hline \hline
\end{tabular}

\begin{tabular}{lccc}
\hline \hline \multirow{2}{*}{ Dep. variable: $\overline{R I S K}$, mean } & \multicolumn{3}{c}{ Experiment STUD } \\
percentage invested in risky asset & TBASE & TRANK & TTOUR \\
\hline$\alpha$ & 12.197 & 21.447 & $40.042^{* *}$ \\
& $(26.741)$ & $(41.177)$ & $(18.981)$ \\
SOCIAL_STATUS & 3.413 & -11.306 & -2.698 \\
& $(4.280)$ & $(4.964)$ & $(2.783)$ \\
FINANCIAL_SUCCESS & -1.347 & $13.038^{*}$ & 0.335 \\
& $(4.982)$ & $(5.457)$ & $(2.649)$ \\
RELATIVE_PERFORMANCE & $-5.575^{*}$ & -3.735 & 0.824 \\
& $(2.240)$ & $(13.860)$ & $(3.312)$ \\
GENERAL_RISK & 7.431 & $18.109^{*}$ & $13.805^{* * *}$ \\
& $(5.158)$ & $(7.679)$ & $(1.833)$ \\
LOSS_TOLERANCE & 97.612 & -7.630 & $45.172^{* *}$ \\
& $(44.486)$ & $(97.097)$ & $(19.016)$ \\
\hline N & 24 & 24 & 144 \\
Clusters & 4 & 4 & 24 \\
R-squared & 0.461 & 0.311 & 0.230 \\
$F$ &. &. & 19.568 \\
Prob $>F$ &. &. & 0.000 \\
\hline \hline
\end{tabular}




\section{Instructions of Experiments PROF and STUD}

\section{Welcome to the experiment and thank you for your participation! ${ }^{37}$}

Please do not talk with the other participants during the experiment from now on.

\section{General Information}

In this experiment we study economic decision-making. The whole experiment consists of two independent parts, where you can earn money independently. For your punctual attendance and participation you will receive a participation fee of 18 euro in addition to the income you can earn in both parts of the experiment. Your entire payment will be paid out to you privately and in cash after the experiment. At the beginning of each part you will receive detailed instructions. If you have questions about the instructions or during the experiment, please raise your hand. One of the experimenters will then come to you and answer your questions privately.

\section{PART 1}

\section{Task}

In Part 1 you have to make investment decisions in a financial market. At the beginning of the experiment, you start with a wealth of 90 euro. You have to decide in each of eight periods (half-years), what percentage of your wealth you want to invest at a risk-free rate of $1.5 \%$ and the percentage you wish to invest in a stock index. The development of the stock index reflects the price development of a basket of shares and is based on actual historical data. In the last 20 years, this development is characterized by price fluctuations. In this period, the index earned a half-year return (semi-annual compounding) of $3.6 \%$ and had a standard deviation of the semi-annual price returns of $15.9 \%$.

Here are some examples on the likelihood of various price fluctuations:

In 50 out of 100 cases, the semi-annual return lies between $-7.1 \%$ and $14.3 \%$.

In 90 out of 100 cases, the semi-annual return lies between $-22.6 \%$ and $29.8 \%$.

In 95 out of 100 cases, the semi-annual return lies between $-27.6 \%$ and $34.7 \%$.

At the beginning of the first period, you have to draw 30 times from this distribution (at your laptop) with a mean of $3.6 \%$ and a standard deviation of $15.9 \%$. The draws are independent for each participant. After each draw the last drawn return is indicated on the screen with a yellow box together with the display of return (see Figure C1).

\footnotetext{
${ }^{37}$ Instructions are for Treatment TBASE in Experiment PROF, additional text for Treatments TRANK and TTOUR of Experiment PROF are in italic. The relevant parts on the payout in Treatment TTOUR are in teletype. Note that instructions for all three treatments in experiment STUD were identical except for the stake size. This means that the participation fee was set to 6 euro and the initial wealth in the investment experiment was 30 euro. Consequently, both examples of the instructions were rescaled accordingly. Of course, original instructions of each treatment can be provided upon request.
} 
The previous return draws are shown with red boxes. Every time you click on the "Draw return" button, a new return is drawn from the distribution and displayed on the screen. Together, the draws give you a feeling for the index changes from period to period. The draws are independent of the random draws during the experiment, but the distribution is identical. Below you see an example of the screen (see Figure C1):

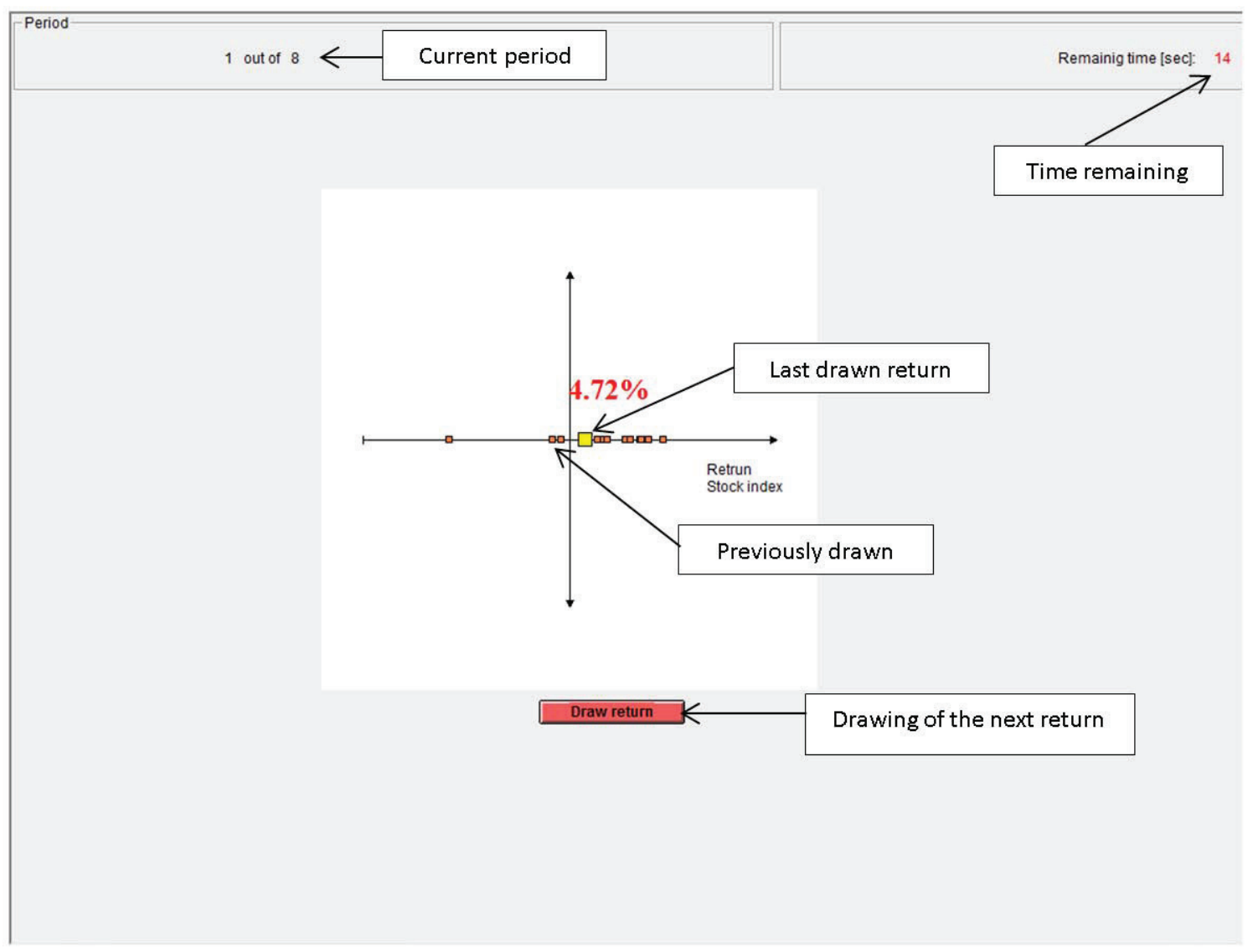

Figure C1: Return screen in Period 1.

In each period you can invest between 0 and $200 \%$ of your current wealth in the stock index. If you invest more than $100 \%$ of your wealth, then the fraction which exceeds $100 \%$ is borrowed at the risk-free rate of $1.5 \%$. If you are investing less than $100 \%$ of your wealth in the stock index, the amount not invested in the stock index is invested at the risk-free rate of $1.5 \%$. You will be selected into a group of 6 participants at the beginning of the experiment and you will remain in the same group for the duration of the experiment ( 8 periods).

At the end of each period the actual return of the stock index is randomly determined from the distribution described above and your wealth will be calculated according to your investment in the stock index and in the risk-free rate. Note that the stock index return is identical for all group members. 


\section{Examples:}

1. Let's assume your wealth is 90 euro and you decide to invest $50 \%$ of it in the stock index. Thus, the remaining $50 \%$ will be invested at the risk-free rate. If the index in this period yields a return of $+10.0 \%$, then your wealth in the next period will be as follows: Profit/loss from the stock index: (50\% Investment $* 90$ euro) $* 10 \%$ Return $=4.5$ euro. Profit from investing in the risk-free interest rate: $(50 \%$ Investment $* 90$ euro) $* 1.5 \%$ Interest $=0.68$ euro. Wealth in the next period: 90 (previous periods wealth) $+4.5+0.68=95.18$ euro.

2. Let's assume your wealth is 90 euro and you decide to invest $150 \%$ of it in the stock index. Thus, you borrow $50 \%$ at the risk-free interest rate. If the index in this period yields a return of $+10.0 \%$, then your wealth in the next period will be as follows: Profit/loss from the stock index: $(150 \%$ Investment $* 90$ euro $) * 10 \%$ Return $=13.5$ euro. Cost of borrowing $50 \%$ at the risk-free rate: $(-50 \%$ Loan $* 90$ euro $) * 1.5 \%$ Interest $=-0.68$ euro. Wealth in the next period: 90 (previous periods wealth) $+13.5-0.68=102.82$ euro.

Return of the stock index in the previous period (in \%)
Fraction you invested into the risk-free rate in the previous period (in \%)
Information on current wealth

Figure C2: Decision screen in each period (note that this screen is only shown in Treatment TBASE).

The decision screen in each period will show your current wealth, the wealth change compared to the previous period, the return of the stock index in the previous period, your invested fraction in the stock index in the previous period, the risk-free rate and your invested fraction in the risk-free asset in the previous period (see Figure C2). ${ }^{38}$

The decision screen in all 8 periods looks as follows:

\footnotetext{
${ }^{38}$ See Figure C3 for Treatments TRANK and TTOUR.
} 


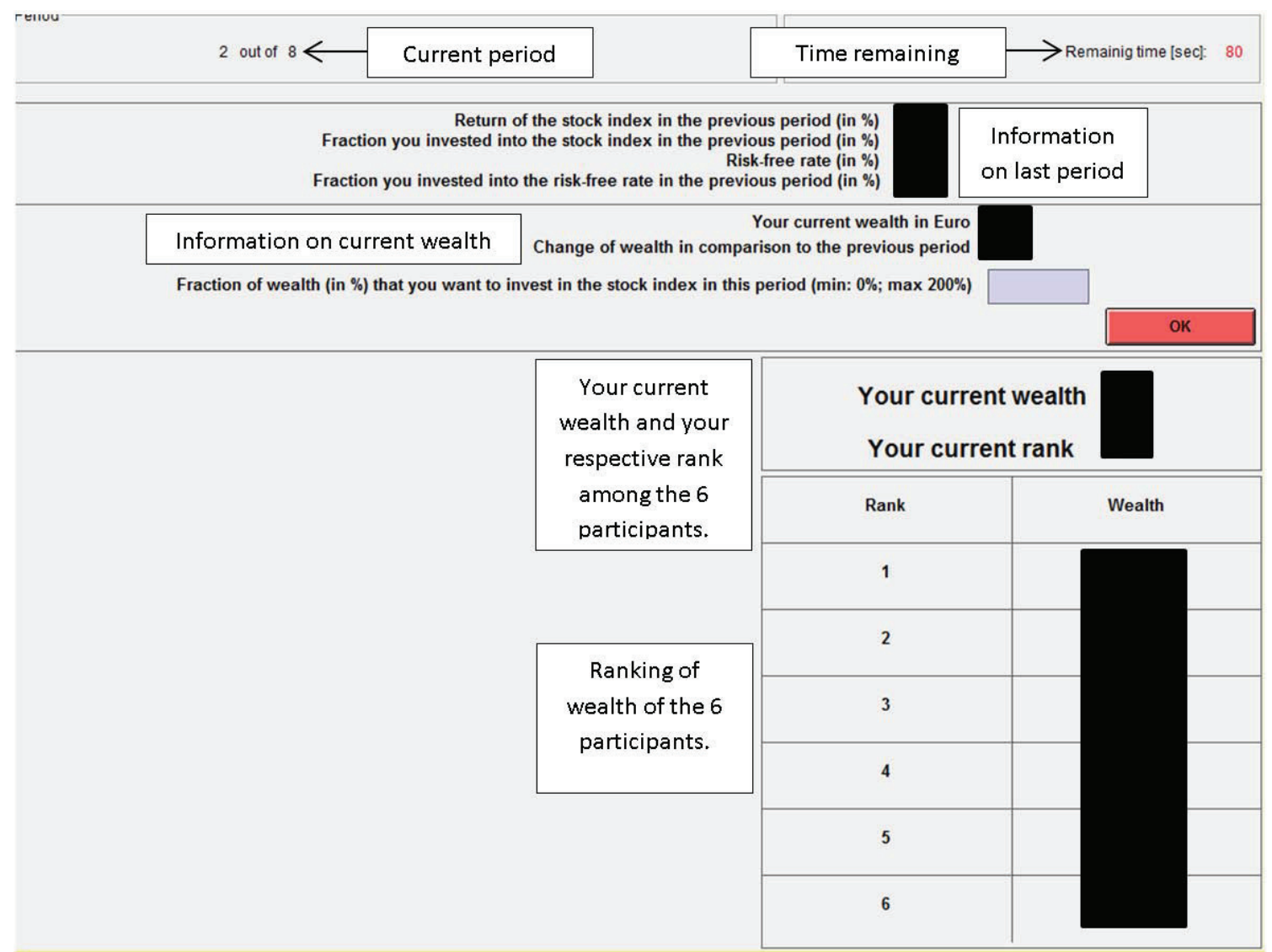

Figure C3: Decision screen in each period (note that this screen is only shown in Treatments TRANK; TTOUR).

[Begin additional text for Treatments TRANK and TTOUR]

Beginning with Period 2, you will be informed in a league table which rank in your group of 6 you currently have based on the current wealth of the participants. You also get information about the current wealth and rank of the other participants in your group. This table appears for 20 seconds at the beginning of each period (see Figure C4) and is also displayed at the bottom of the decision screen (see Figure C3).

[End additional text for Treatments TRANK and TTOUR] 


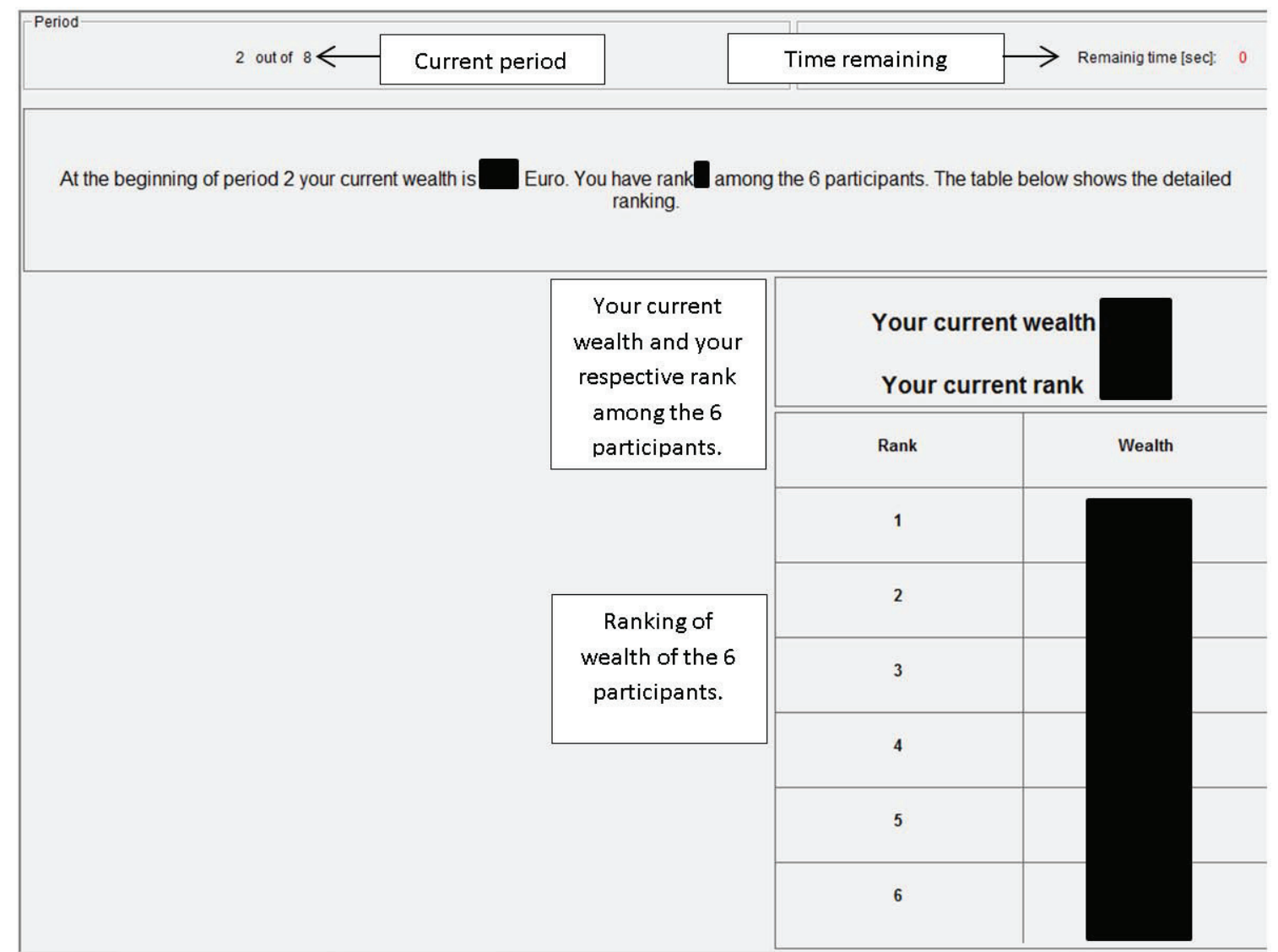

Figure C4: Screen on your ranking and the current wealth of the other participants at the beginning of each period. This table is shown from period 2 onward (note that this screen is only shown in Treatments TRANK; TTOUR).

\section{Payment}

[Begin text for Treatments TBASE and TRANK]

At the end of the experiment, your final wealth (your wealth at the end of period 8) will be paid out to you with a probability of $20 \%$. A random generator determines for each participant separately whether he or she receives the payment. If you are not drawn randomly, you will not receive payment for the first part of the experiment.

[End text for Treatments TBASE and TRANK]

[Begin text for Treatment TTOUR]

At the end of the experiment the wealth of all 6 participants in your group will be summed up and distributed according to your ranking as follows: the participant with rank 1 receives 50\%, rank 2 receives $33.3 \%$, rank 3 receives $16.7 \%$, and the ranks 4,5 , and 6 receive $0 \%$. Your calculated final wealth will be paid out with a probability of $20 \%$. A random generator determines for each participant separately whether he 
or she receives the payment. If you are not drawn randomly, you will not receive payment for the first part of the experiment.

[End text for Treatment TTOUR] 


\section{Welcome to the experiment and thank you for your participation! ${ }^{39}$}

Please do not talk with the other participants during the experiment from now on.

\section{General Information}

In this experiment we study economic decision-making. The whole experiment consists of two independent parts, where you can earn money in both independently. For your punctual attendance and participation, you will receive a participation fee of 18 euro in addition to the income you can earn in both parts of the experiment. Your entire payment will be paid out to you privately and in cash after the experiment. At the beginning of each part you will receive detailed instructions. If you have questions about the instructions or during the experiment, please raise your hand. One of the experimenters will then come to you and answer your questions privately.

\section{PART 1}

\section{Task}

In Part 1 you have to make several decisions. At the beginning of the experiment, you start with 90 Points. You have to decide in each of eight periods how many of your Points you allocate to Alternative A and how many to Alternative B. Alternative A provides you with a fixed payout of $+1.5 \%$ of your amount allocated. Alternative B gives you a payout which is randomly drawn from the computer from a distribution of numbers with a mean of $3.6 \%$ and a standard deviation of $15.9 \%$.

Here are some examples on the distribution:

In 50 out of 100 cases, the randomly drawn number lies between $-7.1 \%$ and $14.3 \%$.

In 90 out of 100 cases, the randomly drawn number lies between $-22.6 \%$ and $29.8 \%$.

In 95 out of 100 cases, the randomly drawn number lies between $-27.6 \%$ and $34.7 \%$.

At the beginning of the first period of the experiment, you have to draw 30 times from the distribution of Alternative B (at your laptop) with a mean of $3.6 \%$ and a standard deviation of $15.9 \%$. The draws are independent for each participant. After each draw the last drawn number is indicated on the screen with a yellow box together with the display of the previously drawn numbers (see Figure C5).

The previously drawn numbers are shown with red boxes. Every time you click on the "Draw number" button, a new number is drawn from the distribution and displayed on the screen. The draws are independent of the random draws during the experiment, but the distribution is identical. Below you see an example of the screen (see Figure C5):

In each period you can allocate between 0 and $200 \%$ of your current Points in Alternative B. If you allocate more than $100 \%$ of your Points to Alternative B, then you incur a cost of $1.5 \%$ for the amount of Points exceeding $100 \%$. If you allocate less than $100 \%$ of your Points to

\footnotetext{
${ }^{39}$ Instructions are relevant for Treatment TRANK ${ }^{\mathrm{LOT}}$.
} 


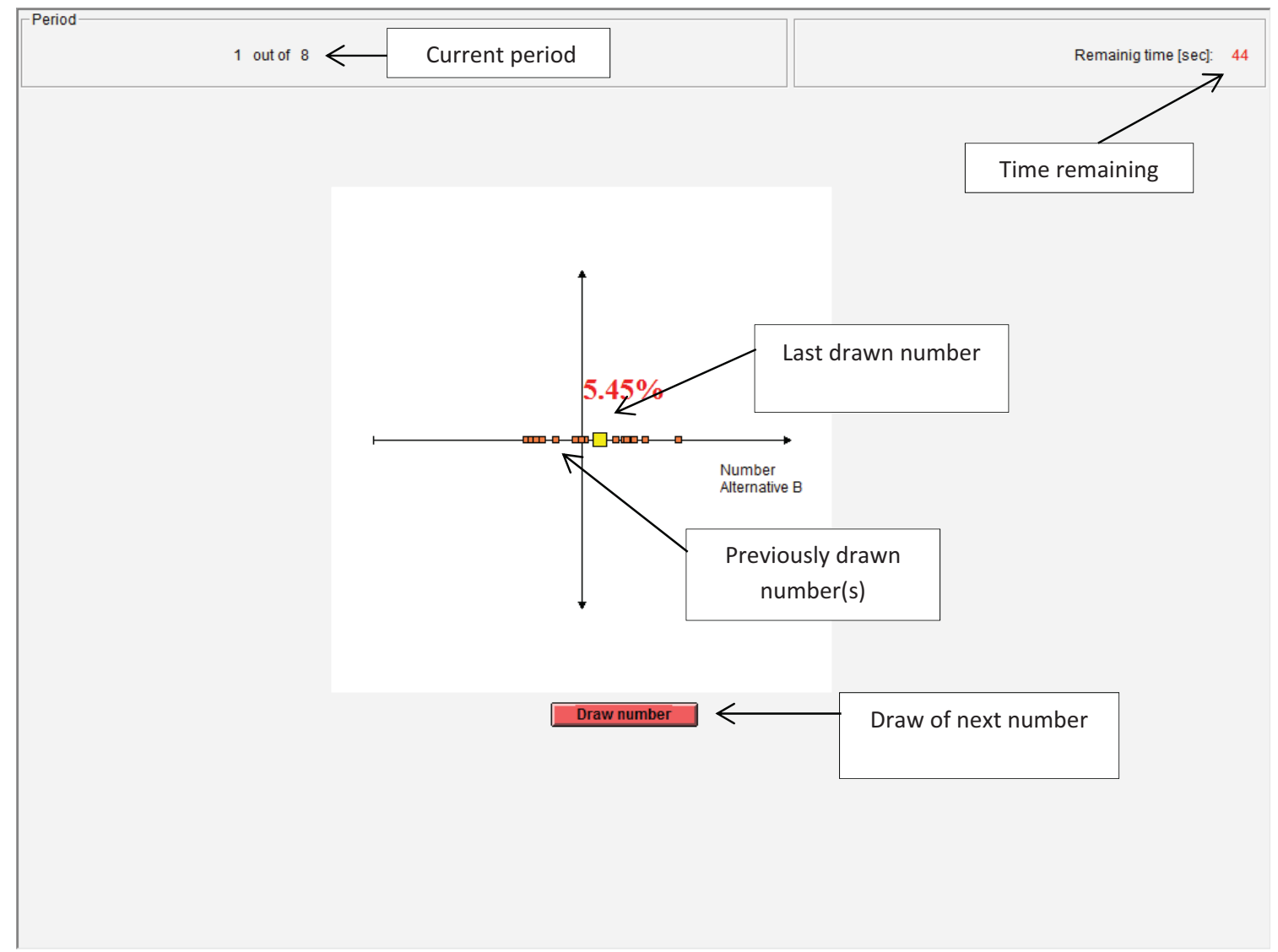

Figure C5: Return screen in Period 1.

Alternative B, the amount not allocated is automatically allocated to Alternative A. You will be selected into a group of 6 participants at the beginning of the experiment and you will remain in the same group for the duration of the experiment (8 periods).

At the end of each period the payout of Alternative B is randomly drawn and your Points will be calculated accordingly. 


\section{Examples:}

1. Let's assume your Points are 90 and you decide to allocate a fraction of $50 \%$ to Alternative B. Thus, the remaining $50 \%$ will be allocated to Alternative A. If Alternative B provides a random number of $+10.0 \%$, then your Points in the next period will be as follows: Points from Alternative B: (50\% allocation * 90 Points) $* 10 \%$ random number $=4.5$ Points Points from Alternative A: (50\% allocation $* 90$ Points $) * 1.5 \%$ fixed payout $=0.68$ Points Points in the subsequent period: 90 (previous period's Points) $+4.5+0.68=95.18$ Points

2. Let's assume your Points are 90 and you decide to allocate a fraction of $150 \%$ to Alternative B. Thus, you have to pay a cost of $1.5 \%$ for the amount exceeding $100 \%$. If Alternative B provides a random number of $+10.0 \%$, then your Points in the next period will be as follows: Points from Alternative B: (150\% allocation $* 90$ Points $) * 10 \%$ random number $=13.5$ Points Fee for the amount exceeding $100 \%$-allocation: $(-50 \% * 90$ Points $)$ $* 1.5 \%$ costs $=-0.68$ Points Points in the subsequent period: 90 (previous period's Points) $+13.5-0.68=$ 102.82 Points

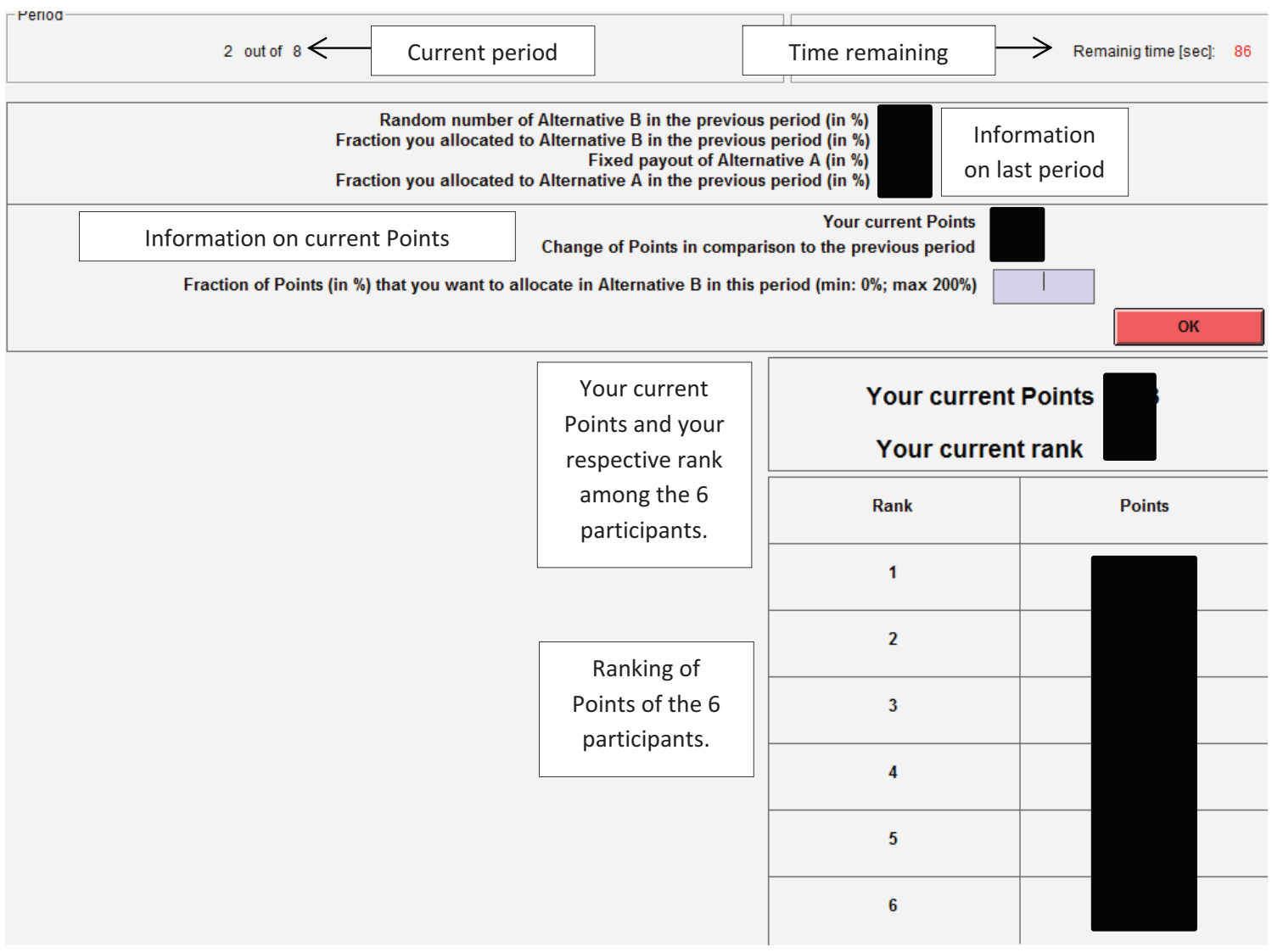

Figure C6: Decision screen in each period.

The decision screen in each period will show your current Points, the change in Points to the previous period, the random number of Alternative B in the previous period, your allocated fraction into Alternative B in the previous period, and the allocated fraction into Alternative A in the previous period (see Figure C6).

The decision screen in all 8 periods looks as follows:

Beginning with Period 2, you will be informed which rank in your group of 6 you currently 


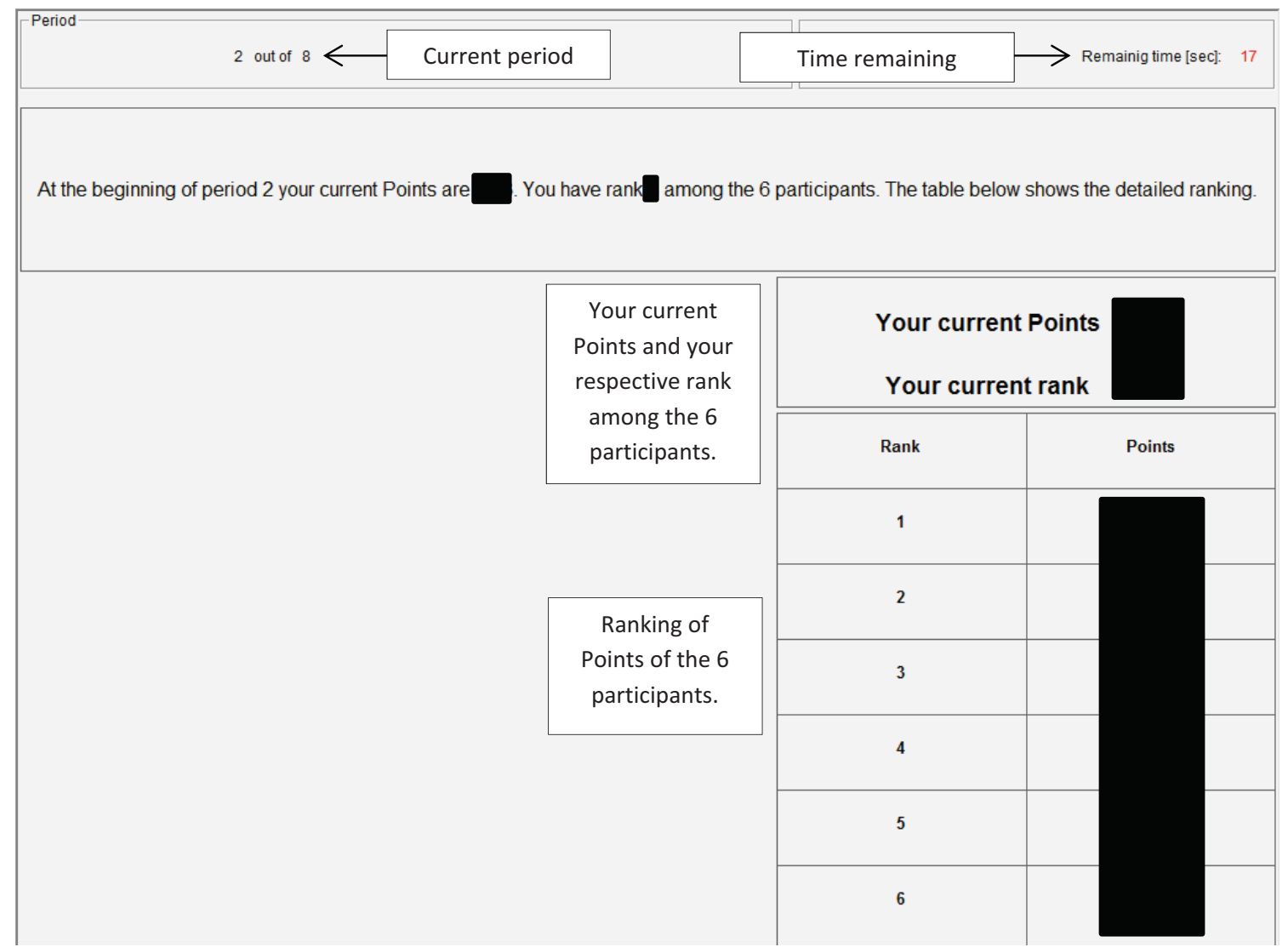

Figure C7: Screen on your ranking and the current Points of the other participants at the beginning of each period. This table is shown from period 2 onward.

have based on the current Points of the participants. You also get information about the current Points and rank of the other participants in your group. This information appears for 20 seconds at the beginning of each period (see Figure $\mathrm{C} 7$ ) and is also displayed at the bottom of the decision screen (see Figure C6).

\section{Payment}

At the end of the experiment, your final Points (your Points at the end of period 8) will be paid out to you with a probability of $20 \%$. A random generator determines for each participant separately whether he or she receives the payment. In this case your Points are translated into euro (ratio of 1:1). If you are not drawn randomly, you will not receive payment for the first part of the experiment. 


\section{Welcome to the experiment and thank you for your participation! ${ }^{40}$}

Please do not talk with the other participants during the experiment from now on.

\section{General Information}

In this experiment we study economic decision-making. The whole experiment consists of two independent parts, where you can earn money in both independently. For your punctual attendance and participation you will receive a participation fee of 18 euro in addition to the income you can earn in both parts of the experiment. Your entire payment will be paid out to you privately and in cash after the experiment. At the beginning of each part you will receive detailed instructions. If you have questions about the instructions or during the experiment, please raise your hand. One of the experimenters will then come to you and answer your questions privately.

\section{PART 1}

\section{Task}

In Part 1 you have to make investment decisions in a financial market. The decisions you make are payout-relevant for you and for one member of your family. At the beginning of the experiment you will be able to choose - on a separate screen - a family member (grandmother, grandfather, mother, father, wife, husband, partner, daughter, son, sister, brother). At the end of the experiment we will pay out your proceeds of your investment decisions directly to you in private and in cash. Your family member's proceeds from your investment decisions will be paid within a couple of days (see details below).

At the beginning of the experiment, we endow you and your family member with a wealth of 90 euro each. For the sake of simplicity the instructions and the investment interface focus on the investment decision for your family member. At the end of the experiment you receive the same payment as your family member.

In each of 8 periods (half-years) you have to decide what percentage of your family member's wealth you want to invest at a risk-free rate of $1.5 \%$ and the percentage you wish to invest in a stock index. The development of the stock index reflects the price development of a basket of shares and is based on actual historical data. In the last 20 years, this development is characterized by price fluctuations. In this period, the index earned a half-year return (semiannual compounding) of $3.6 \%$ and had a standard deviation of the semi-annual price volatility of $15.9 \%$.

Here are some examples on the likelihood of various price fluctuations:

In 50 out of 100 cases, the semi-annual return lies between $-7.1 \%$ and $14.3 \%$.

In 90 out of 100 cases, the semi-annual return lies between $-22.6 \%$ and $29.8 \%$.

In 95 out of 100 cases, the semi-annual return lies between $-27.6 \%$ and $34.7 \%$.

\footnotetext{
${ }^{40}$ Instructions are relevant for Treatment TRANK ${ }^{\text {FAM }}$.
} 
At the beginning of the first period of the experiment, you have to draw 30 times from this distribution (at your laptop) with a mean of $3.6 \%$ and a standard deviation of $15.9 \%$. The draws are independent for each participant. After each draw the last drawn return is indicated on the screen with a yellow box together with the display of the return (see Figure C8).

The previous return draws are shown with red boxes. Every time you click on the "Draw return" button, a new return is drawn from the distribution and displayed on the screen. Together, the draws give you a feeling for the index changes from period to period. The draws are independent of the random draws during the experiment, but the distribution is identical. Below you see an example of the screen (see Figure C8):

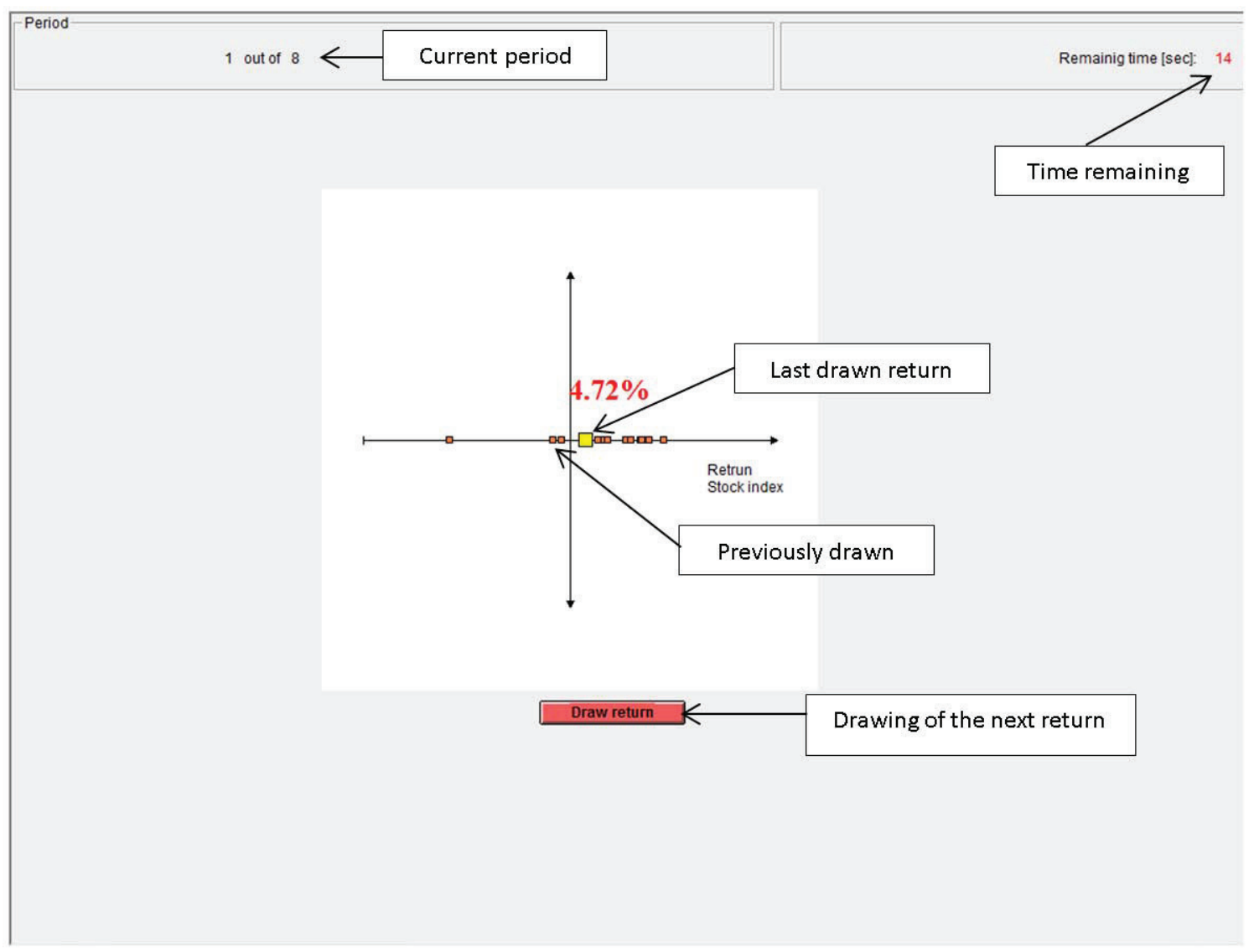

Figure C8: Return screen in Period 1.

In each period you can invest between 0 and $200 \%$ of your family member's current wealth in the stock index. If you invest more than $100 \%$ of your family member's wealth, then the fraction which exceeds $100 \%$ is borrowed at the risk-free rate of $1.5 \%$. If you are investing less than $100 \%$ of your family member's wealth in the stock index, the amount not invested in the stock index is invested at the risk-free rate of $1.5 \%$. You will be selected into a group of 6 participants at the beginning of the experiment and you will remain in the same group for the duration of the 
experiment (8 periods).

At the end of each period the actual return of the stock index is randomly determined from the distribution described above and your family member's wealth will be calculated according to your investment in the stock index and in the risk-free rate.

\section{Examples:}

1. Let's assume your family member's wealth is 90 euro and you decide to invest $50 \%$ of it in the stock index. Thus, the remaining $50 \%$ will be invested at the risk-free rate. If the index in this period yields a return of $+10.0 \%$, then your family member's wealth in the next period will be as follows: Profit / loss from the stock index: $(50 \%$ Investment $* 90$ euro $) * 10 \%$ Return $=4.5$ euro Profit from investing in the risk-free interest rate: (50\% Investment $* 90$ euro $) * 1.5 \%$ Interest $=0.68$ euro Your family member's wealth in the subsequent period: 90 (previous periods wealth) $+4.5+0.68=95.18$ euro

2. Let's assume your family member's wealth is 90 euro and you decide to invest $150 \%$ of it in the stock index. Thus, you borrow $50 \%$ at the risk-free rate. If the index in this period yields a return of $+10.0 \%$, then your family member's wealth in the next period will be as follows: Profit / loss from the stock index: $(150 \%$ Investment $* 90$ euro $) * 10 \%$ Return $=13.5$ euro Cost of borrowing $50 \%$ at the risk-free rate: $(-50 \%$ Loan $* 90$ euro) $* 1.5 \%$ Interest $=-0.68$ euro Your family member's wealth in the subsequent period: 90 (previous periods wealth) $+13.5-0.68=102.82$ euro

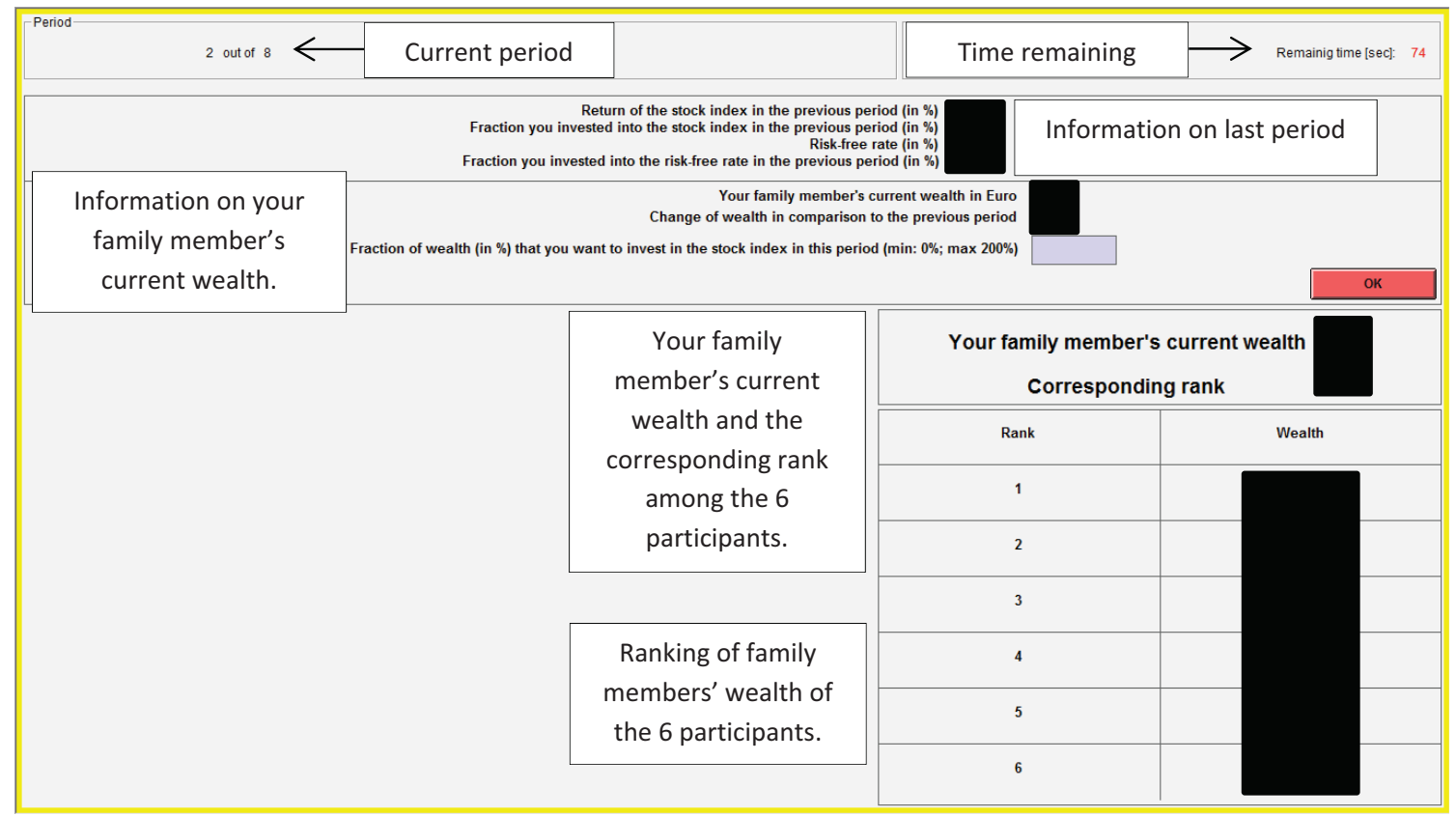

Figure C9: Decision screen in each period.

The decision screen in each period will show your family member's current wealth, the wealth change to the previous period, the return of the stock index in the previous period, your invested fraction into the stock index in the previous period, the risk-free rate and your invested fraction in the risk-free asset in the previous period (see Figure C9).

The decision screen in all 8 periods looks as follows:

Beginning with Period 2, a league-table is displayed which shows your rank in your group of 


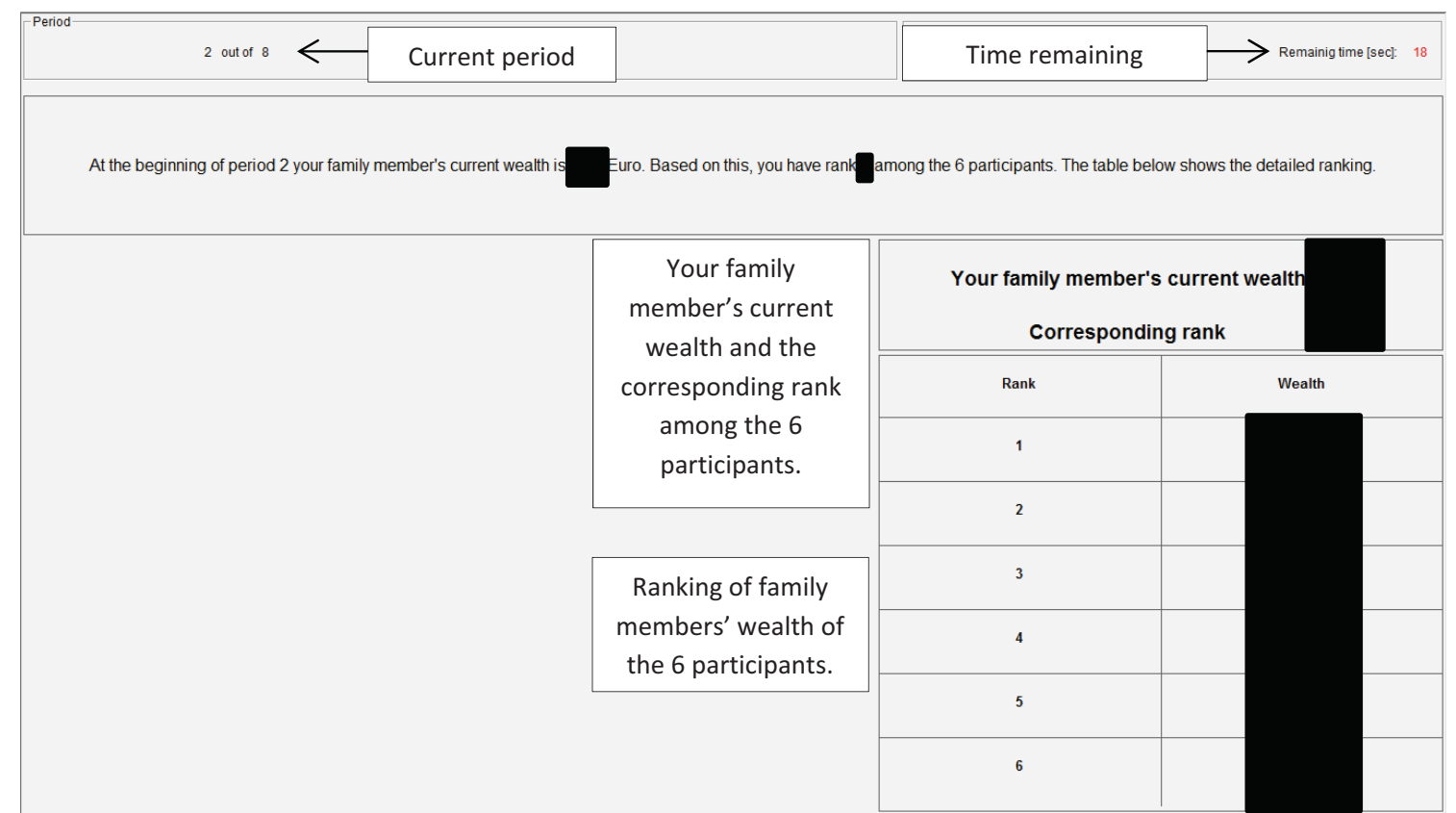

Figure C10: Screen on your ranking and the family member's current wealth of the other participants at the beginning of each period. This table is shown from period 2 onward.

six, based on your family member's current wealth. You also get information about the current wealth and rank of the other participants' family members in your group. This table appears for 20 seconds at the beginning of each period (see Figure C10) and is also displayed at the bottom of the decision screen (see Figure C9). 


\section{Payment}

The procedure of payment to you and your family member works as follows. At the beginning of the experiment you will be able to choose a family member (grandmother, grandfather, mother, father, wife, husband, partner, daughter, son, sister, brother) on a separate screen.

At the beginning of the experiment we also ask you to answer the following questions about your family member:

- What do you think will the chosen family member do with the money?

- How many hours per week do you spend time with the selected family member on average?

- How do you see your selected family: Is he/she willing to take risks or try to avoid risks? 1 , not at all willing to take risks; 7 , very willing to take risks

At the end of the experiment, your family member's final wealth (the wealth at the end of period 8 ) will be paid out to him/her with a probability of $20 \%$. A random generator determines for each participant separately whether the proceeds of their investment decisions will be paid out. You will receive the same payment as your family member. If you are not drawn randomly, you and your family member will not receive payment for the first part of the experiment.

If you are drawn for payout in this part of the experiment, at the end of the experiment, we will ask you to provide us with the address details of the selected family member for payment. We will then contact him/her, explain that you invested for him/her and ask for payment details. If you selected a family member who is a minor, please provide us with an alternative address (not yours) of somebody close to the minor with whom we can organize the payment. You receive your part of the payment privately in cash in an envelope. 


\section{PART $2^{41}$}

Below are the instructions for Part 2 of this experiment.

Remember: You get 18 euro for participating in this experiment. In Part 2, you can earn (and lose) in addition to this participation fee. Part 1 and Part 2 are independent in the decisions and in payment.

Part 2 consists of two sections that are played one after the other. For each of the two sections, your potential payment will be calculated individually and independently. At the end of Part 2 one of the two sections will be randomly selected for your payment for Part 2 (for details on payment, see below).

\section{Section 1}

In Section 1, you are asked to make 7 decisions (decision pairs). For each decision pair, you have the choice between Option A and Option B:

OPTION A: A payment with $100 \%$ probability (certainty) is realized. This option is available in all seven decision pairs.

OPTION B: A payment that is risky - either 0 euro with $50 \%$ probability or 24 euro with $50 \%$ probability.

For your payment, ONE out of the 7 decision pairs will be randomly selected and used for payment according to your decision.

\section{Section 2}

In the 6 questions of Section 2 you have to decide whether you want to participate in a lottery where you can win or lose money. If you choose the lottery, the computer flips a coin. If the coin shows heads, you get 15 euro in addition to your participation fee. If the coin shows tails, you lose a certain amount of your participation fee. If you do not choose the lottery, you will receive 0 euro in addition to your participation fees.

For your payment, ONE out of the 6 decision pairs will be randomly selected and used for payment according to your decision.

In Part 2, one of the two sections will be randomly selected and paid out at the end of the experiment; in addition to the participation fee and in addition to the payment of Part 1. Please note: In Part 2, next to playing out a possible lottery, there is a maximum of two random drawings. The first random draw is used to select which section is relevant for your payment. In a second step, one of the decision pairs will be randomly chosen from the relevant section. Your decision (lottery or fixed payment) is then played out to determine your payment.

\footnotetext{
${ }^{41}$ Instructions for part 2 are identical for all treatments in Experiment PROF and for treatments TRANK ${ }^{\mathrm{LOT}}$ and TRANK ${ }^{\mathrm{FAM}}$. Instructions in Experiment STUD were identical except for the stake size which was one-third.
} 


\section{Questionnaire}

Following Part 2 you will be asked to answer some general questions and provide us with some anonymous demographic details.

Thank you for your participation! 


\section{Instructions of the Online Experiment PROF ${ }^{\text {ONLINE }}$}

\section{[WELCOME SCREEN]}

We are researchers from several universities conducting a study on your personal opinions and attitudes.

Participation will take less than 10 minutes. With your participation, you will make an important contribution to research and you can earn money: one in five participants can win up to $\$ 81$ ! At the end of the data collection (in about 10 days), a random draw will determine whether you are one of those that are paid out according to your decisions. In this case, you will receive your payout in points which you can cash in and retrieve via Paypal or other methods. Note that your earnings can vary according to the decisions you take in this study.

All data will be depersonalized and will only be used for scientific purposes. This online study adheres to the principles of economic experiments: participants are not deceived and earnings are paid out in real.

Thank you very much for participating!

Michael Kirchler (Innsbruck University, Gothenburg University), Utz Weitzel (Utrecht University, Radboud University), Florian Lindner (Innsbruck University)

*** Please click below to start. Note that you will not be able to go back to previous pages throughout the whole study. $* * *$

[PRIMING SCREENS - randomization into treatments]

[A: PROFESSIONAL PRIME]

We start with a few questions. Please answer all of the following questions:

- At which financial institution are you presently employed?

- What is your function at this financial institution?

- For how many years have you been working in the financial sector? (Please enter full years; can be in different organizations and/or functions)

- Why did you decide to become an employee in the financial sector? Please describe your answer in two to three sentences.

- What are, in your opinion, the three major advantages of your occupation as an employee in the financial sector?

- Which three characteristics of your personality do you think are typical for an employee in the financial sector?

- What are the three most important things you learned in your occupation as an employee in the financial sector? 


\section{[B: PRIVATE PRIME]}

We start with a few questions. Please answer all of the following questions:

- What is your favorite leisure activity? Please describe your answer in two to three sentences.

- Which three opportunities for leisure activities would you most like in your area?

- How many hours per week on average do you watch TV?

- Where did you spend your last vacation?

- Which three things did you like most about your last vacation?

- Are you actively involved or have you ever been involved in a club?

- Which three leisure activities do you enjoy most with your friends or family?

\section{[INVESTMENT TASK—SCREEN 1] ${ }^{42}$}

On the following screens you will play a game with five other experimental participants from the financial sector, who will be randomly matched with you. We will show you some depersonalized characteristics of the other participants in your group.

You will play several rounds in each of which you can choose between a fixed payment of $\$ 2.25$ and a lottery where you can win $\$ 9$ with $75 \%$ probability or lose $\$ 18$ with $25 \%$ probability. At the beginning of each round, the computer will hold a lottery and give you and the other players in your group different amounts of money, referred to as initial wealth. You will see a ranking with the initial position you hold in your group according to your wealth. At the end of each round, after your decision, you will see a results screen with your new wealth. We also provide you with an updated ranking indicating your new position based on your decision and that of the others in the group.

In each round you will face a new draw of group members and initial wealth allocations. If you are selected for payment we will randomly draw one of the rounds and pay your new wealth. As any of the following rounds can be the one which is actually paid out, you should play the whole game as if you are playing for real money in each round.

\section{[INVESTMENT TASK—SCREEN 2]}

ROUND 1

You are matched with five other participants from the financial sector. Please click the button below to start. [INVESTMENT TASK—DECISION SCREENS (see next pages)]

\footnotetext{
${ }^{42}$ The following instructions are relevant for Treatment TRANK ${ }^{\text {FIN }}$. Instructions for TRANK ${ }^{\text {PRIV }}$ were identical except that "financial sector" was replaced by "general population". Instructions can be provided upon request.
} 


\section{ROUND 1:}

Your initial wealth: $\mathbf{\$ 4 0 . 5 0}$

Your initial position: 4th Place

Ranking in your group:

\begin{tabular}{|c|c|c|c|c|c|}
\hline Place & Player & Wealth & Function & $\begin{array}{c}\text { Exp. in } \\
\text { yrs }\end{array}$ & $\begin{array}{c}\text { Characteristic } \\
\# 1\end{array}$ \\
\hline 1st & other & $\$ 54$ & Financial Advisor & 38 & Analytical \\
\hline 2nd & other & $\$ 49.50$ & Trading & 38 & Discipline \\
\hline 3rd & other & $\$ 45$ & Financial advisor & 10 & Social \\
\hline 4th & You & $\$ 40.50$ & Portfolio manager & 11 & competitiveness \\
\hline 5th & other & $\$ 36$ & analyst & 10 & assertive \\
\hline 6th & other & $\$ 31.50$ & $\begin{array}{r}\text { Licensed support } \\
\text { speciali }\end{array}$ & 7 & Patient \\
\hline
\end{tabular}

In this round, which would you prefer?

Win $\$ 2.25$ with $100 \%$ probability

Win $\$ 9$ with $75 \%$ probability or lose $\$ 18$ with $25 \%$ probability

Should this round be randomly selected your payment is determined as follows. If you have chosen the upper option, you receive your initial wealth plus $\$ 2.25$. If you have chosen the lower option, you receive your initial wealth plus $\$ 9$ with $75 \%$ probability or you receive your initial wealth minus $\$ 18$ with $25 \%$ probability. All random draws are computer-generated and are independently and separately drawn for each round and player.

Figure D1: Decision screen in Treatment TRANK ${ }^{\mathrm{FIN}}$. 


\section{Your result:}

You chose: Win \$9 with 75\% probability or lose \$18 with 25\% probability

The computer has drawn: \$9

Your new wealth: $\mathbf{\$ 4 9 . 5 0}$

Your new position: 3rd Place

New ranking in your group:

\begin{tabular}{|c|c|c|c|c|c|}
\hline Place & Player & Wealth & Function & $\begin{array}{c}\text { Exp. in } \\
\text { yrs }\end{array}$ & $\begin{array}{c}\text { Characteristic } \\
\# 1\end{array}$ \\
\hline 1st & other & $\$ 58.50$ & Trading & 38 & Discipline \\
\hline 2nd & other & $\$ 56.25$ & Financial Advisor & 38 & Analytical \\
\hline 3rd & You & $\$ 49.50$ & Portfolio manager & 11 & competitiveness \\
\hline 4th & other & $\$ 47.25$ & Financial advisor & 10 & Social \\
\hline 5th & other & $\$ 45$ & analyst & 10 & assertive \\
\hline 6th & other & $\$ 33.75$ & Licensed support & 7 & Patient \\
\hline
\end{tabular}

Figure D2: Results screen in Treatment TRANK ${ }^{\mathrm{FIN}}$.

\section{[MANIPULATION CHECK]}

This is the end of the decision rounds. Please complete the task below: Try to fill the gaps with letters to form existing words. Please enter in each case the full solution word into the input field.

Example: ..ouse - House

..ock

.at

..oker

.oney

Th.n.

B.nd 


\section{[LOSS AVERSION TASK]}

In the 6 decisions below you have to decide whether you want to participate in a lottery where you can win or lose money. If you reject the lottery, you will receive $\$ 0$ (in addition to your initial endowment). If you are one of the participants who receive payment, the initial endowment and one of your 6 decisions below will be paid out.

For this task you receive an initial endowment of \$18.

Please decide for each of the six rows below:

\section{Accept this lottery Reject this lottery}

Loss of $\mathbf{\$ 3}$ with $50 \%$ probability or gain of $\mathbf{\$ 1 5}$ with $50 \%$ probability.

Loss of $\mathbf{\$} \mathbf{6}$ with $50 \%$ probability or gain of $\mathbf{\$ 1 5}$ with $50 \%$ probability.

Loss of $\$ \mathbf{9}$ with $50 \%$ probability or gain of $\$ \mathbf{1 5}$ with $50 \%$ probability.

Loss of $\$ 12$ with $50 \%$ probability or gain of $\$ 15$ with $50 \%$ probability.

Loss of $\$ \mathbf{1 5}$ with $50 \%$ probability or gain of $\$ \mathbf{1 5}$ with $50 \%$ probability.

Loss of $\$ 18$ with $50 \%$ probability or gain of $\$ \mathbf{1 5}$ with $50 \%$ probability.

If you are one of the participants who receive payment, the computer will randomly draw one of the above six rows and will execute your choice in that row. So, if you have chosen to play the lottery in that row, the computer will randomly draw one of the outcomes mentioned in that specific lottery and increase/decrease your initial endowment of $\$ 18$ accordingly. If you have chosen not to play the lottery in that row, you receive the initial endowment of $\$ 18$. The task on this screen is paid out separately from your previous decisions/rounds.

Figure D3: Loss aversion task in both treatments. 


\section{E Modified CRT Questions}

- A football shoe and a ball cost 110 euro together. The shoe costs 70 euro more than the ball. How much costs the ball?

- 5 machines need 5 minutes to produce 5 keyboards. How long would 80 machines need for 80 keyboards?

- An IT company offers you storage space. Every day your volume of data doubles. If it would need 20 days to max out the provided space, how long would it take to max out half of the space? 


\section{F Pictures of the Experimental Laboratories}

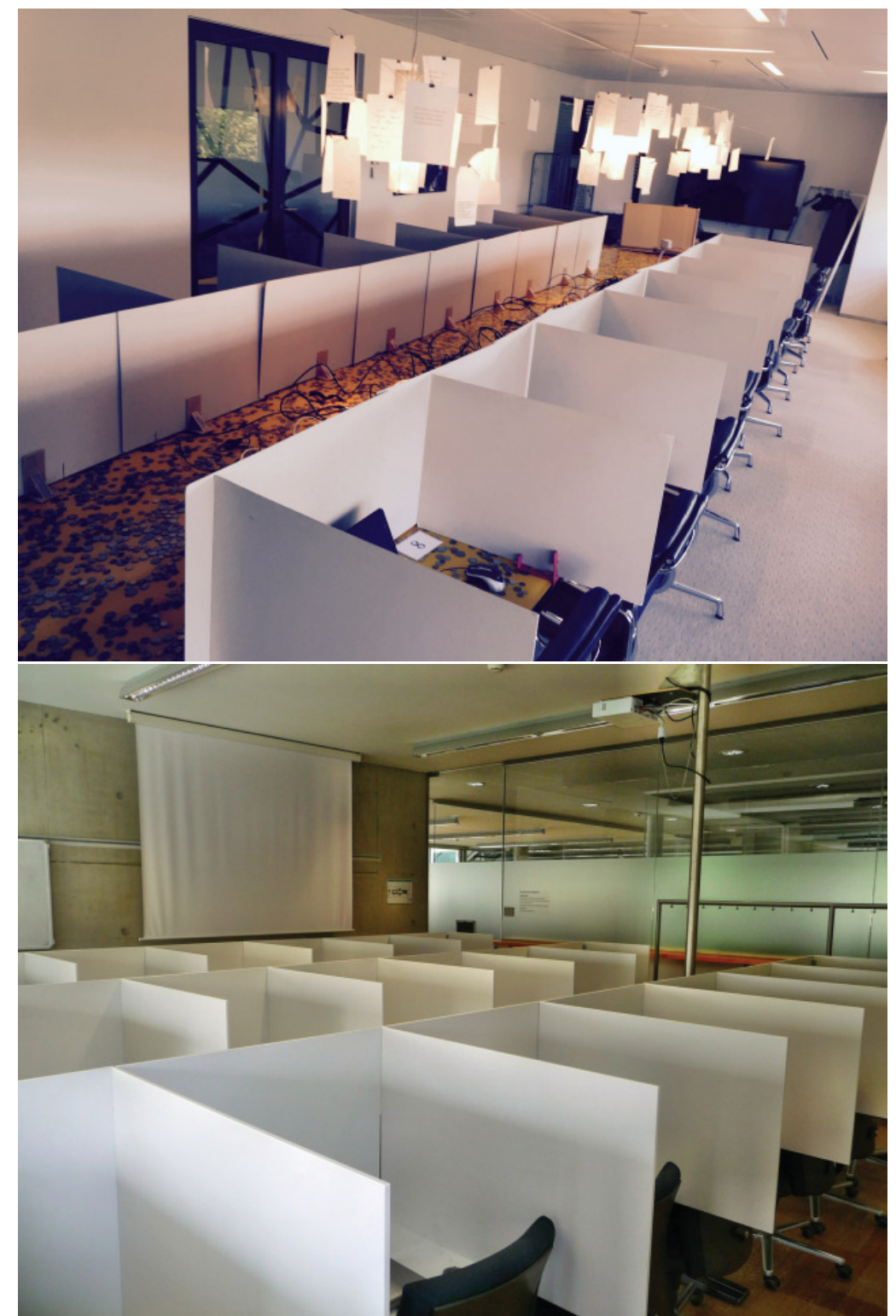

Figure F1: Top: Picture of a mobile laboratory in the conference room of a financial institution. Bottom: Innsbruck EconLab. 
University of Innsbruck - Working Papers in Economics and Statistics Recent Papers can be accessed on the following webpage:

http://eeecon.uibk.ac.at/wopec/

2016-02 Michael Kirchler, Florian Lindner, Utz Weitzel: Rankings and risktaking in the finance industry

2016-01 Sibylle Puntscher, Janette Walde, Gottfried Tappeiner: Do methodical traps lead to wrong development strategies for welfare? A multilevel approach considering heterogeneity across industrialized and developing countries

2015-16 Niall Flynn, Christopher Kah, Rudolf Kerschbamer: Vickrey Auction vs BDM: Difference in bidding behaviour and the impact of other-regarding motives

2015-15 Christopher Kah, Markus Walzl: Stochastic stability in a learning dynamic with best response to noisy play

2015-14 Matthias Siller, Christoph Hauser, Janette Walde, Gottfried Tappeiner: Measuring regional innovation in one dimension: More lost than gained?

2015-13 Christoph Hauser, Gottfried Tappeiner, Janette Walde: The roots of regional trust

2015-12 Christoph Hauser: Effects of employee social capital on wage satisfaction, job satisfaction and organizational commitment

2015-11 Thomas Stöckl: Dishonest or professional behavior? Can we tell? A comment on: Cohn et al. 2014, Nature 516, 86-89, "Business culture and dishonesty in the banking industry"

2015-10 Marjolein Fokkema, Niels Smits, Achim Zeileis, Torsten Hothorn, Henk Kelderman: Detecting treatment-subgroup interactions in clustered data with generalized linear mixed-effects model trees

2015-09 Michael Kirchler, Florian Lindner, Utz Weitzel: The cost-effectiveness of developmental screenings: Evidence from a nationwide programme

2015-08 Lorenz B. Fischer, Michael Pfaffermayr: The more the merrier? Migration and convergence among European regions

2015-07 Silvia Angerer, Daniela Glätzle-Rützler, Philipp Lergetporer, Matthias Sutter: Cooperation and discrimination within and across language borders: Evidence from children in a bilingual city 
2015-06 Martin Geiger, Wolfgang Luhan, Johann Scharler: When do Fiscal Consolidations Lead to Consumption Booms? Lessons from a Laboratory Experiment

2015-05 Alice Sanwald, Engelbert Theurl: Out-of-pocket payments in the Austrian healthcare system - a distributional analysis

2015-04 Rudolf Kerschbamer, Matthias Sutter, Uwe Dulleck: How social preferences shape incentives in (experimental) markets for credence goods

2016-03 Kenneth Harttgen, Stefan Lang, Judith Santer: Multilevel modelling of child mortality in Africa

2015-02 Helene Roth, Stefan Lang, Helga Wagner: Random intercept selection in structured additive regression models

2015-01 Alice Sanwald, Engelbert Theurl: Out-of-pocket expenditures for pharmaceuticals: Lessons from the Austrian household budget survey 


\title{
University of Innsbruck
}

\section{Working Papers in Economics and Statistics}

2016-02

Michael Kirchler, Florian Lindner, Utz Weitzel

Rankings and risk-taking in the finance industry

\begin{abstract}
Rankings and Risk-Taking in the Finance Industry Abstract: Rankings are omnipresent in the finance industry, yet there is no research how they impact financial professionals' behavior. We run lab-in-the-field experiments with 657 professionals and lab experiments with 432 students to investigate how rank incentives affect investment decisions. We find that both rankings and tournament incentives increase risk- taking among underperforming professionals, but rankings do not affect students. We show that the rank-effect is robust to the experimental frame (investment frame versus abstract frame), to payoff consequences (own return versus family return), to social identity priming (private identity versus professional identity), and to professionals' gender (no gender differences among professionals).
\end{abstract}

ISSN 1993-4378 (Print)

ISSN 1993-6885 (Online) 